\title{
Characterization and Calibration of the CheMin Mineralogical Instrument on Mars Science Laboratory
}

\author{
David Blake • David Vaniman • Cherie Achilles • Robert Anderson • David Bish • \\ Tom Bristow • Curtis Chen - Steve Chipera - Joy Crisp • David Des Marais • \\ Robert T. Downs · Jack Farmer · Sabrina Feldman - Mark Fonda • Marc Gailhanou • \\ Hongwei Ma • Doug W. Ming • Richard V. Morris • Philippe Sarrazin • Ed Stolper • \\ Allan Treiman · Albert Yen
}

Received: 15 November 2011 / Accepted: 22 May 2012 / Published online: 23 June 2012

(C) The Author(s) 2012. This article is published with open access at Springerlink.com

\section{Blake $(\bowtie)$}

Exobiology Branch, NASA Ames Research Center, Moffett Field, CA 94035-1000, USA

e-mail: david.blake@nasa.gov

D. Vaniman

Planetary Science Institute, 1700 E. Fort Lowell, Tucson, AZ 85719-2395, USA

C. Achilles

ESCG/Hamilton Sundstrand, 2224 Bay Area Blvd., Houston, TX 77058, USA

R. Anderson · C. Chen · J. Crisp · S. Feldman · A. Yen

Jet Propulsion Laboratory, California Institute of Technology, 4800 Oak Grove Dr., Pasadena,

CA 91109-8099, USA

D. Bish $\cdot$ H. Ma

Dept. of Geological Sciences, Indiana University, 1001 East Tenth St., Bloomington, IN 47405, USA

T. Bristow $\cdot$ D. Des Marais

Exobiology Branch, MS 239-4, NASA Ames Research Center, Moffett Field, CA 94035-1000, USA

S. Chipera

Chesapeake Energy Corp., 6100 N. Western Ave., Oklahoma City, OK 73118, USA

R.T. Downs

Department of Geosciences, University of Arizona, Tucson, AZ 85721-0077, USA

J. Farmer

School of Earth and Space Exploration, Arizona State University, Tempe, AZ 85287, USA

M. Fonda

Space Science Division, MS 245-1, NASA Ames Research Center, Moffett Field, CA 94035-1000, USA

M. Gailhanou

Faculté des Sciences et Techniques, Avenue Escadrille Normandie Niemen, Service 262, 13397

Marseille Cedex 20, France 


\begin{abstract}
A principal goal of the Mars Science Laboratory (MSL) rover Curiosity is to identify and characterize past habitable environments on Mars. Determination of the mineralogical and chemical composition of Martian rocks and soils constrains their formation and alteration pathways, providing information on climate and habitability through time. The CheMin X-ray diffraction (XRD) and X-ray fluorescence (XRF) instrument on MSL will return accurate mineralogical identifications and quantitative phase abundances for scooped soil samples and drilled rock powders collected at Gale Crater during Curiosity's 1-Marsyear nominal mission. The instrument has a Co X-ray source and a cooled charge-coupled device $(\mathrm{CCD})$ detector arranged in transmission geometry with the sample. CheMin's angular range of $5^{\circ}$ to $50^{\circ} 2 \theta$ with $<0.35^{\circ} 2 \theta$ resolution is sufficient to identify and quantify virtually all minerals. CheMin's XRF requirement was descoped for technical and budgetary reasons. However, X-ray energy discrimination is still required to separate $\mathrm{Co} \mathrm{K} \alpha$ from $\mathrm{Co} \mathrm{K} \beta$ and $\mathrm{Fe} \mathrm{K} \alpha$ photons. The $\mathrm{X}$-ray energy-dispersive histograms (EDH) returned along with XRD for instrument evaluation should be useful in identifying elements $Z>13$ that are contained in the sample. The CheMin XRD is equipped with internal chemical and mineralogical standards and 27 reusable sample cells with either Mylar ${ }^{\circledR}$ or Kapton ${ }^{\circledR}$ windows to accommodate acidic-to-basic environmental conditions. The CheMin flight model (FM) instrument will be calibrated utilizing analyses of common samples against a demonstrationmodel (DM) instrument and CheMin-like laboratory instruments. The samples include phyllosilicate and sulfate minerals that are expected at Gale crater on the basis of remote sensing observations.
\end{abstract}

Keywords X-ray diffraction · Mineralogy · Mars habitability · Mars science laboratory · Planetary science $\cdot$ Spacecraft instruments

\title{
1 Introduction
}

\subsection{The Mars Science Laboratory Mission}

The overall science objective of the Mars Exploration Program for the Mars Science Laboratory (MSL) mission is "To explore and quantitatively assess a local region on the Mars surface as a potential habitat for life, past or present." Specific science objectives are: (1), to assess the biological potential of at least one target environment identified prior to MSL or discovered by MSL; (2), to characterize the geology and geochemistry of the landed region at all appropriate spatial scales (i.e., ranging from micrometers to meters); (3), to investigate

D.W. Ming · R.V. Morris

Lyndon B. Johnson Space Center, 2101 NASA Road 1, Houston, TX 77058-3696, USA

P. Sarrazin

SETI Institute, 189 Bernardo Ave., Mountain View, CA 94043, USA

E. Stolper

MC 206-31, California Institute of Technology, Pasadena, CA 91125, USA

A. Treiman

Lunar and Planetary Institute, 3600 Bay Area Blvd., Houston, TX 77058-1113, USA 
Table 1 Composition of Watchtower-class rocks at Gusev Crater (in oxide wt.\%) as determined by Alpha Particle $\mathrm{X}$-ray Spectrometry (APXS) (Gellert et al. 2006)

${ }^{\mathrm{a}} \mathrm{All} \mathrm{Fe}$ is calculated as $\mathrm{FeO}$

\begin{tabular}{lccccc}
\hline Wt.\% & Keystone & Keel Davis & Watchtower & Pequod & Paros \\
\hline $\mathrm{SiO}_{2}$ & 46.9 & 45.2 & 42.4 & 46.0 & 46.6 \\
$\mathrm{TiO}_{2}$ & 1.96 & 1.94 & 2.21 & 1.92 & 1.37 \\
$\mathrm{Al}_{2} \mathrm{O}_{3}$ & 13.61 & 12.07 & 12.33 & 13.1 & 13.73 \\
$\mathrm{Cr}_{2} \mathrm{O}_{3}$ & 0.05 & 0.04 & 0.00 & 0.05 & 0.02 \\
$\mathrm{FeO}^{\mathrm{a}}$ & 10.5 & 10.9 & 13.2 & 11.1 & 11.4 \\
$\mathrm{MnO}$ & 0.27 & 0.22 & 0.22 & 0.20 & 0.17 \\
$\mathrm{MgO}$ & 8.48 & 8.64 & 10.00 & 8.42 & 7.91 \\
$\mathrm{CaO}$ & 6.36 & 6.71 & 7.44 & 7.13 & 6.45 \\
$\mathrm{Na}_{2} \mathrm{O}$ & 3.44 & 3.60 & 2.67 & 3.48 & 3.42 \\
$\mathrm{~K}_{2} \mathrm{O}$ & 0.56 & 0.37 & 0.74 & 0.38 & 0.37 \\
$\mathrm{P}_{2} \mathrm{O}_{5}$ & 2.41 & 2.51 & 4.50 & 2.83 & 2.31 \\
$\mathrm{SO}_{3}$ & 4.15 & 6.43 & 3.34 & 4.29 & 4.97 \\
$\mathrm{Cl}$ & 1.23 & 1.28 & 0.80 & 0.98 & 1.05 \\
$\mathrm{Total}$ & 99.42 & 99.91 & 99.85 & 99.88 & 99.79 \\
\hline
\end{tabular}

planetary processes of relevance to past habitability including the role of water; and (4), to characterize the broad spectrum of surface radiation, including galactic cosmic radiation, solar proton events, and secondary neutrons.

\subsection{Science Goals of the CheMin Mineralogical Instrument}

The CheMin (Chemistry and Mineralogy) instrument directly addresses the Mars Exploration Program objectives by seeking to identify and characterize past or present habitable environments as recorded in the chemical and mineralogical composition of sediments and rocks. CheMin will principally address science objective 2 above, but it will also support goals 1, 3 and 4. To meet these objectives, CheMin will utilize X-ray diffraction (XRD) to perform mineralogical analyses of rocks, sediments, dusts and soils to assess the involvement of water in their formation, deposition or alteration, and to search for potential mineral biosignatures, energy sources for life, or indicators of past habitable environments.

\subsection{The Importance of Mineralogy to MSL Science Goals}

Minerals are natural crystalline materials of uniform inter-atomic structure and limited ranges of chemical composition. The century-old technique of X-ray diffraction (the operating principle of CheMin) is exquisitely sensitive to that structure and secondarily sensitive to chemical composition. Specific minerals can form and persist only through limited ranges of temperature, pressure, and ambient chemical conditions (i.e., humidity, water activity, Eh, $\mathrm{pH}$, etc.). A material of a given chemical composition (like a basalt) may be transformed to a wide range of mineral assemblages depending on the physical and chemical conditions that it experienced (Spear 1993). Thus, knowledge of the minerals present in a sample provides insight into the physical and chemical conditions under which it was formed or altered.

Tables 1 and 2 show the elemental composition (measured by Alpha Particle X-ray Spectroscopy (APXS); Gellert et al. 2006) and iron mineralogy (measured by Mössbauer spectroscopy; Morris et al. 2006) of basaltic rocks of the Watchtower class, investigated by the 
Table 2 Iron mineralogy of Watchtower-class rocks at Gusev Crater (in oxide wt.\%) as determined by Mössbauer Spectroscopy (Morris et al. 2006)

${ }^{\mathrm{a}} \mathrm{Fe}^{3+} / \mathrm{Fe}_{\mathrm{T}}$ is required for norminative calculations. Norms also assume equilibrium crystallization under anhydrous conditions. Chemistry assumes no $\mathrm{H}_{2} \mathrm{O} / \mathrm{OH}$ is present

\begin{tabular}{lccccc}
\hline Mineral & Keystone & Keel Davis & Watchtower & Pequod & Paros \\
\hline Pyroxene & 47 & 13 & 7 & 2 & 1 \\
Olivine & 0 & 4 & 7 & 4 & 3 \\
Garnet & 4 & 0 & 12 & 12 & 11 \\
Magnetite & 10 & 9 & 0 & 0 & 0 \\
Hematite & 15 & 40 & 31 & 14 & 18 \\
Ilmenite & 8 & 8 & 3 & 6 & 2 \\
npOx & 17 & 27 & 39 & 62 & 66 \\
$\mathrm{Fe}^{3+} / \mathrm{Fe}_{\mathrm{T}}{ }^{\mathrm{a}}$ & 0.43 & 0.73 & 0.83 & 0.88 & 0.94 \\
\hline
\end{tabular}

MER-A rover Spirit at Gusev Crater. These rocks have nearly identical chemical compositions (Table 1), but have wildly differing amounts of particular iron-bearing minerals reflective of changes of oxidation state (Table 2). The observed mineralogical changes are inferred to represent progressive alteration and oxidation, something that is not evident from compositional data alone. The Mössbauer instruments on the MER rovers are very sensitive to iron-containing minerals but indifferent to others. On MSL, the CheMin instrument will be able to identify iron-containing as well as iron-free minerals. With a knowledge of the full suite of minerals present, a more complete story can be made of alteration and the history of rock-water interactions on Mars.

\subsection{Integration of CheMin with Other MSL Instruments}

CheMin is one of ten instruments on the MSL rover. The other instrument housed with CheMin in the analytical laboratory within the rover's body is SAM ("Sample Analysis at Mars"), a gas chromatography (GC)-mass spectrometry (MS)-tunable laser spectrometry (TLS) instrument. Integration of CheMin and SAM analyses of splits of the same samples will maximize the information obtained by combining specific mineralogy with results from gas chromatography, mass spectrometry, evolved gas analysis, and tunable laser spectrometry. In addition, complementary quantitative chemical composition for elements $\mathrm{Na}$ and heavier (via XRF-equivalent APXS analysis) will be collected on the raw or brushed surfaces of samples, including those spots drilled to collect powder for CheMin and SAM. These analyses will be supplemented by hand-lens resolution investigation of sample spots with MAHLI (Mars Hand Lens Imager, with up to $14 \mu \mathrm{m}$ resolution) before and after brushing. Remote chemical analyses by the ChemCam instrument using laser induced breakdown spectroscopy (LIBS) will provide guidance to appropriate sampling spots as well as data on elements that will not be measured by either APXS or CheMin (e.g., H, C, N). All analyses will be supported by high-magnification Remote Micro-imager (RMI) images colocated with the ChemCam remote spot analyses, by mast-mounted camera surveys, and by engineering camera data. CheMin data, comprising XRD patterns suitable for quantitative analysis and elemental energy-dispersive histograms (EDH) suitable for identification of elements present in the sample $13<Z<42$, are particularly synergistic with the APXS and ChemCam analyses and the SAM GC-MS-TLS data. The challenge in integration of these datasets will be in identifying and accommodating sample selection differences between instruments, which are:

(1) CheMin will analyze only the $<150 \mu \mathrm{m}$ size fraction of drilled or scooped samples. 
(2) SAM can analyze splits of the same $<150 \mu \mathrm{m}$ material as CheMin, but it can also accommodate splits $<1 \mathrm{~mm}$.

(3) APXS will analyze $1.7 \mathrm{~cm}$ diameter areas on rock or soil, either unmodified or brushed.

(4) ChemCam will obtain rapid compositional data on spots up to $\sim 7 \mathrm{~m}$ distant and $\sim 200$ to $400 \mu \mathrm{m}$ in diameter, with the ability to raster across the sample surface, produce linescans, or to excavate several hundred micrometers into a sample.

Because each MSL instrument has a distinct analytical area, volume and dataset, meaningful integration of the whole MSL dataset will require an understanding of these sampling issues. Dust cover and surficial alteration that might not be penetrated by either ChemCam or APXS is likely to have minimal influence on the deeper drill samples that will be delivered to SAM and CheMin. Grain-size heterogeneity may result in differences between $<1 \mathrm{~mm}$ splits passed to SAM and $<150 \mu \mathrm{m}$ splits analyzed by CheMin. Viewing a sample at such different scales can be a powerful method for improving understanding, but multiple types and scales of analysis can be confusing. In order to address the sampling issue, the MSL rover is equipped with an Observation Tray where splits of the sieved samples delivered to SAM and CheMin can be analyzed by APXS and MAHLI. This permits chemical analysis of both pre-drilled and drilled material, as well as allowing high-magnification imaging of the sample to examine grain properties (UV fluorescence, angularity, size range, color, and "hand lens" mineral identification). In addition, samples on the Observation Tray can be examined by day or by night (with either visible or UV illumination) to determine sample stability over a range of temperatures.

\subsection{CheMin Instrument Overview}

CheMin is part of the Analytical Laboratory of the MSL rover Curiosity, located inside the main body of the rover. CheMin will analyze powdered rock and soil samples delivered to it by the Sample Analysis/Sample Processing and Handling (SA/SPaH) and Collection and Handling for In-Situ Martian Rock Analysis (CHIMRA) systems. CheMin is capable of analyzing up to 27 pristine samples and as many as 74 samples with reuse of sample cells. The total number of analyses will be determined by "drive" vs. "analyze" decisions made by the MSL Science Operations Working Group (SOWG) as Curiosity progresses towards Gale Crater's central mound. Each CheMin analysis can take up to 10 hours of analysis time over two or more Martian nights, although some samples may require only one night for analysis. CheMin measures the mineralogy of crushed or powdered rock samples and/or soil through X-ray diffraction. The geometry of CheMin is shown in Fig. 1.

During an analysis, a collimated X-ray beam from an X-ray tube source is directed through powdered or crushed sample material. An X-ray sensitive CCD imager is positioned on the opposite side of the sample from the source and directly detects X-rays diffracted or fluoresced by the sample (Fig. 1, left). The CCD detector is operated in single-photon counting mode (the detector is read out sufficiently often that most pixels contain either no charge or charge derived from a single photon). When operated in this manner, the CCD can be used to measure the amount of charge generated by each photon (and hence its energy). Diffracted primary beam characteristic X-rays strike the detector and are identified by their energy (for CheMin, with a Co X-ray tube, Co K $\alpha$ X-rays having an energy of $6.929 \mathrm{keV}$ are selected), producing a two-dimensional image of $\mathrm{Co} \mathrm{K} \alpha \mathrm{X}$-rays that constitutes the X-ray diffraction pattern. At incremental radii this pattern is summed circumferentially about the central nondiffracted beam to yield a one-dimensional plot of $2 \theta$ versus intensity comparable to conventional diffractometer data (Fig. 1, upper right). 

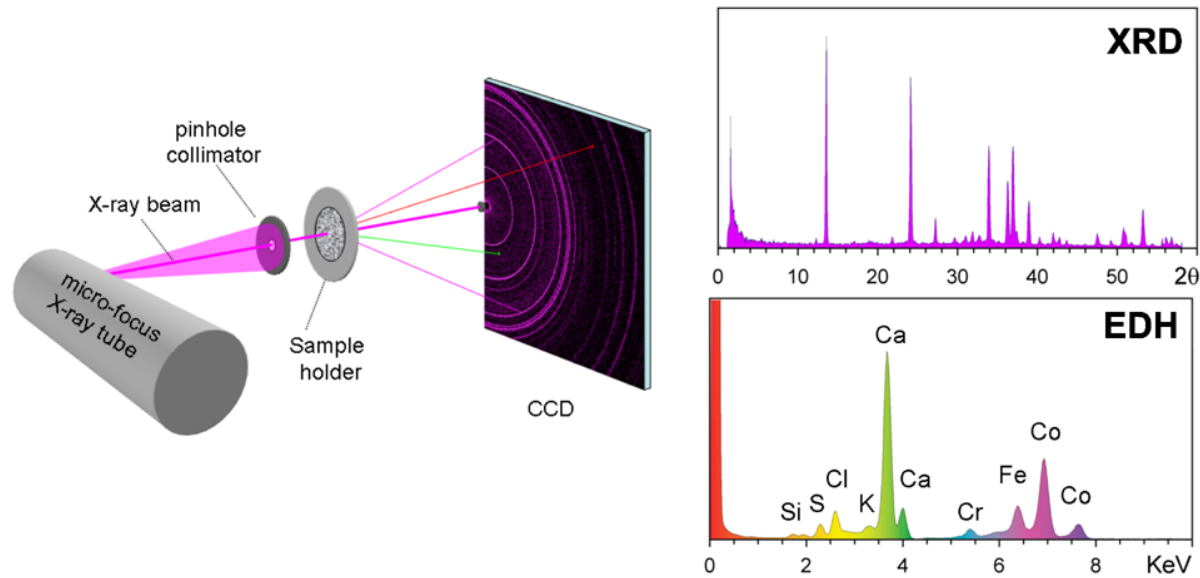

Fig. 1 Geometry of the CheMin instrument. (Left) overall geometry of CheMin; (above right) XRD $2 \theta$ plot obtained by summing diffracted photons from the characteristic $\mathrm{K} \alpha$ line of the X-ray source (Co $\mathrm{K} \alpha$ is colored magenta in Fig. 1 (left); (below right) X-ray energy-dispersive histogram (EDH) obtained by summing all of the X-ray photons detected by the CCD (fluoresced photons from the sample shown schematically in green and red in Fig. 1 (left)

From this diffraction pattern, one can (in theory) determine the minerals present in a sample and their relative abundances. Each mineral has a unique diffraction pattern, and the pattern of an unknown mineral or mineral mixture can be identified by comparison with standard patterns compiled for wide ranges of natural and synthetic materials. Two such compilations are from the International Centre for Diffraction Data (ICDD, Newtown Square, PA) and the Crystal Structure Database (Downs and Hall-Wallace 2003). Abundances of minerals can be retrieved by several methods that seek to model both diffraction peak positions and intensities. Among these methods are Rietveld refinement (Bish and Post 1993), the Reference Intensity Ratio (RIR) method (Chung 1974) and full-pattern fitting methods like FULLPAT (Chipera and Bish 2002). The last is particularly useful because it is well adapted for the processing of CheMin data products to quantify abundances of both crystalline and amorphous materials, a challenging task in remote XRD analysis. The CheMin team includes several clay mineralogists familiar with these and other methods for quantifying difficult phases such as poorly-crystalline clay minerals and X-ray amorphous materials. The diffraction data, including as-received and processed diffraction files, will be archived in NASA's Planetary Data System for public access, where researchers around the world will be able to download, reprocess and reanalyze the data. The legacy of CheMin operations for MSL will be many years of improving mineral analysis as new researchers and new methods revisit the CheMin data archive.

Some of the X-rays that impinge on the sample are absorbed, and portions of their energies are re-emitted (i.e., fluoresced) as characteristic X-rays of elements in the sample (e.g. Ca $\mathrm{K} \alpha$ X-radiation). These fluoresced X-rays provide information about the elemental composition of the sample. These data are compiled into a histogram of the number of CCD-detected X-rays versus X-ray energy (Fig. 1, lower right). This energy-dispersive histogram (EDH) is used by to monitor CheMin's performance (see Sect. 1.9) and to select the energy window for diffracted $\mathrm{Co} \mathrm{K} \alpha$ photons from the $\mathrm{CCD}$, minimizing background from fluoresced X-rays. Raw histograms of the intensities of fluoresced X-rays are used to evaluate $\mathrm{CCD}$ performance and to aid in mineral identification by observations of the presence 
or absence of elements expected to be in the mineral(s). However, because the sensitivity of the CCD detector changes as a function of time, temperature and radiation damage during the mission, these data cannot be accurately quantified.

\subsection{The CheMin Instrument}

\subsubsection{The X-Ray Source}

CheMin has a microfocus X-ray tube with a Co anode and a beam-defining final aperture placed at some distance from the tube, which together produce a collimated X-ray beam. The source produces continuum and characteristic X-radiation from a $50 \mu \mathrm{m}$ diameter spot on the Co anode. The tube has a nominal operating voltage of $28 \mathrm{keV}$ with a filament current of $1.5 \mathrm{~A}$ and cathode output of $100 \mu \mathrm{A}$. The photons emanate from the X-ray tube in a cone of radiation that exits the tube through a beryllium window. At a specific distance from the tube, the pinhole aperture intersects the beam, creating a nearly parallel, collimated $\sim 70 \mu \mathrm{m}$ diameter beam of X-radiation directed at the center of the sample cell. After passing through the sample, the direct beam is stopped by a beam trap mounted on the edge of CCD detector.

The X-ray power supply is enclosed in a housing pressurized with a mixture of sulfur hexafluoride and nitrogen gas, mixed so that the condensation temperature of the gas is below the minimum expected temperature in the body of the rover (to ensure that the gas never liquefies).

\subsubsection{The CheMin Sample Handling System}

The CheMin sample handling system consists of a funnel, a sample wheel (which carries 27 reusable sample cells and 5 permanent reference standards), and a sample sump where material is dumped after analysis (Fig. 2). CheMin receives sieved and portioned drill powders and scoop samples from the SA/SPaH system (Jandura 2010) through the CHIMRA drill, scoop, and sorting assembly (Sunshine 2010). A maximum of $76 \mathrm{~mm}^{3}$ of sample material is delivered to the piezoelectrically vibrated funnel system that penetrates through the rover deck. When CheMin is not receiving samples, the CheMin inlet is protected by a cover. The material received through the funnel passes into a sample cell that consists of a $10 \mathrm{~mm}^{3}$ active cell volume and a $\sim 400 \mathrm{~mm}^{3}$ reservoir above the cell. Excess material, should it be delivered, will remain in the reservoir during analysis. The funnel contains a $1 \mathrm{~mm}$ mesh screen to keep larger grains from entering the CheMin sample handling system. Grains that cannot pass through the screen will remain there for the duration of the mission, although no material is expected because the sample is pre-sieved to $<150 \mu \mathrm{m}$ in the CHIMRA sorting chamber to prevent clogging of the CheMin funnel screen. Any grains smaller than $1.0 \mathrm{~mm}$ but larger than $150 \mu \mathrm{m}$ will pass into the upper reservoir portion of the sample cell, where they will remain until the cell is inverted and they are dumped into the sump. For the lifetime of the mission, nominally one Mars year, CheMin is required to accept and analyze material delivered from $\mathrm{SA} / \mathrm{SPaH}$ with no more than $5 \%$ internal contamination between samples. Self-generated contamination may originate from material that has remained in the funnel from previously delivered samples (and delivered along with subsequent samples), or from material that has remained in previously used analysis cells (CheMin will be capable of reusing each cell two to three times to accommodate 74 or more analyses during an extended mission). Cells are emptied after an analysis by rotating the sample wheel $180^{\circ}$ (to invert the cell) and vibrating the cell so that the sample material is emptied into a sump at the bottom of the instrument. If contamination is suspected either from the funnel or from a previously used cell, CheMin can reduce sample-to-sample contamination by dilution. Aliquots 


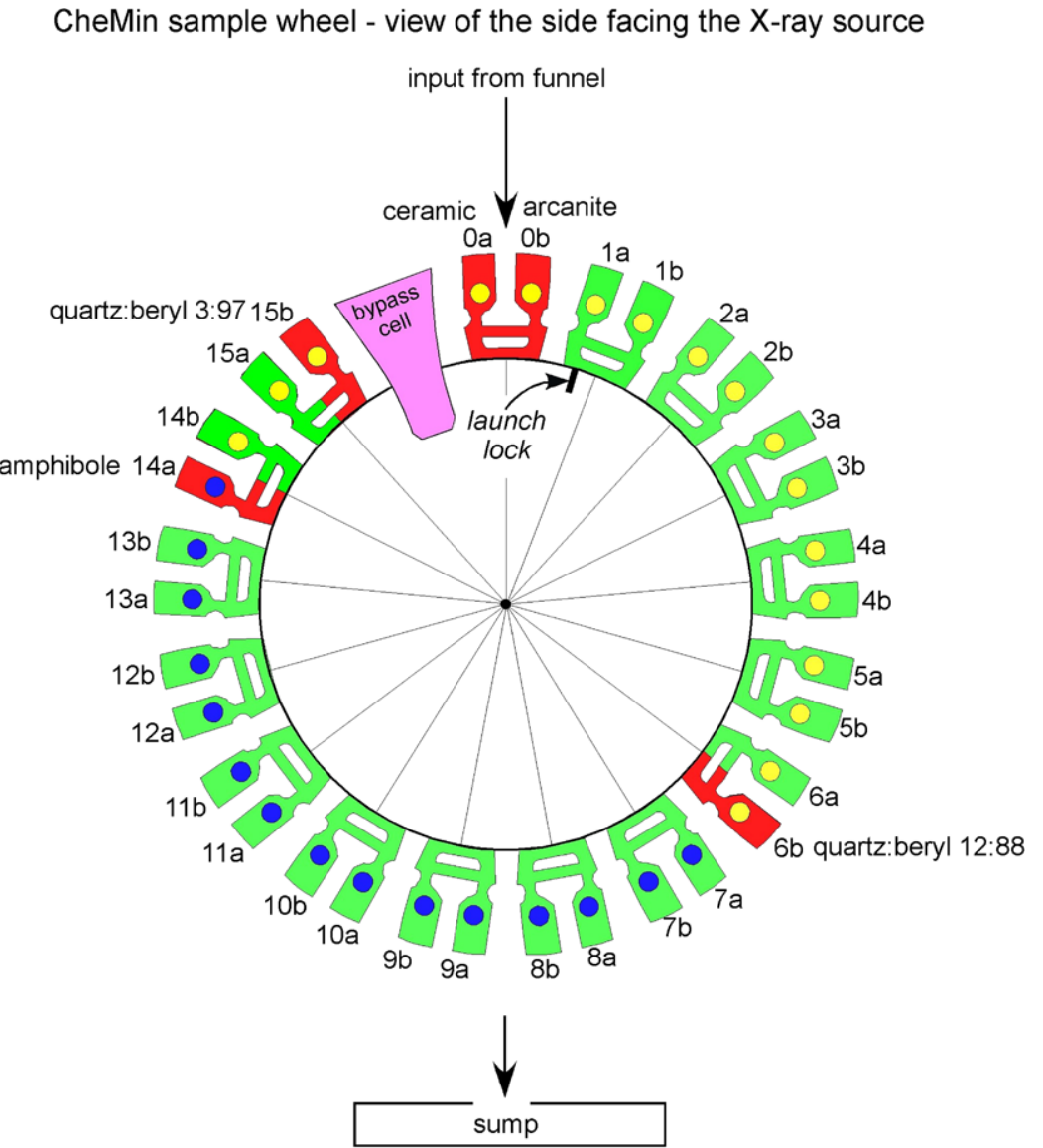

red cells - permanent standards green cells - reusable

blue cells - Mylar yellow cells - Kapton

Fig. 2 Schematic diagram of the CheMin sample wheel. Individual sample cells can hold as much as $400 \mathrm{~mm}^{3}$, but only $\sim 10 \mathrm{~mm}^{3}$ is required to fill the active analytical volume of a cell. Twenty-seven reusable cells are available for analysis of drilled or scooped samples sieved to $<150 \mu \mathrm{m}$. Sample cells are filled at the top and dumped at the bottom. Cells in red hold standard materials that are accessible during the mission for calibration purposes

of sample material can either be dumped into the funnel and delivered directly to the sump through a shunt in the wheel without entering a sample cell (to entrain and remove funnel contamination), or a previously used sample cell can be filled, shaken and emptied to the sump prior to receiving a second aliquot of sample for analysis (to entrain and remove sample cell contamination). These processes will require coordination with SA/SPaH to deliver more than one aliquot of a given sample.

The collimated $\sim 70 \mu \mathrm{m}$ diameter X-ray beam illuminates the center of a sample cell having $6 \mu \mathrm{m}$ thick Mylar ${ }^{\circledR}$ or $10 \mu \mathrm{m}$ Kapton $^{\circledR}$ windows. The sample introduced into the funnel consists of $\leq 76 \mathrm{~mm}^{3}$ of powdered material with a grain size of $<150 \mu \mathrm{m}$. Only about $10 \mathrm{~mm}^{3}$ of material is required to fill the active volume of the sample cell, which is a disc-shaped volume with an $8 \mathrm{~mm}$ diameter and $175 \mu \mathrm{m}$ thickness. The remaining sample 

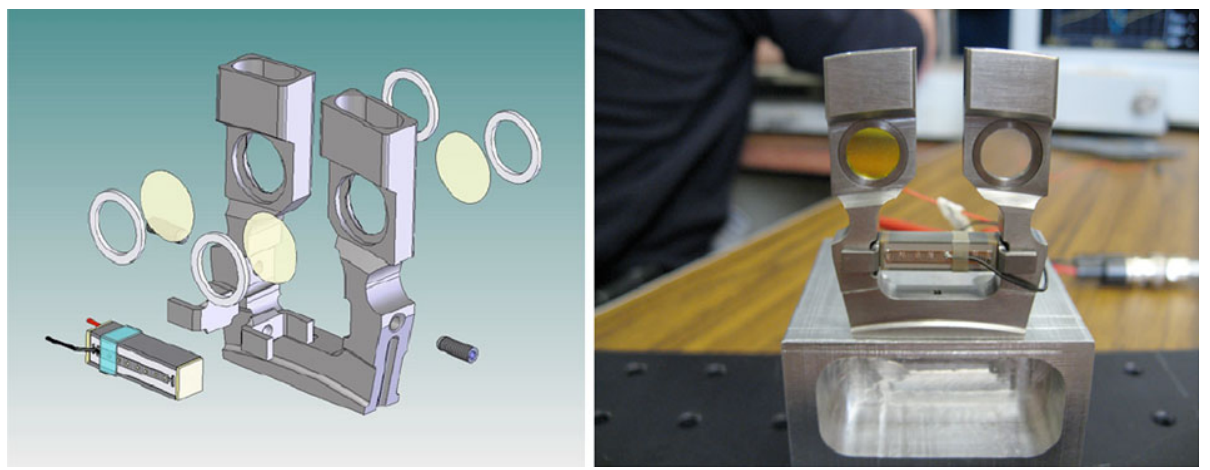

Fig. 3 CheMin cell geometry. (Left) Exploded view of dual-cell assembly, showing windows, tuning-fork assembly and piezodriver. (Right) Assembled cell, ready for testing (note yellow Kapton ${ }^{\circledR}$ window on left, clear Mylar ${ }^{\circledR}$ window on right)

material occupies the reservoir above the cell (see Fig. 3). During filling, analysis and sample dumping, the sample cell is shaken by piezoelectric actuators ("piezos"). The modes in which the piezos will be driven are still under test and may vary from sample to sample, depending on sample-dependent characteristics such as grain cohesion (e.g., clay-rich samples versus samples that lack fine particles). In CheMin testbeds and prototype instruments, the frequency of the piezo-actuator is varied so that during a part of the cycle the sample holder is at resonance, at which time the sample exhibits bulk convective movement similar to a liquid, delivering sample grains in random orientation into the volume exposed to the beam. In the CheMin Flight Model (FM) and the equivalent Demonstration Model (DM) a nominal resonant frequency of $2150 \mathrm{~Hz}$ is maintained during analysis, and shaking amplitude is varied to adjust the intensity of grain motion.

During the moderate shaking that produces granular convection, it is possible that phase separation will occur as a result of size, density or shape differences between individual mineral grains. To mitigate this problem CheMin at intervals uses episodically larger shaking amplitudes (i.e., "chaos mode") to re-homogenize the material in the sample chamber.

The CheMin sample cells are paired in dual-cell "tuning-fork" assemblies with a single horizontally driven piezoelectric actuator in each assembly (Fig. 3). Sixteen of the dual-cell assemblies are mounted around the circumference of the sample wheel (Figs. 2 and 4). Five of the cells will be devoted to carrying standards; the other 27 cells are available for sample analysis and can be reused by emptying samples into the sump after analysis. Cells are filled and analyzed at the top of the wheel. A cover assembly sits directly above the sample cell during analysis to keep material in the sample reservoir from being ejected during vibration. Inlets to the cells holding standards are sealed with HEPA filters to prevent the material from falling out as the wheel is moved, while allowing for pressure equalization within the cells.

Both Mylar ${ }^{\circledR}$ - and Kapton ${ }^{\circledR}$-windowed cells are mounted on the wheel. The rationale for using two types of cell windows is based on our experience with CheMin prototype instruments. Mylar ${ }^{\circledR}$ windows exhibit a very flat diffraction background across the full range of $2 \theta$. However Mylar ${ }^{\mathrm{TM}}$ is less durable than Kapton $^{\circledR}$ under severe vibration and is susceptible to destruction if highly acidic samples (e.g., copiapite; a hydrated iron sulfate) are encountered. What is known about mineralogy on Mars suggests that acidic conditions are not unlikely (e.g., determination of jarosite occurrences at both MER landing sites). Kapton ${ }^{\circledR}$ windows are more durable and are not susceptible to acid attack, but they have a small diffraction contribution at $\sim 6-7^{\circ} 2 \theta$ that could interfere with the 001 diffraction peak from 


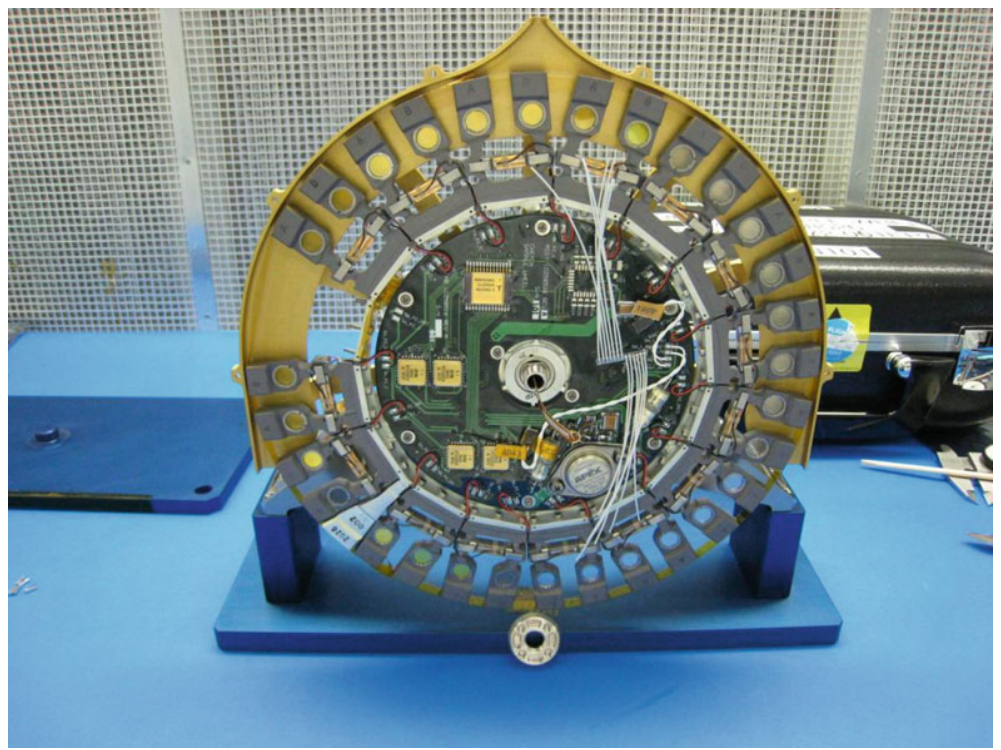

Fig. 4 The CheMin sample wheel. The wheel is shown inverted in this picture. A shroud (gold colored metal) covers the lower part of the wheel so that as filled cells are inverted, material that falls out of the cells prematurely will be directed into the sump

some clay minerals. For security and to assure that CheMin can handle a wide range of sample types on Mars, both Kapton ${ }^{\circledR}$ windows (in 13 cells) and Mylar ${ }^{\circledR}$ windows (in 14 cells) are used in the reusable cells. None of the remaining 5 cells, loaded with standards, have any concern related to clay-mineral diffraction so Kapton ${ }^{\circledR}$ is the norm for standard cells, but one of the standards (amphibole), useful for both XRD and EDH analysis, is loaded into a Mylar ${ }^{\circledR}$-windowed cell to provide access to at least one standard with this window design throughout the duration of the mission.

Once data from an observation are sent to ground and accepted, the analyzed material is emptied from the cell and that cell is ready to be reused. CheMin does not have the capability to store previously analyzed samples for later re-analysis once the wheel has been moved to receive another sample or to analyze one of the standards.

\subsubsection{The CCD Detector}

CheMin uses a $600 \times 1182$ pixel E2V CCD-224 frame transfer imager operated with a $600 \times 582$ pixel data collection area (Fig. 5). Once the $600 \times 582$ pixel active area is exposed to X-ray photons for a brief period (5-30 seconds), it can be rapidly transferred into a $600 \times$ 600 pixel shielded area (the "transfer frame"). This allows data collection to take place continuously without the use of an X-ray shutter or electronic beam blanking. The pixels in the active portion of the array are $40 \times 40$ micrometers square, and the active region of deep depleted silicon is $50 \mu \mathrm{m}$ thick. The front surface passivation layer is thinned over a substantial fraction of the active pixel area. This imager is a modern version of the E2V CCD-22 that was specially built for an X-ray astronomy application (Kraft et al. 1994). The large size of the individual pixels (relative to those present in conventional CCD imagers) causes a greater percentage of X-ray photons to deposit their charge inside a single pixel rather than splitting the charge between pixels. The enhanced deep depletion zone results 


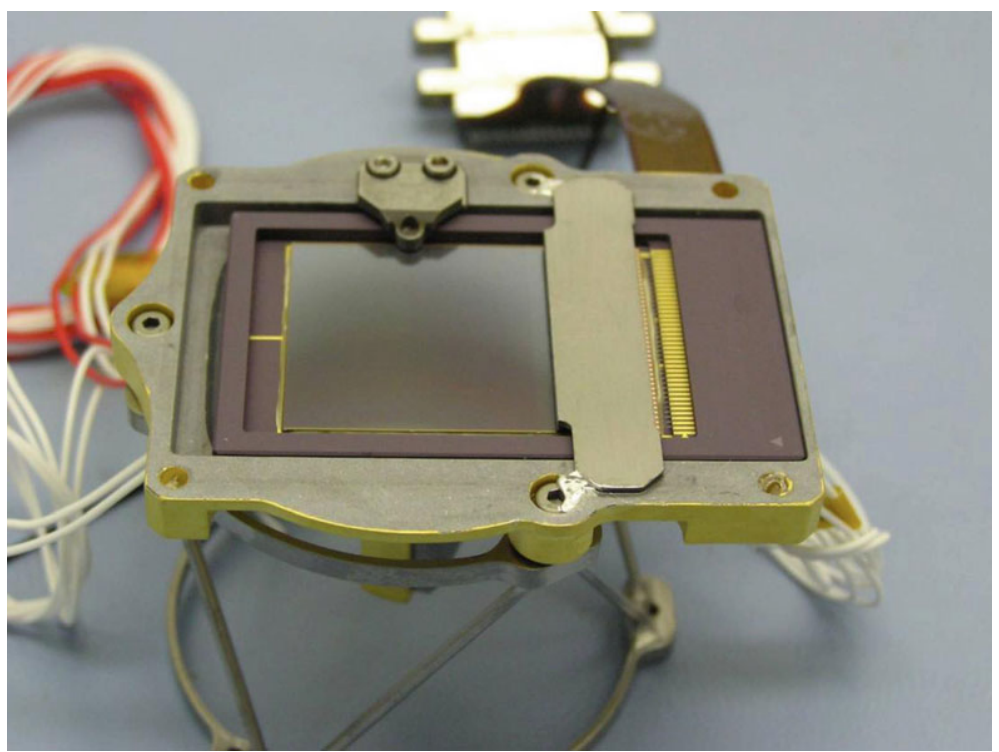

Fig. 5 The CheMin CCD. The active $600 \times 582$ pixel region of the CCD is the exposed portion in the center. The frame transfer region of the CCD is the shielded portion to the right of the active area. The beam stop can be seen in the center of the upper edge of the active area (held with two screws). The CCD is cooled with an active cryocooler that is attached to the back of the CCD by a thermal strap. The CCD support/attachment hexapod structure (seen below the CCD assembly) supports but thermally isolates the CCD assembly from its attachment plate

in improved charge collection efficiency for high energy X-rays. The thin passivation layer makes the CCD sensitive to relatively low-energy X-rays (down to Si and in some samples, down to $\mathrm{Al}$ ). The frame transfer region of the CCD (the portion of the CCD in Fig. 5 that is covered by a metal bar) has much smaller pixels than the active region because they are only meant to hold the charge associated with an X-ray photon, not to absorb it. An individual pixel in the array can hold hundreds of thousands of electrons, many more than the few thousand electrons deposited by a single X-ray photon. The active portion of the CD has larger pixels because the charge cloud of electrons that is deposited from an absorbed photon can be tens of microns in size.

In order to keep the CCD from being exposed to photons in the visible energy range (from X-ray induced optical fluorescence from the sample) during analysis, a $150 \mathrm{~nm} \mathrm{Al}$ film supported on a $200 \mathrm{~nm}$ polyimide film is suspended on a frame placed in front of the detector. The detector itself is cooled by a cryocooler to approximately $48{ }^{\circ} \mathrm{C}$ below the temperature of the Rover Avionics Mounting Platform (RAMP) that is used as a heat sink by the cryocooler. The RAMP is expected to be between $0{ }^{\circ} \mathrm{C}$ and $+26{ }^{\circ} \mathrm{C}$ during the mission, yielding $\mathrm{CCD}$ temperatures of $-48{ }^{\circ} \mathrm{C}$ to $-22{ }^{\circ} \mathrm{C}$. By cooling, dark current in the CCD is reduced.

A number of interactions occur between the sample and the X-ray beam to produce photon fluxes detected by the CCD. The two interactions of importance to the CheMin experiment are elastic interactions in which primary beam photons are absorbed and re-emitted by sample atoms (i.e., diffraction events), and inelastic interactions in which sample atom inner shell electrons are ejected from the nucleus, resulting in the emission of a characteristic photon from the sample (i.e., fluorescence events). In X-ray diffraction, elastic interactions of 

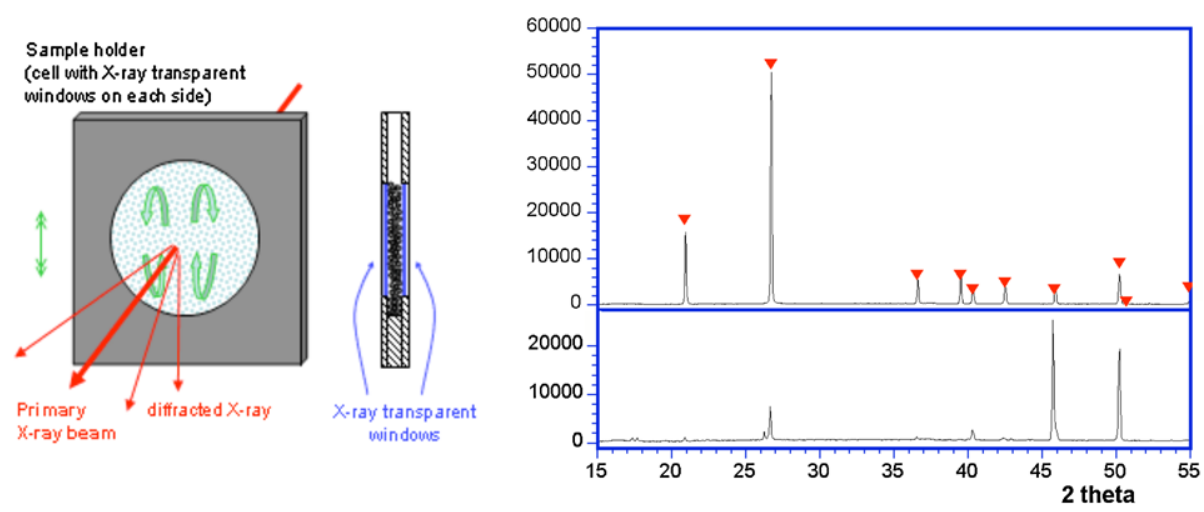

Fig. 6 Left: Schematic diagram of a vibrating sample holder for granular convection. Right: $\mathrm{Cu} \mathrm{K} \alpha$ diffraction pattern of the $75-150 \mu \mathrm{m}$ size fraction of a crushed quartz crystal sample in a laboratory instrument with convective sample holder. Upper: sample with vibration (ICDD database intensity reference values shown by red triangles); Lower: same sample without vibration

primary beam photons with sample atoms constructively or destructively interfere, resulting in maxima in discrete angular directions ("Laue cones" or "Debye rings") representative of the crystal structure of the sample. In fluorescence, sample-generated photons are emitted uniformly in all directions and the energies of individual photons can be used to identify the elements present in the sample.

\subsection{Refinement of CheMin Instrument Performance}

\subsubsection{Analysis of Grain Motion in Vibrated Sample Cells}

X-ray diffraction analysis consists of the measurement of the directions and intensities at which crystalline matter diffracts X-rays. Placing an individual crystal in fixed orientation in a monochromatic X-ray beam will at most lead to a single diffracted beam, and most likely no diffraction at all. To accurately identify a crystalline phase, it must be exposed to the X-ray beam in all orientations to record all possible diffracted beams within the angular range covered. Powder XRD achieves this condition by using powdered materials—or solid polycrystalline materials - to create a sample that offers all possible crystalline orientations within the analytical volume. In laboratory powder-XRD instruments, fine-grained samples (ideally $<10 \mu \mathrm{m}$ grainsize) offer a very large number of crystallites in random orientations in the analytical volume. Miniaturized XRD instruments have even more stringent grain-size constraints because their analytical volume is scaled down. In an instrument like CheMin, an ideal sample would have a submicron grain size, difficult to achieve by grinding. When coarser than ideal powders must be analyzed, a means of increasing crystalline orientation statistics is necessary. A common method used in laboratories is to spin the sample in a thin glass capillary. For CheMin, a new approach was developed based on granular convection of the sample in vibrated cells. The analytical volume represents a small fraction of the sample cell volume $(\sim 1 / 6000)$ but the internal flow of material through granular convection ensures that the entire sample is analyzed in random orientation over time (Fig. 6). Granular convection is obtained by vibrating the sample holder to fluidize the powder. Gravity combined with the interaction of the powder with the oscillating cell walls leads to convective flow. In addition to allowing quality XRD to be obtained with large grain sizes (up 
to $150 \mu \mathrm{m}$ ), the vibrations facilitate sample insertion and removal. Conventional methods of XRD sample handling would have required CheMin to be fitted with a grinder, a cell filling mechanism and possibly a cell spinner, increasing mechanical complexity, cost and risk. The benefits of the convective cells in producing XRD data suitable for quantitative analysis have been demonstrated in a number of CheMin precursor and laboratory analog instruments.

A convective sample holder must ensure an intense vibration in the cell, thousands of $\mathrm{m} \mathrm{s}^{-2}$ (hundreds of $\mathrm{g}$ ) being typically required to obtain reliable convection. This is achieved by using a balanced mechanical resonator similar to a tuning fork. A sample cell is integral to each arm of the tuning fork, and both cells are vibrated at the same time. The balanced design ensures minimal transmission of the vibration to the structure of the instrument; the energy is kept in the resonator. The vibration is induced by a piezoelectric actuator placed at the base of the tuning fork and driven at the resonance frequency of the assembly. The intensity of vibration is pulsed at about $1 \mathrm{~Hz}$. A short period of intense shaking ensures that convection is initiated and a period of lower intensity maintains the motion while preventing the bed of powder from expanding and losing bulk density which would be detrimental to the XRD measurement.

Granular convection is a well-known phenomenon that finds few practical applications. It has been studied principally with reference to large beds of mm-sized particles, but little was known about the physics of granular convection in the micrometer range of the CheMin samples, or in the thin bed geometry of the CheMin sample cell. Granular flow in CheMin cells was modeled by Dr. C. Campbell (USC) using discrete particle computer simulations, and studied empirically by Particle Image Velocimetry (PIV). In PIV, contrast features (not necessarily individual grains - in fact the grains can be below the resolution of the observations) are identified and tracked from frame to frame in a sequence of captured video frames of particle motion. Vectors are drawn between the features to calculate granular flow velocities and bulk powder movement.

Both PIV and discrete particle computer simulations were carried out to better understand granular flow phenomena and predict the operation of the system at Mars surface conditions (lower gravity and lower pressure). The study of XRD data quality versus convection speed demonstrated that the velocity of convection has no real influence on quality of diffraction as long as the bed of powder is kept moving constantly. A pause in the motion will cause large grains to stay in a diffraction condition for an extended period of time, resulting in bright diffraction spots on the detector that anomalously increase the relative intensity of the corresponding XRD peaks. The main requirement for granular convection therefore, is that is must be robust.

Using PIV measurements, the velocity of granular flow was evaluated as a function of shaking conditions. It was found that above a specific vibration amplitude threshold, granular velocities are linear with amplitude for a given frequency (Fig. 7-left). The onset threshold for granular convection is reduced at higher frequencies (Fig. 7-right).

The granular flow model was used to evaluate the effect of Mars gravity. Simulations run under Earth (E) and Mars (M) gravity (Fig. 8) show that at slightly higher velocities, flow patterns at Mars gravity are equivalent to those at Earth gravity. This is at odds with what is known about conventional granular convection in large beds of particles, for which the vibration required for a given velocity scales linearly with gravity. This difference in behavior is due to the predominance of grain-wall interactions in the thin cells of the CheMin instrument, as opposed to the predominance of inertial effects in thick beds.

The effect of gravity was also studied experimentally by making PIV measurements of granular convection in a vibrated cell aboard a Piper Cherokee aircraft while performing 

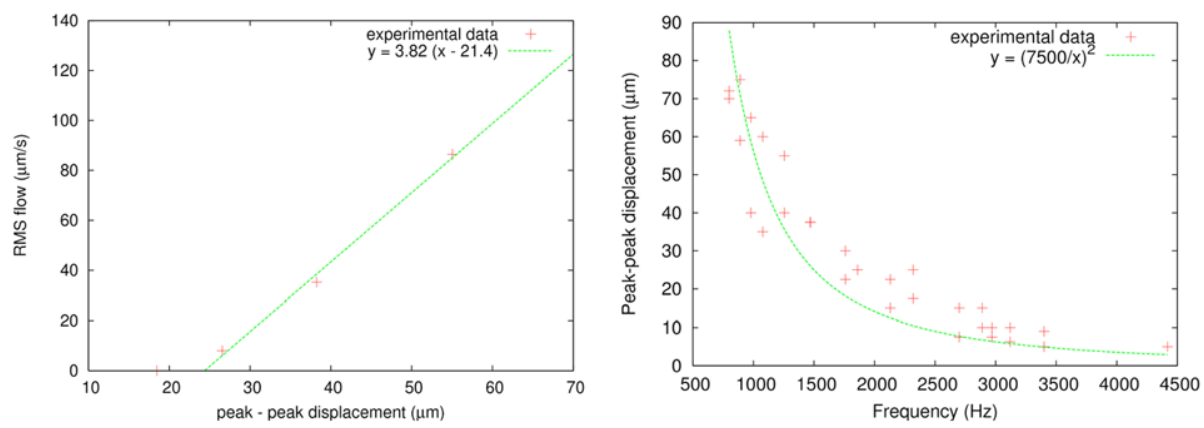

Fig. 7 Left: PIV velocity averaged over entire cell as a function of peak-peak shaking amplitude $(960 \mathrm{~Hz})$, Right: Plot of vibration amplitude threshold necessary to initiate convection, as a function of frequency

Fig. 8 Granular flow pattern simulations at Earth gravity (E, left) and Mars gravity (M, right) showing similar flow patterns and slightly higher velocities at Mars gravity
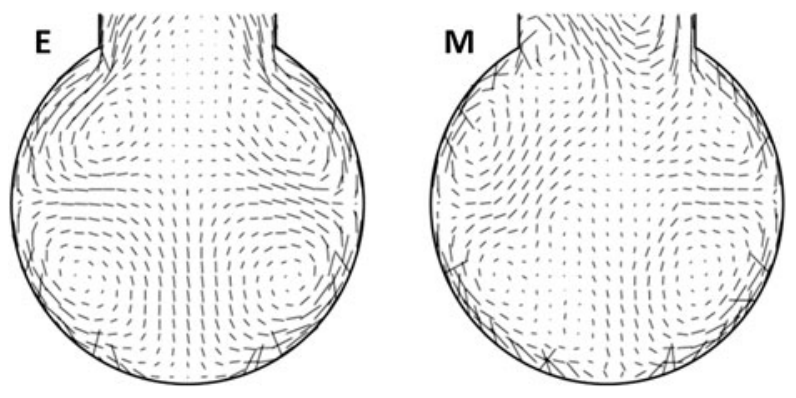

a series of mini parabolic flights over the Pacific Ocean. Periods of 3-4 s at Mars gravity could be obtained. Slightly faster convection was observed under Mars gravity conditions. It was shown that only a small reduction of the vibration amplitude is required to maintain the same convection velocity from Earth to Mars gravity. For example a $30 \mu \mathrm{m}$ peak-to-peak vibration at Earth gravity is equivalent to $25-28 \mu \mathrm{m}$ at Mars gravity. Practically speaking, therefore, granular convection in Earth gravity is roughly equivalent to granular convection in Mars gravity.

The effect of the reduced atmospheric pressure on Mars was studied with the model and tested in a chamber at Mars pressure under dry conditions. No substantial effect could be associated with reduced pressure, although the transition from non-dry Earth conditions to low-pressure Mars conditions substantially slowed the convection. The transient state is due to water adsorbed on grains that increases the grain-grain cohesion when the pressure in reduced. Once the adsorbed water is removed, dry samples showed convection similar to that observed at ambient conditions.

The effect of electrostatic charging on granular flow under dry Mars conditions was also evaluated. A dedicated study was conducted by both modeling and experimental measurement of granular convection in a vibrated cell placed in a Mars atmospheric chamber. PIV measurements were made and charge accumulation on the windows measured. It was observed that granular flow initially creates a voltage on the windows by tribocharging, but this charge does not accumulate or persist. Most likely the charge is transported away by grain flow. PIV measurements showed no influence of this charge on granular convection. Based on this research, convective flow in vibrated sample cells on Mars should be similar to that observed on Earth. 
Vibration is known to cause grain segregation when grains vary in size, density, shape or some other feature. Grain segregation in the CheMin vibrated cells is a concern because the analysis is performed in a very small volume in the middle of the cell. Preferential settling of a phase in any region of the cell would affect the measurement of mineral composition. Segregation in vibrated beds has been observed in particular when vibration amplitude is reduced to the point the convection no longer happens or happens very slowly, finer or denser particles are allowed to settle in lower regions of the cell. With higher vibration levels, the convective flow mixes the materials inside the cell at higher speed than segregation occurs, resulting in a cancellation of the effects of segregation in most cases. Segregation is still observed in the presence of convection in some extreme cases such as prepared mixtures of coarse grained materials with substantially different density (example: quartz + corundum). In order to limit this bias, the vibration profile includes a periodical shaking at very high amplitude for periods of a few seconds. This intense shaking is referred to as "Chaos mode" for the fast unstructured motion resulting in the cell, and has the effect of mixing and homogenizing the material. A case of apparent segregation in a beryl-quartz calibration sample data set from the flight instrument is presented in Sect. 4.2.1, thought to be due to the lack of chaos mode pulses during this particular measurement.

Another possible bias in the measurement of mineral composition is agglomeration of particles in the cell. This is observed at the edges of the cell in particular when the sample contains fines. The agglomerates are wedged between the polymer windows where they can least flex. These agglomerates grow over time as additional particles are jammed into them. As an example, crushed sandstone is likely to show a preferential agglomeration of the fine-grained cement matrix phases at the edge of the window, resulting in an apparent enrichment of the coarse sand particles (quartz) in the middle of the cell where the analysis is performed. The chaos mode also proves effective at limiting this agglomeration as long as the intense shaking pulses are applied frequently to break agglomerates in an early state of formation. If agglomerates are allowed to grow and compact over tens of minutes or hours, their compactness and resulting cohesion can make them difficult to break up and disperse with the chaos mode.

While segregation and agglomeration are of concern, methods have been found to mitigate or cancel them, and such methods have been validated by accurate quantitative analyses obtained with CheMin derived XRD instruments used at NASA Ames Research Center, NASA Johnson Space Center, Jet Propulsion Laboratory, Los Alamos National Laboratory, and Indiana University (see for example, Bish et al. 2008; Blake et al. 2009; Treiman et al. 2010; Achilles et al. 2011; Taylor et al. 2012). A good metric to evaluate the presence or absence of either segregation or agglomeration is to monitor the measured composition as a function of time during an analysis. Selective segregation or agglomeration progressively increases the proportion of one or more specific phases during an analysis. In such cases, more accurate compositional data are obtained at the beginning of the analysis, assuming the cell has not been shaken for an extended period between loading and start of the analysis.

\subsubsection{Optimization of the CheMin Geometry for X-Ray Flux and $2 \theta$ Resolution}

The first optimization of the CheMin X-ray geometry from an XRD performance standpoint was performed using a dedicated ray-tracing program called CheminRay that can simulate diffraction geometry based on the following components:

(1) A microfocused X-ray tube with adjustable spot size. The spectral characteristics of this source include $\mathrm{K} \alpha_{1}, \mathrm{~K} \alpha_{2}$ and $\mathrm{K} \beta$ lines with their specific peak width, shape and relative intensity, and bremsstrahlung radiation. 
(2) An elliptical (or circular ) pinhole with an adjustable radius and thickness or a slit collimator with adjustable size $(x-y)$ and distance to the X-ray source.

(3) A flat sample of a perfect randomly oriented powder in transmission with adjustable angle to the X-ray beam, distance to the collimator, thickness, compactness and composition (mineral or mixture of minerals). The interaction with the powder is calculated as a "reflectivity" (probability of diffraction) for each photon, as it depends on its energy and direction. When a photon is diffracted its path through the sample is modeled and an absorption probability is calculated. Any photon may be diffracted, transmitted or absorbed.

(4) A CCD of adjustable dimensions, pixel size, angular orientation to the direct beam, and $x, y$ position relative to the direct beam. An energy range can be selected taking into account the energy resolution capability of the CCD (allowing simulation of K $\alpha$ data, for example).

All parameters can be set manually to simulate a specific geometry. Up to 3 parameters can be set as variables, scanned within a grid to study a range of configurations, and any set of parameters can be used as variables for optimization with a genetic algorithm approach. The data products of CheminRay include a 2-D image representing the distribution of diffracted photons on the CCD and a 1-D diffractogram resulting from the circumferential integration of intensity around the diffraction rings. An automatic line fitting tool imbedded in the application produces XRD peak intensities, peak shapes and peak positions which can be used for the optimization.

CheminRay is a virtual prototyping and testing tool. The advantage of ray tracing over other modeling approaches is that numerous parameters can be taken into account, yielding a numerical simulation with high fidelity to the real-world experiment. A drawback however, is that such simulations are time-consuming because as with real experiments the signal to noise ratio depends on the number of photons used in the model, hence the amount of computation time.

The starting point of the geometry optimization was the CheMin III instrument (a precursor to CheMin IV, the principal testbed of the CheMin flight instrument) available in the laboratory. The accuracy of CheminRay was first verified by comparing experimental data from CheMin III to simulated data of the CheMin III geometry as shown in Fig. 9. The CheMin III collimator design was then optimized using both a genetic algorithm and a grid scanning approach. Genetic algorithms apply techniques inspired by evolutionary biology to optimize a result by evolution from generation to generation of a population of potential solutions. In each generation, the fitness of the whole population is evaluated and individuals are selected and combined with a fitness-dependent probability to form a next generation of parameters. The formulation of "fitness factors" and "evolutionary rules" is critical in achieving an actual parameter optimization. The objective of the optimization of CheMin was to achieve the best resolution with the highest flux intensity. A number of fitness factor definitions were tested based on a mathematical combination of resolution and intensity, but all definitions proved to be too restrictive, leading to a particular throughput / resolution compromise. The genetic algorithm was modified to maximize the throughput of classes of XRD resolution as defined as the maximum FWHM observed in the XRD pattern. Computed populations of configurations were then reported in throughput versus resolution. After selecting a target resolution, the optimum configuration (in this case, a refinement of pinhole diameter and distance to the source) was obtained from the best configurations in the corresponding resolution class. Studies utilizing a grid scan led to similar results. The optimized geometry, which results in a resolution of $0.3^{\circ} 2 \theta$ was chosen for implementation 

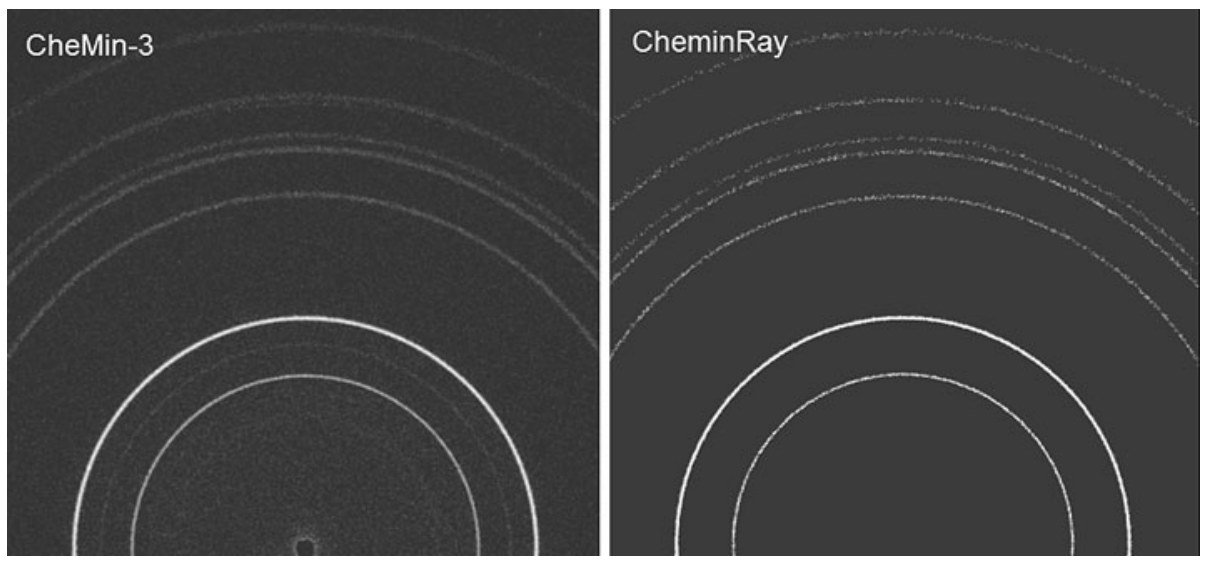

Fig. 9 Experimental K $\alpha$ 2-D patterns from the CheMin III instrument (left) compared to CheminRay results for the same geometry (right). The patterns differ mostly in background intensity and residual $\mathrm{K} \beta$ rings present in the experimental data
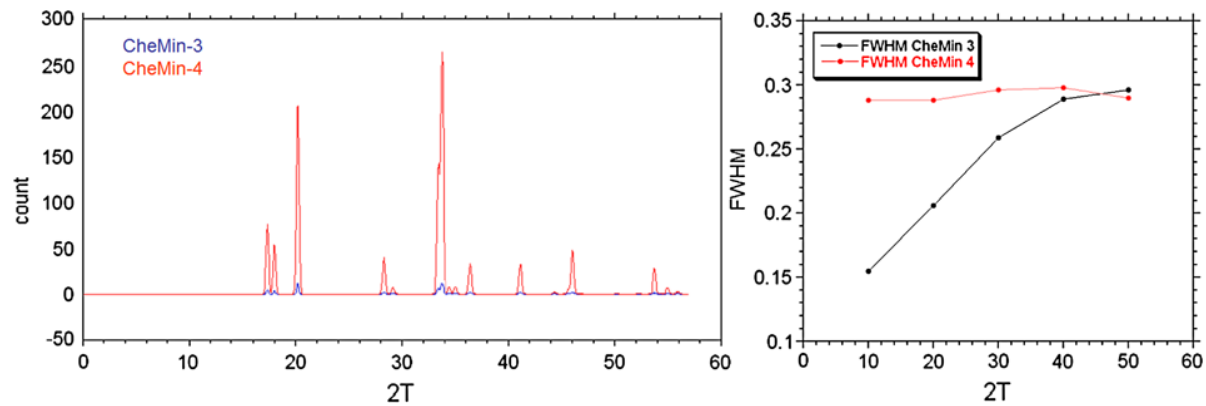

Fig. 10 Comparison of performance of CheMin III (blue) and optimized CheMin IV geometry (red) using CheminRay simulations. Left: computed XRD pattern of Jarosite showing a $20 \times$ increase in integral intensity for the CheminRay optimization. Right: Resolution curve for the optimized geometry. While CheMin III offers higher resolution at low $2 \theta$ angles, for minerals, such high resolution at low $2 \theta$ is not required. The chosen optimization is based on high photon throughput with a flat resolution curve across $2 \theta$

in the CheMin IV instrument. A $20 \times$ increase in the XRD throughput (X-ray flux) was calculated compared to the CheMin III geometry, with a uniform $2 \theta$ resolution along the full range of $2 \theta$ (e.g., see Fig. 10).

Similar optimization approaches with more parameters were taken to explore the potential of different instrument parameters for the flight instrument. In particular, optimized geometries were proposed based on a dual X-ray tube layout as specified in the early stage of the flight instrument development. After the second X-ray source was descoped, an instrument geometry was proposed based on a slight evolution of the CheMin IV design, having a single X-ray tube, and sample and CCD detector both perpendicular to the beam. CheminRay was used to study the effect of parameters such as pinhole diameter or sample thickness on resolution, intensity, peak asymmetry and peak shift. Ray tracing results were backed by experimental verification of selected geometries using a dedicated breadboard instrument based on commercial grade components. 
Once the geometry of the system was established, a second model was developed based on a mathematical description of the diffracted intensity at the CCD taking into account all critical parameters of the geometry. Unlike the ray tracing model which could virtually explore all possible configurations but required extensive computation time, this model limits its scope to the chosen geometry through a number of approximations, but requires far less computation time. The output of the mathematical model was verified with ray tracing results as well as experimental data from breadboard instruments. This model was a critical engineering tool for the design of the flight instrument, allowing detailed investigation of the effect of small variations of design parameters on the resulting patterns. The model was used primarily to link engineering requirements to MSL level II science objectives. Small but significant adjustments were made to the geometry using this tool.

\subsubsection{Fundamental-Parameters Modeling of Profiles Produced by CheMin}

Line profile fitting is the basic approach to obtain phase contents and structure information from X-ray powder diffraction data. Typically, two methods are used for line profile fitting: Constrained or unconstrained analytical profile fitting, and the fundamental parameters method.

In the first method, empirical instrument profile functions (mathematical functions) are used to simulate the observed diffraction pattern. In some cases, these mathematical functions are convolved with other empirical descriptions of instrument- and sample-related contributions to generate a simulated diffraction pattern. The disadvantage of this method is that refinable variables relating to the instrument profile functions have no clear physical meaning; they are simply empirical mathematical functions. Profile parameters resulting from a refinement are generally not sensible, even though refinements converge well, giving acceptable residual factors. In such cases, it is often common to apply mathematical constraints to the refinement to obtain reasonable results.

In the case of fundamental parameter descriptions of profiles, all of the geometrical parameters of the entire instrument are mathematically described and are convolved together. In this case, results of refinement have definite physical meanings. By convolving the individual instrument parameter functions together, an instrument profile can be generated, and if these functions accurately describe the instrument, the simulated instrument profile can be very accurate (as determined through the use of profile standards such as NIST SRM 660a $\mathrm{LaB}_{6}$ ). This instrument profile can then be convolved with sample-related profiles to simulate the experimental diffraction pattern. Generally the individual instrument contributions to the observed profile are well known, for example, the diffraction geometry, slits, radius, etc., employed in a Bragg-Brentano powder diffractometer. Some instrument-related parameters are not precisely known, and refinement of these within a limited range can ultimately provide instrument functions that have physical meaning, in contrast to the analytical profile functions used in the empirical line profile fitting method. As a result, structure and phase information resulting from a refinement are more realistic and accurate.

The geometry of the CheMin instrument is shown schematically in Fig. 1. X-rays are generated by a Co radiation source, they are shaped by a collimator, and they are ultimately diffracted by the sample. The instrument profile for this configuration can be simulated by convolving the radiation source spectrum of $\mathrm{Co}$ with a function for the beam size aberration, a function for the collimator, and a function accounting for sample thickness. The source emission profile is generated by convolving seven $\mathrm{Co} \mathrm{K} \alpha$ lines and six $\mathrm{Co} \mathrm{K} \beta$ lines with a Lorentzian function (Hölzer et al. 1997). The $\mathrm{K} \beta$ lines in the diffraction pattern originate from radiation leakage (e.g., $\mathrm{K} \beta$ photons that have lost charge ("split events") and fall into 


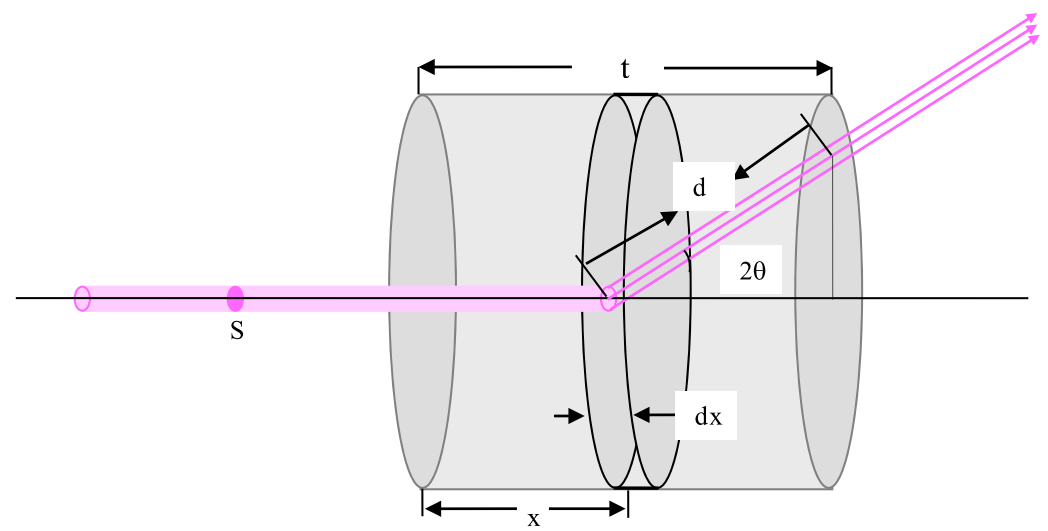

Fig. $11 \mathrm{X}$-ray paths in the sample for normal-beam-transmission diffraction. $S$ is the cross sectional area of the X-ray beam after being shaped by the pinhole collimator. Parameter $t$ is sample thickness, $X$ is the distance the X-rays travel before diffraction, and $d$ is the path of the diffracted beam in the sample. Parameter $d x$ is the thickness of the volume element, and $2 \theta$ is the diffraction angle. The total diffracted intensity at any angle $2 \theta$ is the integration of the volume element over the sample thickness

the $\mathrm{K} \alpha$ energy window), and the intensities are thus allowed to be refinable, maintaining their relative intensities. The finite X-ray beam size effect is approximated by a Gaussian function rather than an impulse function (Young 1993), and the collimator is described by a circular function.

Absorption Correction for the Normal-Beam-Transmission Diffraction Experiment The diffraction geometry for the CheMin instrument is a normal-beam-transmission geometry. As shown below, diffraction intensities vary systematically with diffraction angle $2 \theta$ for this instrument geometry resulting from sample absorption (which is not the case in Bragg-Brentano geometry). Thus an absorption correction must be applied to obtain accurate diffraction intensities for Rietveld refinement, in order to provide reasonable phase contents and structural details. With reference to Fig. 11, $I_{0}$ is the diffraction intensity of a unit volume sample at angle $2 \theta$ under the condition of zero absorption, $S$ is the crosssectional area of the direct beam at position $x$ in a sample of thickness $t, x$ and $d$ are the path lengths of the X-ray in the sample before and after diffraction, and $\mu$ is the linear absorption coefficient of the sample. The diffracted intensity from the volume element $S d x$ with diffraction angle, $2 \theta$, is:

$$
d I=I_{0} e^{-\mu(x+d)} S d x=I_{0} S e^{-\mu[x+(t-x) \sec 2 \vartheta]} d x
$$

The total diffracted intensity at diffraction angle $2 \theta$ is the integration of $d I$ at the same angle over the range of sample thickness $x \in[0, t]$.

$$
\begin{aligned}
I_{2 \vartheta} & =\int_{0}^{t} d I=\int_{0}^{t} I_{0} S e^{-\mu[x+(t-x) \sec 2 \vartheta]} d x \\
& =\frac{I_{0} S e^{-\mu t \sec 2 \vartheta}}{\mu(1-\sec 2 \vartheta)}\left(1-e^{-\mu t(1-\sec 2 \vartheta)}\right)
\end{aligned}
$$

Relative intensities are used instead of absolute intensities in Rietveld refinement, in both the analytical profile fitting and fundamental parameter method, and therefore the intensities at diffraction angle $2 \theta$ can be normalized to the intensities at $2 \theta=0$ :

$$
I_{2 \theta=0}=I_{0} S t e^{-\mu t}
$$


The normalization factor for the intensity correction is

$$
f_{2 \vartheta}=\frac{I_{2 \vartheta}}{I_{2 \vartheta=0}}=\frac{e^{\mu t(1-\sec 2 \vartheta)}-1}{\mu t(1-\sec 2 \vartheta)}
$$

Beryl-Quartz Mixture Results Diffraction data were obtained in the CheMin FM instrument for a $97 \%$ beryl, $3 \%$ quartz mixture by integration of the Debye rings on the 2-D diffraction image. Intensities were corrected for sample absorption according to Eq. (4). During Rietveld refinement, data in the range $5-8^{\circ} 2 \theta$ were excluded to remove the contribution from the Kapton ${ }^{\circledR}$ window. Data above $53^{\circ} 2 \theta$ were also excluded, as data in this region originate from the edges of the $\mathrm{CCD}$ detector and resultant Debye rings are poorly represented. The quality of the fit for the four minor peaks at high diffraction angles is comparatively poor, probably for the same reason. Both structural parameters and instrumental parameters were refined using the FM instrument diffraction data and the fundamental parameters method. Sample linear absorption coefficients, sample thickness, and sample packing factors were also refined. The refinement converged to a weighted profile or agreement factor ("Rwp") of $12.6 \%$. Beryl is the major phase in the sample and quartz is only a minor phase, with a refined wt.\% of 1.9. These data were also fit using the analytical profile fitting method, using the popular modified Thompson-Cox-Hasting pseudo-Voigt function (Young 1993). The refinement converged to a larger Rwp factor of $18.2 \%$, with a large difference between calculated and experimental intensities, particularly for the first beryl peak. Although the phase content of quartz resulting from this refinement $(2.6 \%)$ is more accurate than the result obtained with the fundamental parameters method, the fit quality is significantly inferior and it is not possible to obtain information on sample-related broadening effects. For this reason, the fundamental parameter approach will be used in the refinement of the CheMin instrumental broadening function and the analysis of CheMin data.

\subsection{Measurement of the Energies of Individual Photons}

The CCD-224 directly detects individual X-ray photons that are absorbed by the active silicon, producing a number of electron-hole pairs equal to the energy of the X-ray in electron volts, divided by 3.65 (the energy of an electron-hole pair in the silicon structure). For example, a Co K $\alpha$ X-ray with an energy of $6.93 \mathrm{keV}$ will produce 1,899 electron-hole pairs. XRD and XRF data products are described in 1.9 below. The X-ray fluorescence requirement was descoped from the CheMin instrument for technical and budgetary reasons. However, energy discrimination is still required for the energy binning that will segregate $\mathrm{Co} \mathrm{K} \alpha$ and other energies critical to XRD. Although of secondary importance to the energy resolution of primary Co X-rays, qualitative elemental information from sample-generated secondary $\mathrm{X}$-ray fluorescence will also be important for supporting mineral identification by pinpointing the elements to be included or excluded in mineral search/match routines.

\subsection{XRD and XRF Data Products}

In order to retain energy information from individual X-ray photons, it is necessary to operate the CCD in "single photon counting mode." This is accomplished by exposing the CCD to the X-ray flux for only a brief interval between read cycles. During a nominal 5-30 second single-frame exposure, the likelihood is low that more than one photon (characteristic, Bremsstralung or fluorescent) will be collected in any single pixel of the array (most of the nearly 360,000 pixels will contain background). Raw data consist of $600 \times 582$ arrays that store charge collected from individual CCD frames. The data are stored as "Digital 

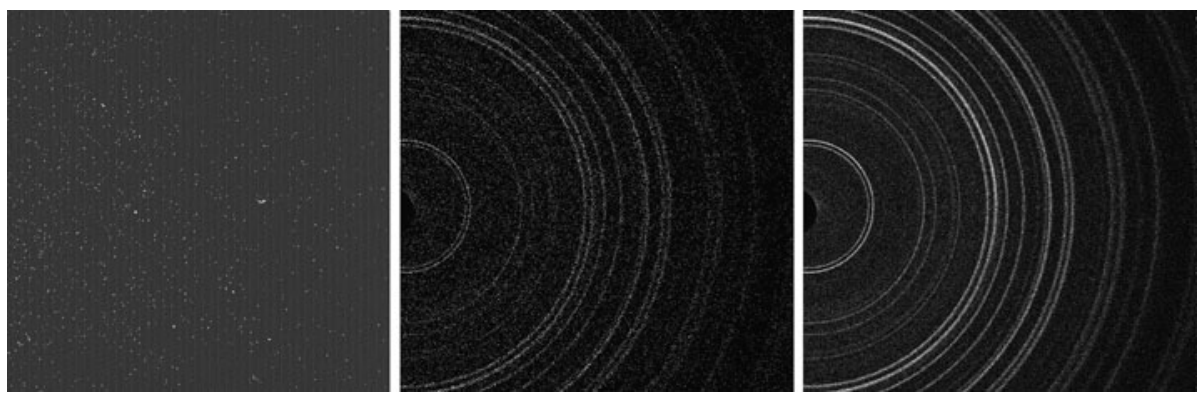

Fig. 12 2-D diffractograms from the Gore Mountain amphibole (obtained from the CheMin Flight Model (FM) during ThermoVac testing). Left: A single 30-second frame of raw data containing all detected photons (characteristic and continuum radiation from the X-ray tube plus sample-generated secondary fluorescence). Middle: Minor frame of energy-selected Co K $\alpha$ data, summed from 200 single frames. Right: Major frame of energy-selected Co K $\alpha$ data, summed from 7 minor frames

Numbers" or "DN" that are transformed to energy (in keV) subsequent to downlink. During a CheMin analysis, individual CCD images are stored in memory (up to a total of 2,730 images or frames of $600 \times 582$ pixels). Ideally, all raw frames would be transmitted to ground for processing. However the data volume is too large for this to be feasible. The raw CCD frames are therefore processed into a number of higher-level data products by the Rover Compute Element (RCE) and selected data products are subsequently transmitted to ground. However, a small number of individual raw frames will be downlinked to monitor background before the X-ray tube is powered on, at intervals during the analysis, and after the X-ray tube is powered off. These raw frames will be utilized to assess the health of the CCD over time and to choose DN values suitable for background and high and low DN limits for energy-selected diffraction products (such as $\mathrm{CoK} \alpha$ ). If for whatever reason, the background or high and low limit DN values have changed between analyses or even between individual minor frames, the quality of the higher-level data products will have been compromised. In this event, the correct DN values can be determined on the ground from the raw frame data and uplinked to the spacecraft on a following Sol. The full complement of raw frames from an analysis are retained in CheMin's flash memory and can be reprocessed by the RCE using the correct DN values, and a corrected set of higher-level data products can be retransmitted to ground. Ten to 200 raw frames are collected and processed by the RCE to produce "Minor Frame" data products (described below). Five to 20 minor frames collected within a single sol, typically at night, are referred to as a "Major Frame." A complete analysis of an individual sample, which may require one or more sols, is called an "Observation." Major frames and Observations are assembled on the ground from downlinked Minor Frame products.

Figure 12 shows data obtained from the CheMin FM instrument during ThermoVac testing. Background-subtracted single raw frames (Fig. 12, left) contain all photons detected by the CCD during a single 30 -second exposure. Various minor frame products are generated from raw frames by the RCE and transmitted to ground. Figure 12 (middle) shows an energy-selected $\mathrm{Co} \mathrm{K} \alpha$ data product, summed from $\sim 200$ single frame images. Figure 12 (right) shows a major frame product, assembled on the ground from 7 minor frame images.

Minor frame and major frame 1-D patterns are constructed on the ground by summing the images circumferentially around the central beam, resulting in a 1-D diffractogram similar to that obtained by conventional XRD instruments (e.g., Fig. 13). Phase identification and quantitative analysis are performed on the 1-D data. 

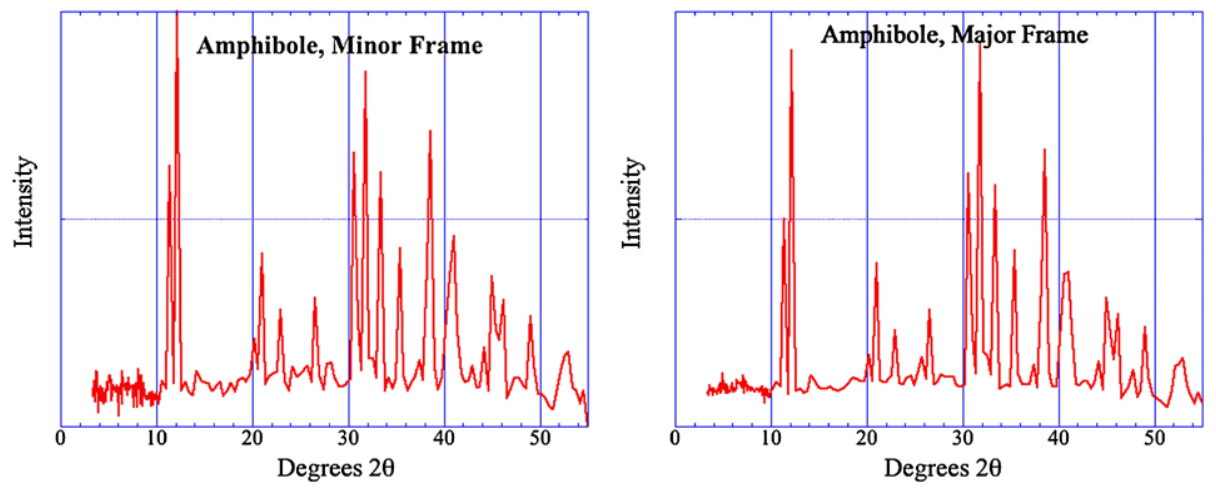

Fig. 13 1-D diffractograms from the Gore Mountain amphibole. At incremental radii 2-D patterns as in Fig. 12 are summed circumferentially about the central nondiffracted beam to yield a one-dimensional plot of $2 \theta$ versus intensity comparable to conventional XRD data. Left: Minor frame Co K $\alpha$ diffractogram. Right: Major frame $\mathrm{Co} \mathrm{K} \alpha$ diffractogram. Intensity in arbitrary units

CheMin's XRF detector was descoped from the instrument due to perceived cost and risk factors. However, limited XRF data from the CCD detector will be provided to the extent they are available. Figure 14 shows single frame, minor frame and major frame XRF data from the Gore Mountain amphibole. The instrument is only sparingly sensitive to elements below atomic number $19(\mathrm{~K})$ as a result of sample self-absorption, the aluminized light shield, and Mars atmosphere absorption. However, even the limited XRF data provided by the $\mathrm{CCD}$ detector will be useful in the discrimination of mineral phases.

"Fully Processed" Data "Fully processed" data are comprised of $600 \times 582$ twodimensional (2-D) arrays of energy-selected Co $\mathrm{K} \alpha$ and $\mathrm{Co} \mathrm{K} \beta$ X-rays, plus a onedimensional (1-D) Energy-Dispersive Histogram (EDH). The integer value in a particular $x, y$ position in a $\mathrm{Co} \mathrm{K} \alpha$ or $\mathrm{Co} \mathrm{K} \beta$ array represents the number of $\mathrm{Co} \mathrm{K} \alpha$ or $\mathrm{Co} \mathrm{K} \beta \mathrm{X}$-rays that were detected in the corresponding $x, y$ pixel of the CCD array (a DN value in the array is considered to represent a $\operatorname{Co~} \mathrm{K} \alpha$ or $\operatorname{Co~} \mathrm{K} \beta$ photon if its background-subtracted value fits within upper and lower values ground-specified for $\mathrm{Co} \mathrm{K} \alpha$ or Co $\mathrm{K} \beta$ events). Co $\mathrm{K} \alpha$ and Co $\mathrm{K} \beta$ diffraction events can be treated separately; in practice the Co $\mathrm{K} \alpha$ pattern is significantly stronger and will be the primary product. The 2-D patterns are transformed into 1-D diffractograms on the ground by the CheMin science team by summing circumferentially about the central beam. The resulting 1-D patterns are normalized for number of pixels versus $2 \theta$ and normalized to account for variable arc length. The energy histograms provide performance-check information on CCD function and may be used to aid in constraining search/match procedures in XRD analysis. Several ground-selectable Minor Frame products that utilize the energy-discriminating capability of the CCD can be calculated by the RCE and transmitted to ground. These include:

"XRD energy-selected mode": If the background-subtracted DN value in an $x, y$ pixel falls between ground-specified low and high values, a 2-D counting number array is incremented by one at that $x, y$ location in the counting number array. The result is a 2-D array that represents all of the detected X-ray events that lie within a specified energy window. Windows may be chosen for the energies of $\mathrm{Co} \mathrm{K} \alpha$ and $\mathrm{Co} \mathrm{K} \beta$ photons (these constitute Co $\mathrm{K} \alpha$ or $\mathrm{Co} \mathrm{K} \beta$ diffraction patterns); as noted above the general case will be selection of $\mathrm{Co} \mathrm{K} \alpha$. Two further refinements of this mode can be selected: 

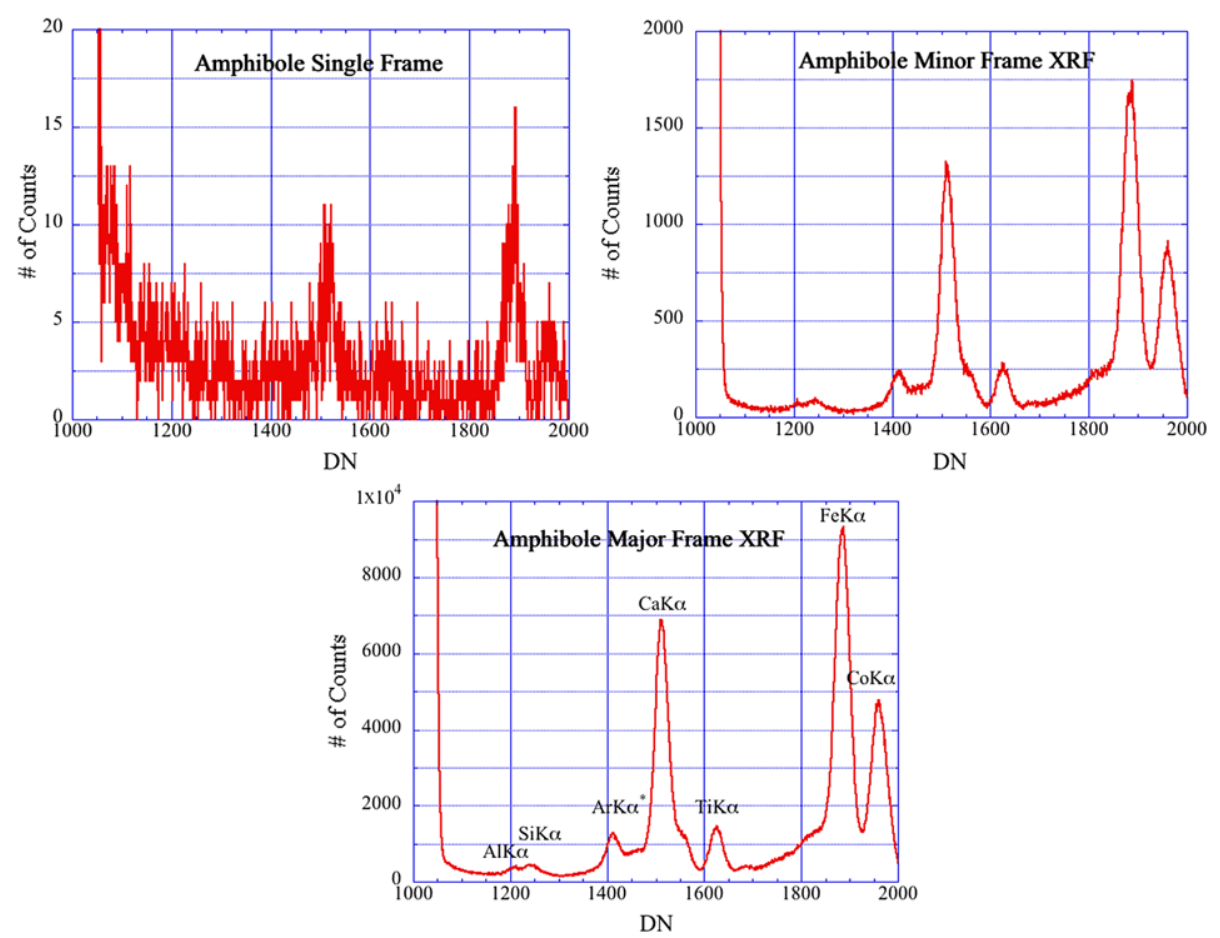

Fig. 14 XRF Energy-Dispersive Histograms (EDH). Left: Single frame EDH from Gore Mountain amphibole. Right: Minor frame EDH, sum of 200 single frame EDH. Middle: Major frame EDH, sum of 7 minor frame EDH. Elements detected from the sample include $\mathrm{Fe}$, Ti and $\mathrm{Ca}$. Cobalt originates from the X-ray tube, argon from the 7 Torr argon atmosphere of the test chamber, silicon from self-fluorescence of the CCD detector and aluminum from the CCD light shield, and only in part from the amphibole

"Single pixel mode": If the background-subtracted DN value in an $x, y$ pixel falls between ground-specified low and high values, and nominal zero values are present in the four pixels immediately above, below, right and left of the $x, y$ pixel of interest, a 2-D counting number array is incremented by one at that $x, y$ location in the counting number array. This mode differs from the general case in that X-ray "split pixel" events, in which charge from a single photon is shared within two or more adjacent pixels, will not be counted. Single pixel mode $\mathrm{Co} \mathrm{K} \alpha$ patterns have fewer peak artifacts in their patterns because in normal energy-selected mode, $\mathrm{Co} \mathrm{K} \beta$ photons which split a small amount of charge into an adjacent pixel may be counted as $\mathrm{Co} \mathrm{K} \alpha$ photons.

"Summed Split Pixel mode": If the background-subtracted sum of the DN values of an $x, y$ pixel plus the four pixels immediately above, below, right and left of the $x, y$ pixel of interest falls between ground-specified low and high values, a 2-D counting number array is incremented by one at that $x, y$ location in the counting number array. This mode attempts to count single pixel events as well as split pixel events. Summed split pixel mode patterns will maximize the number of $\mathrm{Co} \mathrm{K} \alpha$ counts while removing $\mathrm{Co} \mathrm{K} \beta$ photons which have split a small amount of charge into an adjacent pixel.

"XRF (all photons) mode": All of the background-subtracted DN values in the $600 \times 582$ CCD array are summed into a 1-D histogram of DN value vs. number of counts. This array amounts to an energy-dispersive histogram (EDH) of the sample, plus characteristic 
and Bremsstrahlung photons from the X-ray tube. XRF all photons mode EDH have a higher background and poorer energy resolution due to split pixel events that broaden the energy distribution of observed peaks. Two further refinements of this mode can be groundselected:

"XRF single pixel mode": Background-subtracted DN values from each $x, y$ pixel that have nominal zero values in the four pixels immediately above, below, right, and left of the pixel of interest are summed into a 1-D histogram of DN value vs. number of counts. This array amounts to an energy-dispersive histogram (EDH) of the sample, plus characteristic and bremsstrahlung photons from the X-ray tube, excluding split pixel events. XRF single pixel mode EDH provide for the lowest background and highest energy resolution because split pixel events, which broaden the energy distribution of observed peaks, are removed.

"XRF split pixel mode": Background-subtracted DN values from each $\mathrm{x}, \mathrm{y}$ pixel plus the DN values in the four pixels immediately above, below, right and left of the pixel of interest are summed into a 1-D histogram of DN value vs. number of counts. This array amounts to an energy-dispersive histogram (EDH) of the sample, plus characteristic and bremsstrahlung photons from the X-ray tube, including reconstituted split-pixel events. $\mathrm{XRF}$ split pixel mode processing will provide the maximum count rate but will provide poorer resolution because of split events, which when summed, show some energy losses relative to the charge deposited by the incoming photon.

"Modified Raw" Patterns Modified raw patterns are produced by background subtracting a frame, setting CCD pixels below a specified DN value to zero and run-length encoding the data. The DN cutoff can be near zero or just below the most useful energies (Fe $\mathrm{K} \alpha$ to $\mathrm{Co} \mathrm{K} \beta$ ). Following downlink, the 2-D patterns are reconstructed, transformed into 1-D diffractograms, and treated as in the fully processed mode.

"Film-Mode" Patterns In film mode, background values are subtracted from each frame and the DN values in the frame are then summed into a $600 \times 582$ counting number array. The resulting Minor Frame acts similarly to a piece of photographic film, detecting all photon events, including diffraction, fluorescence, bremsstrahlung, etc. This data product maximizes the number of counts that can contribute to the pattern, but background can be raised substantially if the sample exhibits strong fluorescence. There is a higher background associated with film-mode patterns and interpretation of film-mode diffraction is complicated by presence of both $\mathrm{Co} \mathrm{K} \alpha$ and $\mathrm{Co} \mathrm{K} \beta$ characteristic diffraction, as well as diffraction from tungsten L-line radiation that is produced as the cathode of the X-ray tube sputters onto the anode (this problem increases in severity as the tube ages). An additional complication arises when poor grain movement in the sample cell results in "spottiness" in the pattern due to multiple photon detections in the same pixel from grains that remain in the diffraction orientation. Indeed, film-mode images are used to diagnose grain movement problems if anomalous peak intensities are suspected in 1-D patterns. The 2-D patterns that are downlinked in film mode are transformed into 1-D patterns as in the previous data types but the multiple diffraction energies produce a pattern that is more difficult to interpret uniquely. Mixed intensities and multiple peaks for each d-value can preclude accurate phase identification or quantification in some samples. Film mode generally will not be used because of these problems and because of the high and irregular background, which degrades detection limits and removes any capability of detecting and quantifying amorphous components. However, under certain circumstances (e.g., extensive neutron damage from the RTG) the energy-dispersive function of the CCD may degrade to the point where separation of Co K $\alpha$ 
Table 3 Critical source and detector flight requirements for the CheMin flight instrument

\begin{tabular}{ll}
\hline Parameter & $\begin{array}{l}\text { Source and Detector } \\
\text { Characteristics }\end{array}$ \\
\hline $2 \theta$ range & $5-50^{\circ} 2 \theta$ \\
$2 \theta$ resolution & $\leq 0.35^{\circ} 2 \theta$ \\
Operating voltage & $28 \mathrm{keV}$ \\
Total flux & $5.6 \mathrm{E} 5$ \\
CCD energy range & $1-15 \mathrm{keV}$ \\
CCD energy resolution @ $6.93 \mathrm{keV}$ & $\leq 250 \mathrm{eV}$
\end{tabular}

and $\mathrm{Co} \mathrm{K} \beta$ XRD patterns is not possible. In such cases, XRD will still be possible in film mode.

Once a 1-D plot of $2 \theta$ versus intensity is obtained, standard methods of analysis for laboratory XRD data are applicable. The baseline approach for MSL XRD data will be to use the mineral identification utilities in programs such as Jade ${ }^{\circledR}$ (MDI, Pleasanton, CA), TOPAS (Bruker Corp.), and Xpowder ${ }^{\circledR}$ (Martin 2004), typically using ICDD or AMCSD library data and operator knowledge to identify minerals based on analysis of the 1-D diffraction pattern. Qualitative chemical information obtained from the EDH can be used to include or exclude certain elements, refining the search. Following identification of all minerals detectable in the sample, mineral abundances will be quantified. Quantification will be accomplished using either a program such as FULLPAT (Chipera and Bish 2002) or Rietveld methods (reconstruction of the full 1-D pattern from fundamental crystallographic properties of all phases present). The presence of amorphous material will be determined from broad scattering reflecting the radial distribution properties of the amorphous material.

\section{CheMin Science and Measurement Requirements}

\subsection{CheMin Science Requirements}

The overarching science requirement of the CheMin instrument is that it be able to “... utilize X-ray Diffraction to establish the mineralogy of rocks and soils, allowing the MSL science team to infer the formation and alteration histories of samples acquired by the mission." The CheMin measurement objectives are to provide: (1), mineral identification and quantitative mineralogy of rock and soil samples utilizing powder X-ray diffraction; (2), qualitative elemental composition of rocks and soils utilizing energy dispersive histograms (EDH); and (3), analyses of as many as 74 samples supplied by SA/SPaH CHIMRA during the nominal one-Mars-year surface mission.

\subsection{CheMin Measurement Requirements}

The CheMin measurement requirements are listed below. Critical source and detector requirements necessary to achieve these measurements are shown in Table 3.

- Detection limit of 3 wt.\%. "The CheMin instrument shall have the ability to achieve a detection limit of better than 3 wt.\% for crystalline phases (demonstrated by showing a minimum detection limit (MDL) of less than or equal to 3 weight percent abundance of quartz in a quartz-beryl mixture)." 
The rationale for this requirement is based on MER A (Spirit) observations of mineralogy at Gusev Crater (Ming et al. 2006; Morris et al. 2006, 2008). With a $2 \%$ detection limit, CheMin would not detect halides $\left(\mathrm{NaCl}, \mathrm{KCl}, \mathrm{MgCl}_{2}\right)$, indicators of groundwater action or deposition by acid fog ( $\sim 2 \%$ abundance at Clovis outcrop). With a $5 \%$ detection limit, CheMin would not detect goethite $(\mathrm{FeOOH})$, a positive indicator of basalt altered by water at oxidizing conditions ( $\sim 5 \%$ abundance at Clovis outcrop) and hematite $\left(\mathrm{Fe}_{2} \mathrm{O}_{3}\right)$, a probable indication of aqueous alteration $(\sim 4 \%$ abundance at Paso Robles outcrop). With a $10 \%$ detection limit, CheMin would not detect sulfates (gypsum/anhydrite and magnesium sulfates), positive indicators of aqueous alteration and soil forming processes (Clovis outcrop).

With a $3 \%$ MDL, the phases observed by CheMin are sufficient to identify the suite of sulfates at Clovis as well as phosphates, with local information bearing on outcrop vs. soil origins. In concert with APXS results, inferences could be made about the halide associations.

- Measurement accuracy of $15 \%$ relative and precision of $10 \%$ relative. "The CheMin instrument shall have the ability to determine the abundance of crystalline mineral phases present in the sample at 4 times the MDL to an accuracy of $15 \%$ relative $(1 \sigma)$ and a precision of $10 \%$ relative. This will be demonstrated by determining the abundance of quartz in a quartz-beryl mixture having $12 \mathrm{wt}$.\% quartz (4 times the required MDL).” This test is specifically written for the FM, but extended calibration using the DM will use a broad suite of natural and synthetic mineral mixtures of known abundance.

The rationale for this requirement is as follows: $15 \%$ relative accuracy and $10 \%$ relative precision for the measurement of $12 \%$ quartz in a quartz-beryl mixture is representative for many mineral mixtures and is a realistic goal for quantitative XRD in polyphase mixtures. However, the presence of amorphous or X-ray amorphous materials, or poorly crystalline materials such as clay minerals and Fe-Ox-hydroxide phases is expected to reduce both the precision and accuracy of analyses. This level of accuracy and precision in mineralogical measurements will be critical for mass-balance calculations of both igneous and sedimentary systems on Mars. There is an extensive literature of mass balance determinations for soils and sediments based solely on chemical (XRF or APXS) data using "assumed" mineral mixtures; a quantum improvement in these calculations will be attained when both mineral presence and abundance are constrained.

- Distinguish minerals at abundances above detection limits in a rock matrix. "The CheMin instrument shall, with an integration time of 10 hours, have the ability to distinguish unique minerals at abundances above detection limits in a rock matrix (e.g., calcite, gypsum and jarosite in an evaporite; apatite in a basalt). This will be demonstrated by measurement of the full-width at half-maximum (FWHM) intensity showing angular $(2 \theta)$ resolution of better than or equal to $0.35^{\circ}$ over the $2 \theta$ range from $24^{\circ}$ to $45^{\circ}(\mathrm{Co} \mathrm{K} \alpha)$, for quartz and beryl peaks in a mixture of $12 \mathrm{wt} . \%$ quartz and $88 \mathrm{wt} . \%$ beryl."

The rationale for this requirement can be illustrated using a model of the complex mineralogy thought to be present in Peace Outcrop, Columbia Hills (case 2 from Table 5 of Ming et al. 2006) on the basis of seven minerals modeled from APXS data. The modeled mineralogy includes forsterite, augite, labradorite, magnetite, chlorapatite, kieserite and gypsum. In Fig. 15 (upper) the principal lines for these seven minerals are shown over the $2 \theta$ range detectable by the CheMin instrument. There are clearly many close or overlapping lines in the important range from $30^{\circ}$ to $45^{\circ} 2 \theta$. Figure 15 (lower) shows the same stick diffractogram of 7 minerals, but with patterns that have been given artificial resolutions ranging from $0.30^{\circ}$ to $0.60^{\circ} 2 \theta$. Clearly, the decrease in $2 \theta$ resolution yields cases in which some minerals will not be identified in the analysis. Figure 16 shows the 
Fig. 15 (Upper): Positions of the major diffraction peaks of 7 minerals inferred from APXS data to be present in the Peace Outcrop, Columbia Hills by Ming et al. (2006), over the $2 \theta$ range detected by the CheMin instrument. Positions and intensities of the peaks were obtained from the ICDD powder diffraction database. Lower: as above, but showing the effect of instrumental $2 \theta$ resolution on modeled patterns. Resolution varies from $0.30^{\circ}$ to $0.60^{\circ} 2 \theta$
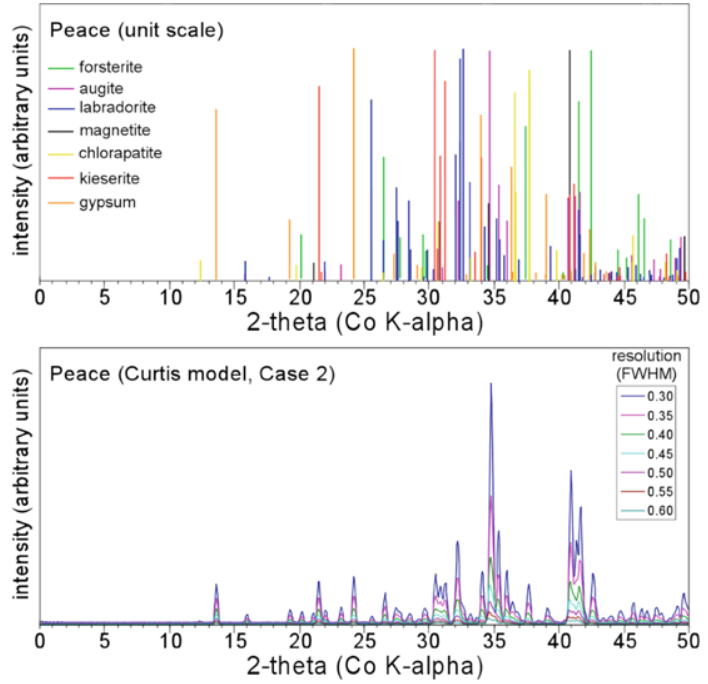

Fig. 16 A portion of the diffractogram shown in Fig. 15 (lower), showing the region between $30^{\circ}$ and $32^{\circ} 2 \theta$. As $2 \theta$ resolution is degraded below $0.30^{\circ} 2 \theta$, the ability to identify kieserite is lost. The presence of kieserite is suspected but not confirmed if the FWHM is worse than $0.35^{\circ} 2 \theta$

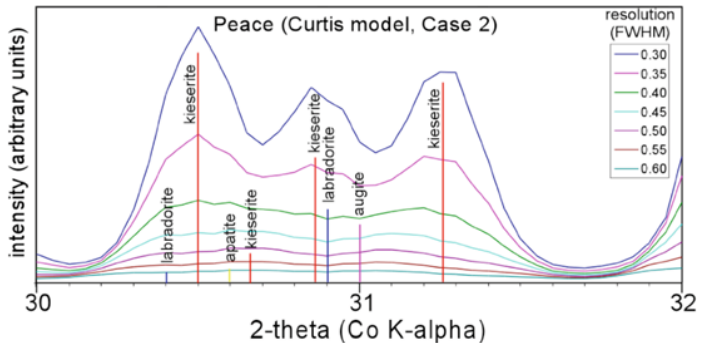

range from $30^{\circ}$ to $32^{\circ} 2 \theta$, a region in which labradorite, kieserite, apatite and augite peaks overlap. Although the kieserite $(-111)$ peak is still identifiable at $21.5^{\circ} 2 \theta$, identification of the kieserite triplet at $30^{\circ}$ to $32^{\circ} 2 \theta$ is lost as the FWHM goes from $0.35^{\circ}$ to $0.40^{\circ}$. The presence of kieserite is suspected but not confirmed if the FWHM is worse than $0.35^{\circ}$. The presence of kieserite vs. gypsum in an otherwise igneous rock has implications for the activity of activity of water, and the salinity of the hydrous fluid involved.

- Provide an energy-dispersive histogram $(E D H)$ with specified energy range and resolution. The CheMin instrument shall have the ability to return an energy-dispersive histogram (EDH) over the $0-15 \mathrm{keV}$ range with energy resolution sufficient to separate $\mathrm{Fe}$ $\mathrm{K} \alpha$, Co $\mathrm{K} \alpha$ and $\mathrm{Co} \mathrm{K} \beta$. This requirement can be met by analysis of an Fe-containing amphibole standard for 10 hours showing energy resolution of $250 \mathrm{eV}$ at $\mathrm{Fe} \mathrm{K} \alpha$ or $\mathrm{Co}$ $\mathrm{K} \alpha$.

The rationale for this requirement is as follows: The full $0-15 \mathrm{keV}$ energy range is needed for characterization of split events and to diagnose the quality of sample cell vibration by characterization of the incidence of double Co K $\alpha$ photon detections. A FWHM energy resolution $<250 \mathrm{eV}$ is a first priority requirement, needed to separate diffracted primary $\mathrm{Co} \mathrm{K} \alpha$ photons from fluoresced $\mathrm{Fe} \mathrm{K} \alpha$ (iron will be present as a major element in virtually all samples). As the FWHM of the detector increases above $250 \mathrm{eV}$, there will be an increase in the number of $\mathrm{Fe} \mathrm{K} \alpha$ photons that are included in the energy window chosen for $\mathrm{Co} \mathrm{K} \alpha$ detection. This will result in a decrease in the peak/background ratio in 

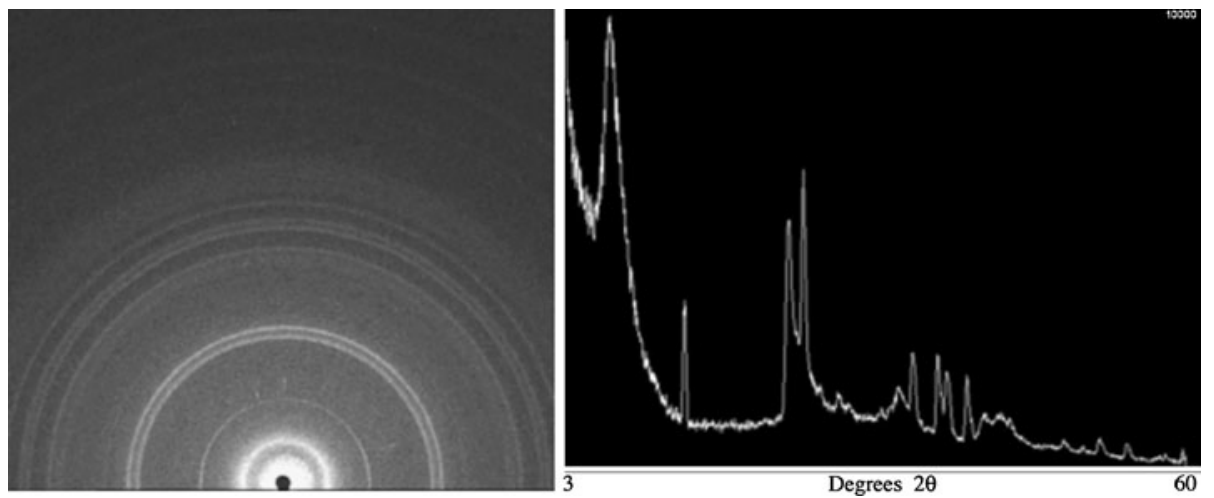

Fig. 17 (Left): 2-D image of diffraction pattern from a synthetic clay-bearing evaporite sample. The direct beam is at the lower center of the image; $2 \theta$ increases radially with distance from this point. Right: 1-D $2 \theta$ diffractogram derived from the 2-D image. The low angle detection capabilities of the CheMin IV instrument (which match the $2 \theta$ range and $2 \theta$ resolution of the CheMin flight instrument) are capable of detecting the basal spacing of all known natural phyllosilicates

diffraction patterns, and a degradation of the minimum detection limit. As a second level priority, while XRF analysis has been descoped, a simple determination of the presence or absence of an element will greatly aid in search/match mineral determinations.

\subsection{List of Available Flight, Demonstration, and Testbed Instruments and Components}

In addition to the Flight Model (FM) and Demonstration Model (DM) CheMin instruments, several prototype and testbed instruments or components have been and are being used during the calibration and characterization process. These are discussed below with a brief description of how each will be used in calibration and characterization.

\subsubsection{CheMin IV Testbeds}

CheMin IV instruments, fitted with a $1200 \times 1152$ pixel E2V 5530 CCD rather than the CCD-224 used in the FM and DM, but having comparable $2 \theta$ resolution, are currently operational at Ames Research Center, Jet Propulsion Laboratory and Johnson Space Center. These testbeds were used for early evaluation of candidate FM standards and evaluation of quantitative XRD performance using synthetic rocks, and are presently in use for the development of an XRD pattern library appropriate to the CheMin configuration. For example, Fig. 17 and Table 4 show CheMin IV results obtained from a synthetic mixture of phyllosilicate and evaporite minerals. In Fig. 17 (left), the $\sim 15 \AA$ d-value from nontronite $\left(7^{\circ} 2 \theta\right)$ is seen as the first spatially distinct bright ring of intensity around the undiffracted beam (a silhouette of the beam stop is seen at the center of the lower edge of the image). Figure 17 (right) shows the conventional 1-D diffractogram that results from summing the 2-D pattern circumferentially around the central undiffracted beam. Table 4 shows a quantitative analysis of this sample using the program FULLPAT. These results and others were used to establish and validate the required mineral detection level, analytical precision and accuracy of mineralogical results from the flight instrument. 
Table 4 Quantitative XRD analysis of a synthetic clay-bearing evaporate (CheMin IV data)

\begin{tabular}{lllll}
\hline Phase & $\begin{array}{l}\text { Measured } \\
\text { wt.\% }\end{array}$ & $\begin{array}{l}\text { Known } \\
\text { wt.\% }\end{array}$ & $\begin{array}{l}\text { relative } \\
\text { difference, } \\
\text { wt.\% }\end{array}$ & Comment \\
\hline Nontronite & 69 & 61 & 13.1 & within 15\% \\
Gypsum & 22.6 & 25 & -9.6 & within 15\% \\
Halite & 2.8 & 8.7 & -67.8 & not within $15 \%$ \\
Hematite & 5.7 & 5.3 & 7.5 & within $15 \%$ \\
\hline
\end{tabular}

\subsubsection{Inel Testbed}

A commercial Inel MPD ${ }^{\circledR}$ laboratory XRD (Inel, Inc., Artenay, France) with a positionsensitive detector is housed in the Planetary Mineralogy and Spectroscopy Laboratory at Ames Research Center. The instrument is configured to analyze Mars analog rocks in a diffraction geometry nearly identical to the CheMin flight instrument. The instrument is equipped with a monochromated Co source and a $120^{\circ}$ position-sensitive detection system capable of collecting XRD patterns with resolutions in excess of the spacecraft instrument (but which can be degraded to MSL CheMin resolution for comparison and pattern matching). A Mars atmosphere chamber is installed with a 12-sample carousel, MSL-style funnel and a CheMin transmission sample cell that can be filled, piezoelectrically shaken during analysis and dumped many times, all under Mars pressure. The Inel instrument has been used to measure the candidate FM standards under Mars atmosphere conditions, to measure specimen-to-specimen contamination in tests of sample cell reuse, and to measure "real" rocks under simulated Mars conditions, whether those rocks are obtained from SA/SPaH tests or from field collections intended for the CheMin XRD library. There are significant differences between the experiments as they were conducted on the Inel instrument for validation and verification $(\mathrm{V} \& \mathrm{~V})$ of requirements, and as they will be conducted on either the MSL DM or FM instruments. These differences include:

1. The Inel instrument was operated at $10 \mathrm{~mA}$ and $30 \mathrm{keV}$, yielding a much higher count rate than the MSL instrument.

2. The Inel machine utilizes a doubly monochromated source, so there is no Bremsstrahlung or $\mathrm{Co} \mathrm{K} \beta$ radiation in the beam.

3. The actual diameter of the beam at the sample is $\sim 300 \mu \mathrm{m}$, much larger that in the MSL instrument. The distance from the sample to the detector is larger, so that the instrumental resolution is not critically dependent on beam diameter.

4. The piezo is driven by a controller that ramps its frequency through resonance in $1 / 2-$ 5 second cycles. At 60 -second intervals, the controller pulses the piezo at resonance at a higher excitation to produce a "chaos mode" in the sample holder. The CheMin FM piezos are driven by a controller that locks onto sample cell resonance and varies amplitude during an analysis.

There are similarities between the experiments as they were conducted on the Inel XRD for $\mathrm{V} \& \mathrm{~V}$, and as they will be performed on the CheMin DM or FM instruments. These similarities principally involve the sample cell and the environment in which the sample is analyzed. Of all of the CheMin testbed instruments available (with the exception of the DM), only the Inel instrument can collect diffraction patterns utilizing an MSL cell in a 7 torr atmosphere. The principal use of the Inel machine is to study, evaluate and understand grain motion during diffraction. The following experiments were conducted in the Inel testbed during $\mathrm{V} \& \mathrm{~V}$. 
Table 5 Sequential analyses of a $65 \mathrm{~mm}^{3}$ aliquot of 88:12 beryl:quartz mixture (by weight) to test for sample homogeneity over time. Analyses performed under Mars atmospheric pressure, using a CheMin FM sample cell. Sample size $=65 \mathrm{~mm}^{3}$

\begin{tabular}{llc}
\hline Cumulative Analysis time & Beryl \% & Quartz \% \\
\hline 30 minutes & $90.6 \pm 1$ & $09.4 \pm 1$ \\
60 minutes & $87.6 \pm 1.2$ & $12.4 \pm 1.2$ \\
90 minutes & $88.2 \pm 1.2$ & $11.8 \pm 1.2$ \\
120 minutes & $89.8 \pm 1$ & $10.2 \pm 1$ \\
150 minutes & $90.6 \pm 1$ & $09.4 \pm 1$ \\
Average & & 10.64 \\
Std. Dev. & & 1.39 \\
Rel. Accuracy & & $11.33 \%$ \\
Rel. Precision & & $13.05 \%$ \\
\hline & & \\
\hline Cumulative Analysis time & & $1.25 \%$ \\
\hline 30 minutes & Beryl \% & $6.66 \%$ \\
60 minutes & $87.7 \pm 1.2$ & $12.3 \pm 1.2$ \\
90 minutes & $87.2 \pm 2.6$ & $12.8 \pm 3.3$ \\
120 minutes & & $11.6 \pm 2.6$ \\
Average & & 10.7 \\
Rel. Accuracy & & \\
Rel. Precision & & \\
\hline & & \\
\hline
\end{tabular}

\begin{tabular}{llc}
\hline Cumulative Analysis time & Beryl \% & Quartz \% \\
\hline 30 minutes & $90.6 \pm 1$ & $09.4 \pm 1$ \\
60 minutes & $87.6 \pm 1.2$ & $12.4 \pm 1.2$ \\
90 minutes & $88.2 \pm 1.2$ & $11.8 \pm 1.2$ \\
120 minutes & $89.8 \pm 1$ & $10.2 \pm 1$ \\
150 minutes & $90.6 \pm 1$ & $09.4 \pm 1$ \\
Average & & 10.64 \\
Std. Dev. & & 1.39 \\
Rel. Accuracy & & $11.33 \%$ \\
Rel. Precision & & $13.05 \%$ \\
\hline & & \\
\hline Cumulative Analysis time & & $1.25 \%$ \\
\hline 30 minutes & Beryl \% & $6.66 \%$ \\
60 minutes & $87.7 \pm 1.2$ & $12.3 \pm 1.2$ \\
90 minutes & $87.2 \pm 2.6$ & $12.8 \pm 3.3$ \\
120 minutes & $88.4 \pm 2.6$ & $11.6 \pm 2.6$ \\
Average & & 0.79 \\
Rel. Accuracy & & \\
Rel. Precision & & \\
\hline & & \\
\hline
\end{tabular}

Table 6 Sequential analyses of a $45 \mathrm{~mm}^{3}$ portion of $88: 12$ beryl:quartz mixture (by weight) to test for sample homogeneity over time. Sample size $=$ $45 \mathrm{~mm}^{3}$

Precision and Accuracy of Quantification of Mineral Mixtures Beryl and quartz standards were crushed and sieved to $<150 \mu \mathrm{m}$ grain size. Mixtures were made of $88 \%$ beryl:12\% quartz (by weight), and $65 \mathrm{~mm}^{3}$ aliquots of the mixture were loaded in the sample carousel and kept at 7 Torr atmosphere for several days. Samples were delivered through the funnel into the sample cell and analyzed to obtain a series of measurements of the same sample over several hours, to see if phase segregation (and observed changes in composition) had occurred. Quantitative analyses were obtained with the MDI program Jade ${ }^{\circledR}$, using Rietveld refinement. Table 5 shows the results of five analyses, obtained after 30, 60, 90, 120 and 150 minutes of accumulated data.

Delivery to CheMin of Less than the Specified Quantity of Sample Material A second test was performed with the Inel instrument to evaluate the effect on quantification (if any) caused by the delivery of less than the nominal $76 \mathrm{~mm}^{3}$ volume of a 12:88 quartz:beryl mixture. Table 6 shows the results of replicate analyses of the beryl:quartz sample, collected over several hours, using a $45 \mathrm{~mm}^{3}$ portion (2/3 fill).

Sample-to-Sample Contamination Tests An additional requirement of the CheMin sample handling system is that there should be no more than $5 \%$ contamination between successive analyses. A test was performed to evaluate the sample-to-sample contamination when successive samples are analyzed. Two sources of contamination exist-material that remains in the funnel and is delivered to the sample cell with a subsequent sample, and material that remains in a sample cell after it is dumped, contaminating a subsequent sample when that sample cell is reused. There is no sample shunt in the Inel testbed as there is on the CheMin 
Table 7 Results of sample-to-sample contamination test

\begin{tabular}{lll}
\hline & Beryl \% & Quartz \% \\
\hline No dilution & 99.69 & 0.31 \\
1 dilution & 99.76 & 0.24 \\
2 dilutions & 99.89 & 0.11 \\
\hline
\end{tabular}

sample wheel (see Fig. 2), so that funnel-generated contamination cannot be evaluated separately from sample cell-generated contamination.

Using the sample carousel, the Inel sample cell was loaded with powdered quartz (half $<45 \mu \mathrm{m}$ and half $45-150 \mu \mathrm{m})$ and run for sufficient time to acquire a major frame. The quartz was then emptied and a load of beryl (half $<45 \mu \mathrm{m}$ and half $45-150 \mu \mathrm{m}$ ) was analyzed. This was followed by two separate experiments in which one and two purge loads of beryl were loaded, vibrated for ten minutes and dumped, followed by analysis of a postpurge beryl load to test for $<5 \%$ quartz contamination. If quartz was detected, the amount present was quantified using Rietveld refinement. It was found that the $\%$ contamination of quartz in beryl decreased as additional purges of beryl were applied. All three analyses passed the $<5 \%$ requirement (Table 7 ).

\subsubsection{Mini-CheMin "Terra" Testbeds}

Several Terra ${ }^{\circledR}$ instruments (a commercial spinoff instrument of CheMin, manufactured by inXitu, Inc., Campbell, CA) are in use at Ames Research Center, Jet Propulsion Laboratory, Los Alamos National Laboratory, Johnson Space Center and Goddard Space Flight Center. They are battery-operated, field-portable instruments designed with enough fidelity to the CheMin FM to allow practical evaluation of how the CheMin design functions in field situations and for the development of XRD libraries. The Terra ${ }^{\circledR}$ instrument at GSFC is being used for direct comparisons of mineral and rock analyses between SAM and CheMin testbeds. The Terra instrument at JSC is likewise being used for direct comparisons of mineral and rock analyses between CheMin and the ChemCam testbed at LANL.

\subsubsection{Prototype 1 Funnel-Wheel-Sump Assembly and Stand-Alone Funnel Assembly}

A test assembly ("Prototype 1") consisting of the CheMin funnel, a sample wheel with mounted cells and piezovibration actuators was used to evaluate sample handling and grain motion properties of the CheMin sample handling system. The assembly does not include the dust shroud that will cover the bottom part of the wheel or the sump as in the FM and DM. The entire assembly was operated in a Mars-atmosphere chamber (pumped to 2 torr and back-filled with 7 torr $\mathrm{CO}_{2}$ ) at cold temperatures (approximately $-40{ }^{\circ} \mathrm{C}$ ); samples were loaded into a carousel above the assembly for delivery to the cells on the sample wheel. The goal of these tests was to determine the sample loading, movement, and sample dumping characteristics of the CheMin design using a range of materials expected on Mars or selected to test sample handling for extremes of size, cohesion, hydration, hardness and electrostatic properties. Samples used in these tests are listed in Table 8. A Column marked with an " $\mathrm{X}$ " denotes the particular characteristic that is being investigated with a specified sample.

In addition to the Prototype 1 assembly, a separate funnel assembly was used to evaluate funnel functions. The funnel assembly was used to examine grain movement and amount of remnant contamination with a variety of samples. The stand-alone funnel was tested at 
Table 8 Samples for CheMin Funnel-Wheel-Sump assembly tests, and properties basis for selection

a JSC MARS-1 is a natural palagonite sample provided by NASA-Johnson Space Center

\begin{tabular}{|c|c|c|c|c|c|}
\hline sample & $\begin{array}{l}\text { fine } \\
\text { size }\end{array}$ & cohesion & $\begin{array}{l}\text { platy or } \\
\text { acicular }\end{array}$ & hard & $\begin{array}{l}\text { electrostatics } \\
\text { or magnetics }\end{array}$ \\
\hline JSC MARS- $1^{\mathrm{a}}$ & $\mathrm{X}$ & & & & \\
\hline arkose & $\mathrm{X}$ & $\mathrm{X}$ & & & \\
\hline basalt (Saddleback) & & & & $\mathrm{X}$ & \\
\hline quartz & $\mathrm{X}$ & & & & $\mathrm{X}$ \\
\hline kaolinite & $\mathrm{X}$ & $\mathrm{X}$ & $\mathrm{X}$ & & \\
\hline hematite (red ocher) & $\mathrm{X}$ & $\mathrm{X}$ & & & \\
\hline smectite & $\mathrm{X}$ & $\mathrm{X}$ & & & \\
\hline
\end{tabular}

angles up to the maximum tilt design for CheMin FM operation (up to $20^{\circ}$ with the rover parked). The funnel assembly tilt tests were done in the same Mars chamber used to test samples with Prototype 1.

\subsubsection{Flight Model (FM)}

The flight model (FM) has elemental and XRD standards in five permanently loaded sample cells (discussed below in Sect. 3.3). Prior to integration with the rover, these standards were analyzed in a simulated Mars atmosphere at a range of RAMP temperatures to obtain baseline function data from the FM, for (1) defining initial pre-mission functionality and (2) cross-calibration with identical samples that are loaded in the demonstration model (DM). Results of FM analyses of the permanently loaded standards are shown in Sect. 4.

\subsubsection{Demonstration Model (DM)}

The demonstration model (DM) was built from components identical or equivalent to those used in constructing the FM. Identical standards to the FM are loaded in five permanent cells and are used to evaluate any changes in functionality of the FM that might be related to ATLO, launch, flight, and landed operations. The DM will be cross-calibrated to the FM using these common standards. DM testing prior to and during the mission with a variety of samples is critical to interpreting FM data, because no end-to-end testing was performed in which samples were loaded through the funnel and analyzed in one of the 27 open sample cells of the FM (doing so would have exposed the inside of the instrument to contamination from sample powder with unknown consequences during launch and spaceflight).

The DM will be kept on-site at JPL for purposes of (1) continuing evaluation of DM performance relative to results returned by the FM; (2) prototyping possible changes in function (analytical sequence, piezovibration operation, temperature cycling, etc.) before applying such changes to operation of the FM on Mars; and (3) analyzing selected known mineral and rock samples in open cells, which could not be performed in the FM.

\subsubsection{Cell Window Assemblies for Durability Tests}

Sample holders have been subjected to long-duration vibration tests to determine whether the sample cell windows will degrade after repeated and prolonged vibration. Table 9 summarizes test results for cell window durability in Mylar ${ }^{\mathrm{TM}}$ and Kapton ${ }^{\mathrm{TM}}$ cells. 
Table 9 Window durability tests using 75-150 $\mu \mathrm{m}$ quartz and intense $(\sim 100 \mu \mathrm{m}$ amplitude $)$ shaking in CheMin FM sample cells

${ }^{\text {a } U s e d ~ i n ~ F M, ~ D M ~ a n d ~ t e s t b e d ~}$ instruments

\begin{tabular}{lll}
\hline material & thickness $(\mu \mathrm{m})$ & result \\
\hline Mylar $^{\circledR}$ & 3.6 & $50 \%$ failure after 16 hours \\
Mylar $^{\circledR}$ & $6^{\mathrm{a}}$ & $50 \%$ failure after 168 hours \\
Kapton $^{\circledR}$ & $7.5^{\mathrm{a}}$ & no failures at $>170$ hours
\end{tabular}

\section{Calibration and Standards}

\subsection{Calibration of X-Ray Diffraction Patterns}

\subsubsection{Effects of $2 \theta$ Statistics, $2 \theta$ Range, $2 \theta$ FWHM and Instrumental Broadening Function on Calibration}

Detection limits for individual phases as well as the precision and accuracy of mineralogic analysis are influenced by geometrical factors. Because the CCD is off-center and has a finite size, diffraction rings are not fully captured by the CCD. The proportion of each ring captured by the CCD is a function of $2 \theta$. At high $2 \theta$ values, less of the ring is captured. At low $2 \theta$, the effective radius of the diffraction ring is so small that relatively few pixels define the ring. A diffracted peak at very high or very low $2 \theta$ will consequently have poorer statistics than one at moderate $2 \theta$. Of equal importance, the CCD has a specific Charge Collection Efficiency (CCE) for $\mathrm{Co} \mathrm{K} \alpha$ and $\mathrm{Co} \mathrm{K} \beta$ photons (i.e., as a function of photon energy, only a fraction of the photons that strike the CCD will be absorbed by the silicon), as well as a characteristic energy-dependent and device-dependent ratio of single events vs. split events (photons that are of higher energy and are absorbed deeper in the silicon have a tendency to form an electron charge cloud that diffuses across pixel boundaries). Each of these factors will influence the statistics of the final diffraction pattern.

Crystalline standards having diffraction maxima across the range of observed $2 \theta$ are sufficient to determine and calibrate $2 \theta, 2 \theta$ range, and $2 \theta$ resolution values for the DM and the FM. Of importance to this calibration (and to all diffraction data from CheMin) is the random orientation of crystallites presented to the beam during an analysis. For these measurements, a standardized powder size range is used (45-90 $\mu \mathrm{m}$ grain size; this same size range is used in loading all of the standards in the FM and DM) as well as a standard protocol for shaking the sample. Under normal circumstances, the grain size distribution of the sample will be a function of the SA/SPaH sampling system as well as the nature of the sample.

An important parameter in quantitative XRD is the instrumental broadening function (described in Sect. 1.7.3). In a sample of finite thickness, diffraction can take place anywhere along the beam path through the sample. Once diffracted, photons can be reabsorbed or rediffracted along their path inside the sample. In weakly absorbing samples, diffracted photons originating from near the front surface of the sample (X-ray source side) will contribute proportionally more to the pattern than in strongly absorbing samples. This results in an asymmetry in the individual diffraction peaks that is a function of the linear absorption coefficient of the material for $\mathrm{Co} \mathrm{K} \alpha$ and $\mathrm{Co} \mathrm{K} \beta$ photons - and the thickness of the sample.

Absorption by the sample of transmitted $\operatorname{Co} \mathrm{K} \alpha$ and $\operatorname{Co} \mathrm{K} \beta$ photons will vary as a function of composition. In addition, the mass thickness of the sample will vary depending on the proportion of solid material and void space present in the beam as the sample is shaken and different components of the powder pass through the beam. Granular standards are used to ensure that these materials are as much like the unknowns as possible, to account for such effects. 


\subsubsection{X-Ray Diffraction Calibration for 2 $\theta$ Resolution (FM and DM)}

A mixture of two minerals with several closely spaced diffraction maxima is used to calibrate $2 \theta$ resolution at low, medium, and high ranges of $2 \theta$. The minerals selected were beryl (a synthetic emerald donated by Chatham Created Gems, Inc., San Francisco, CA) and quartz. Grain size distribution is controlled $(45-90 \mu \mathrm{m})$ to minimize grain size effects and cell loading is standardized to control particle mass thickness along the pathways of diffracted photons.

\subsubsection{X-ray Diffraction Calibration for Mineral Identification (FM and DM)}

Known standard minerals are used to calibrate both $\mathrm{Co} \mathrm{K} \alpha$ and $\mathrm{Co} \mathrm{K} \beta$ diffraction patterns for peak locations and relative peak heights. Minerals chosen were amphibole, beryl, quartz, and arcanite. Grain size distribution is controlled $(45-90 \mu \mathrm{m})$ to minimize grain size effects and cell loading is standardized to control particle mass thickness along the pathways of diffracted photons.

\subsubsection{X-Ray Diffraction Calibration for Mineral Quantification (FM and DM and Testbeds)}

Artificial mixtures of mineral standards are used for quantitative XRD (QXRD) calibration. In the FM and DM, 3:97 and 12:88 quartz:beryl mixtures are used for determining the accuracy and precision of quantitative analysis, peak positions and peak FWHM across CheMin's 5-55 $2 \theta$ range. Mineral mixtures allow tighter mineral composition control than possible with natural rocks. For the DM and testbeds, in addition to the quartz/beryl mixtures, known standard minerals will be physically admixed to simulate basalts, evaporites, and other lithologies, particularly those relevant to the Gale Crater site (e.g., mixtures including clay and evaporite minerals; see Sect. 3.4.2 and Table 10). During the mission, the DM instrument will be used for troubleshooting off-nominal behaviors of the FM, and for collecting XRD patterns and XRF spectra from analog samples for comparison with flight data. The quartz:beryl standards will be available throughout the mission to evaluate instrument performance (instrument profile, peak position, peak FWHM, etc.).

\subsubsection{Quantitative Techniques for X-Ray Diffraction Analysis}

For mineral identification, the search/match utilities in commercial XRD analysis programs such as Jade ${ }^{\circledR}$ (MDI, Inc., Pleasanton, CA) and Xpowder ${ }^{\circledR}$ (Martin 2004) will be used. During the mission, "Payload Downlink Leads" will analyze CheMin data in a tactical timeframe (minutes) to produce "quicklook" data products for use in planning the next Sol's activities (these qualitative analyses will use search-match programs such as Jade ${ }^{\circledR}$ ). Following mineral identification, quantification will be accomplished using one or more of several established quantitative analysis methods on a non-tactical timeframe (weeks). For samples in which constituent minerals do not have known crystal structures, or minerals and components without well-defined structures (e.g., glasses and many clay minerals) a program such as FULLPAT will be used. In FULLPAT analyses, individual library standard patterns for all phases believed to be present in the sample are simultaneously fit to the observed pattern using a least-squares refinement. These library patterns can be calculated from crystal structures, simulated from ICDD data, or directly measured on the DM or testbed instruments. A version of FULLPAT tailored specifically to CheMin instrument parameters is being developed by co-I Steve Chipera. Several hundred mineral, rock and soil samples, including 
Table 10 Composition of four synthetic rock mixtures to be tested in the CheMin DM and CheMin testbed instruments

\begin{tabular}{|c|c|c|}
\hline Component & Origin & Wt. $\%$ \\
\hline \multicolumn{3}{|c|}{ Synthetic Basalt (BST-01) } \\
\hline Bytownite & Sonora, Mexico & 45.0 \\
\hline Augite & Ceder Butte, OR & 31.0 \\
\hline Forsterite & San Carlos, AZ & 16.8 \\
\hline Fluorapatite & Wilberforce, ONT & 7.1 \\
\hline \multicolumn{3}{|c|}{ Synthetic Altered Basalt (BST-20) } \\
\hline Bytownite & Sonora, Mexico & $43.2 \%$ \\
\hline Augite & Ceder Butte, OR & $32.2 \%$ \\
\hline Hematite & Cleator Moor, England & $16.7 \%$ \\
\hline Chlorite (clinochlore) & Clay Minerals Soc. Ref. CCa-1 & $7.9 \%$ \\
\hline \multicolumn{3}{|c|}{ Synthetic Evaporite (EVAP-01) } \\
\hline Gypsum & WY Selenite & $48.3 \%$ \\
\hline Halite & Morton Salt & $33.6 \%$ \\
\hline Arcanite & synthesized from solution & $18.0 \%$ \\
\hline \multicolumn{3}{|c|}{ Synthetic Clay-mineral-bearing Evaporite (EVAP-02) } \\
\hline Nontronite & Clay Minerals Soc. Ref. NAu-2 & $61 \%$ \\
\hline Gypsum & Wy Selenite & $25.0 \%$ \\
\hline Halite & Morton Salt & $8.7 \%$ \\
\hline Hematite & Cleator Moor, England & $5.3 \%$ \\
\hline
\end{tabular}

phyllosilicates, carbonates and evaporites, are being measured in the CheMin IV instrument at Ames Research Center, for use in FULLPAT analysis. A subset of this sample suite will be analyzed on the CheMin DM instrument at JPL. For samples composed of minerals with well-known crystal structures, full-pattern fitting and Rietveld refinement will be used, in conjunction with Jade ${ }^{\circledR}$ or TOPAS ${ }^{\circledR}$ software to determine mineralogical compositions. For Rietveld refinements, patterns are calculated from first principles for all the phases in the sample, using known crystal structures. The calculated patterns are used to simulate the observed pattern and the quantitative abundances are obtained directly from scale factors. There are advantages to both methods. FULLPAT can be used for phases that are not fully characterized or whose three-dimensional structures are poorly constrained, such as many clay minerals and X-ray amorphous materials. The Rietveld method is potentially more accurate but requires a full description of the crystal structures.

\subsection{Calibration of Energy Dispersive Histograms}

Determination of Energy-Dispersive Peak Statistics, Energy Range, Peak FWHM, and Sample Mass Absorption Coefficients The quality of the energy dispersive histogram (EDH) provided by the CCD is determined in part by the energy distribution and the total flux of the continuum and characteristic fluorescent radiation that strikes the sample, the FWHM of individual X-ray peaks, the geometrically corrected mass absorption coefficient of the sample, and CCD parameters such as charge collection efficiency (CCE) and the ratio of single events versus split events. Each of these factors will influence the statistics of the final energy-dispersive histogram. A single multi-element standard, homogeneous at the spatial resolution of the X-ray beam, is sufficient to determine detection sensitivity and FWHM (in $\mathrm{eV}$ ) of detected elemental peaks as a function of photon energy and CCD temperature, both 
for the FM and DM. These properties may change as the mission progresses, the CCD ages, and cells are reused. In the FM and the DM multi-element standards include amphibole and a ceramic containing high concentrations of most elements reported in APXS data from earlier missions. The arcanite sample provides a standard for sulfur, an element of particular interest at the Gale Crater site.

Energy Dispersive Histogram Performance Checks and Instrument Calibration (FM, DM, and Testbeds) For EDH performance checks (energy resolution and energy response as a function of CCD temperature, age, evaluation of neutron effects on the CCD, etc.) and for calibration, several standards are used. These have compositions that span a concentration range from light elements to heavy elements (Sect. 3.3). The standards provide fluorescence maxima that represent the energy range up to characteristic $\mathrm{Co} \mathrm{K} \beta$ radiation $(7.65 \mathrm{keV})$ and beyond (e.g., Sr K $\alpha$ ). Within the five sealed sample cells of the FM and DM, minerals and a doped ceramic evaluated for this purpose are listed in Sect. 3.3.3. For all standards in the sealed cells, grain size distributions are controlled $(45-90 \mu \mathrm{m})$, primarily to avoid powder clumping or packing in permanent standard cells that must be used several times during the mission and for minimizing grain-size effects that can induce asymmetry in diffraction peaks. In other cases, specific to the DM and testbeds, grain sizes will reflect the standard $\mathrm{SA} / \mathrm{SPaH}$ powder collection and sieving protocol, to examine powdered materials as similar to the unknown samples as possible.

3.3 Standards Mounted Permanently in the Sealed Cells of the FM and DM for XRD and EDH Calibration and Evaluation

\subsubsection{Requirements of XRD Standards}

XRD Standards will be used as checks on the following:

1. Peak $2 \theta$ position calibration (Peaks that $\operatorname{span} \sim 5$ to $50^{\circ} 2 \theta$, Co K $\alpha$ radiation).

2. Peak intensity calibration (Check on instrument, sample vibration, and data processing effects)

3. Peak shape characterization (Check on instrument response required for data processing - e.g., FULLPAT and Rietveld analyses). This is important in CheMin because peak shapes are affected by sample absorption (diffracted photons near the exit side of the sample are more likely to reach the CCD than those produced near the entrance side of the sample).

4. Calibration of $2 \theta$ resolution. This is particularly important in CheMin; although the geometry is fixed when the instrument is fabricated, factors such as aging of cell windows with repeated use on Mars could increase the "drumming" effect during vibration, effectively increasing sample thickness and degrading $2 \theta$ resolution.

\subsubsection{Requirements of EDH Standards}

EDH standards will be used to check the following:

1. $\mathrm{CCD}$ energy resolution for $\mathrm{Fe} \mathrm{K} \alpha$, $\mathrm{Co} \mathrm{K} \alpha$, and $\mathrm{Co} \mathrm{K} \beta$. Knowledge of how well these three energies are separated is critical for determination of whether Fe fluorescence is effectively separated from Co $\mathrm{K} \alpha$ diffraction, and whether Co $\mathrm{K} \beta$ diffraction events might be misinterpreted as $\mathrm{Co} \mathrm{K} \alpha$ diffraction. 
2. Baseline split-event characterization for the CCD and follow-on characterization as the CCD ages (e.g., accumulated neutron damage) or as supporting components age (e.g., cryocooler).

3. Energy resolution across the effective range of elements detected by the CCD. This is important because the search-match methods to be used for mineral identification are greatly enhanced by the ability to exclude or include particular elements in the search routine. This is especially important in CheMin because $2 \theta$ resolution is poorer than in standard laboratory diffractometers and even qualitative chemical information can improve mineral discrimination. Of lesser importance, but nevertheless of interest, is the potential to perform XRF analysis on a "best effort" basis using the EDH data.

\subsubsection{Standards for Calibration of XRD and EDH Performance in the FM}

Several potential standards were examined in laboratory diffractometers, testbeds, and by other methods (e.g., thermogravimetric analysis; XRF analysis; electron microprobe analysis) to determine suitability as standard materials. Five were selected for use (Table 11). Two cells in the FM and DM carry quartz:beryl mixtures (3:97 and 12:88) that are required for calibration and verification and validation of the FM. Three other cells are loaded with standards chosen for varied fluorescence with diverse chemical composition, namely amphibole (Fe-containing, to measure $\mathrm{Fe} \mathrm{K} \alpha$ and $\mathrm{Co} \mathrm{K} \alpha$ separation in energy-dispersive histograms), arcanite (a sulfate mineral), and a synthetic ceramic containing a wide range of elements (to understand FWHM of individual elemental peaks as a function of energy and CCD temperature in the EDH, as well as split-pixel effects).

Table 11 lists the five standards that were chosen. Column 1 lists an amphibole standard (from Gore Mountain, New York) with both an acceptable range of diffraction maxima and varied chemical composition that includes high Fe content. Columns 2-3 list the two standards selected specifically for strong diffraction over a range of $2 \theta$ (beryl:quartz). Columns 4-5 list a high-fluorescence S-rich composition (arcanite), and the chemically diverse doped ceramic. Table 11 also lists the hardness and density for each of the standards selected. Density is an important factor in determining which minerals can be mixed together in a single cell (e.g., beryl and quartz); minerals of comparable density are less likely to exhibit grain segregation during piezovibration of the sample cell. Hardness is also a factor if different minerals are mixed together, as the harder minerals will tend to abrade softer minerals.

The amphibole has several closely-spaced diffraction maxima that provide a means of evaluating $2 \theta$ resolution and peak-profile parameters from low $2 \theta\left(\sim 12^{\circ}\right)$ to $48^{\circ} 2 \theta$. This standard also has a relatively complex composition (magnesiohastingsite or pargasite, depending on ferrous/ferric ratio), useful for evaluation of CCD EDH performance; composition determined by INAA and electron microprobe is shown in Table 11. It has a significant $\mathrm{Fe}$ content that can be monitored to evaluate any overlap of $\mathrm{Fe} \mathrm{K} \alpha$ into the energy range selected for analysis of the diffracted primary Co K $\alpha$ used for X-ray diffraction. There are no known stability issues with use of amphibole as a diffraction standard.

The beryl used in the DM and FM is a synthetic emerald supplied by Thomas Chatham of Chatham Created Gems, Inc. The sample from Chatham used in the DM and FM contains 0.73 weight percent $\mathrm{Cr}_{2} \mathrm{O}_{3}$ as determined by INAA; other constituents ( $\mathrm{Be}, \mathrm{Al}, \mathrm{Si}$ ) will not be detected or are poorly determined by EDH with CheMin. Beryl has three well-defined and separated peaks of high intensity $(I>60)$ across a $2 \theta$ range from $13^{\circ}$ to $36^{\circ}$ in $\mathrm{Co} \mathrm{K} \alpha$ radiation. It also has a high reference intensity ratio (RIR of 2.1), providing a strong signal after relatively short exposures. There are no known stability issues with the use of beryl as a diffraction standard. Beryl has diffraction maxima that are relatively simple and widely 
Table 11 Flight model (FM) and demonstration model (DM) standards: composition (weight \%), linear absorption coefficients for $\mathrm{Co} \mathrm{K} \alpha$, reference intensity ratio, density, and mohs hardness

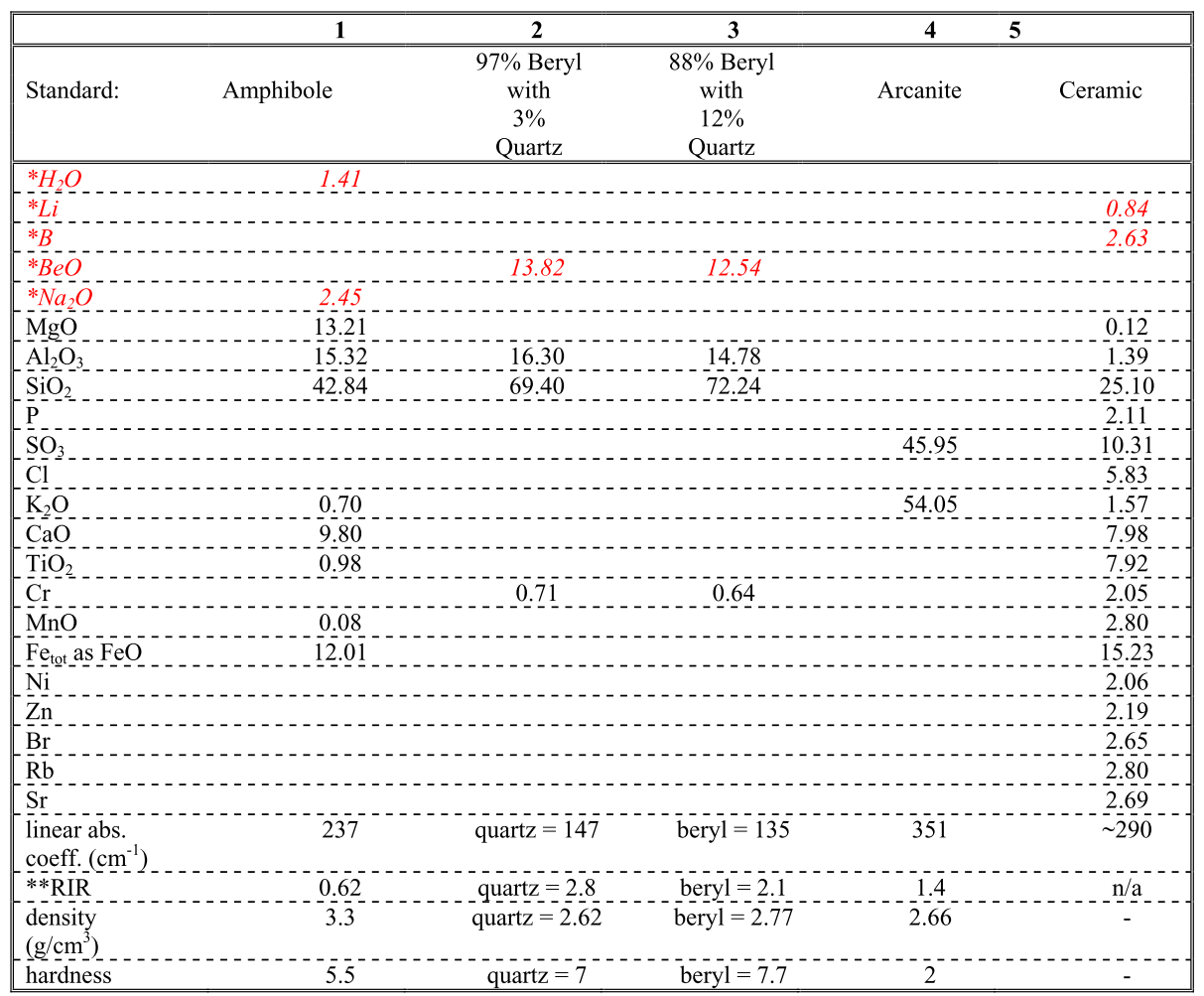

*Light-element components in red italics are not be detectable by CheMin and are shown for completeness only

**RIR is the reference intensity ratio: the ratio of the strongest peak of the phase of interest to that of the (113) corundum peak in a 1:1 mixture (50-50 by weight)

spaced, providing a capability for evaluation of peak profiles. The small amount ( $3 \%$ and $12 \%$ ) of quartz mixed with this sample for V\&V purposes will not interfere with XRD calibration based solely on the beryl component.

Arcanite in the DM and FM is synthetic, prepared by crystal growth from saturated solutions of reagent $\mathrm{K}_{2} \mathrm{SO}_{4}$. The stoichiometric composition is listed in Table 11. The arcanite has high $\mathrm{K}$ and $\mathrm{S}$ content that will produce fluorescence at 3.31 and $2.31 \mathrm{keV}$, respectively, creating fluorescence background in the diffraction pattern in a manner comparable to some of the sedimentary samples likely to be examined by the MSL rover at Gale Crater. In addition, arcanite has diffraction maxima that will provide a means of evaluating $2 \theta$ resolution and peak-profile parameters from $\sim 25^{\circ}$ to $48^{\circ} 2 \theta$. It has the highest sulfate content among the standards. Arcanite is rare among sulfate salts in that it does not readily hydrate; as such it provides an exceptionally stable sulfate calibration standard. It is also very stable on heating. 
The doped ceramic used in the DM and FM is synthesized from $41 \%$ of the Clay Minerals Society nontronite NAu-2 (pre-fired to $1000{ }^{\circ} \mathrm{C}$ to avoid vessiculation during later firing) mixed with smaller portions of calcium phosphate, anhydrite, potassium bromide, rutile, zinc sulfate, Mn-sulfate, rubidium chloride, strontium chloride, chromium oxide, nickel chloride, and $9.5 \%$ Li-tetraborate flux. This mix was ball-milled, pressed, and fired in a porcelain crucible to $800{ }^{\circ} \mathrm{C}$ (firing temperature is kept low to minimize sulfur loss). The ceramic produced is a fine-grained mixture of complex synthetic phases with a small amount of borosilicate glassy matrix. This material was crushed and sieved to $45-90 \mu \mathrm{m}$ to provide a polycrystalline sample containing most of the elements of interest to the MSL mission that are also within the detection range $(13<Z<42)$ of the CheMin CCD. The analysis listed in Table 11 is calculated for the as-fired ceramic before crushing and sieving.

\subsubsection{Stabilities of Standards to Be Flown in the FM}

The candidate standards must be able to survive thermal and vacuum testing, decontamination bakeout, and several months at space vacuum, followed by two Earth years (one Mars year) in the MSL rover body on Mars. Of these conditions, decontamination bakeout at $80^{\circ} \mathrm{C}$ and $10^{-5}$ torr is most severe. Unstable minerals, especially hydrous phases that readily exchange water, are not suitable. Quartz and beryl contain no water, hydroxyl, or other potentially volatile constituents and will remain stable. To assess stability of the arcanite, ceramic and hornblende, thermogravimetric data were collected to $800{ }^{\circ} \mathrm{C}$ with dry $\mathrm{N}_{2}$ flush (overheating to $10 \times$ the expected maximum temperature compensates for lack of vacuum conditions). Of the standards to be flown, arcanite showed no weight loss. Dehydroxylation of amphibole occurs at high enough temperature $\left(>400{ }^{\circ} \mathrm{C}\right)$ that stability should not be an issue. A small weight loss begins at $\sim 400-500{ }^{\circ} \mathrm{C}$ in the ceramic and it too will be stable throughout the mission.

\subsection{Cross-calibration of the FM and DM, and Samples to Be Tested in the CheMin DM and CheMin IV}

\subsubsection{Blind Samples and Test Samples}

Cross-calibration of the CheMin DM and FM is based on the five standards carried in and common to both. Extended calibration using the DM and other instruments, principally CheMin IV, is planned and results will be reported later. The CheMin DM and the CheMin IV instruments will be used to analyze blind samples provided to the CheMin science team by the MSL Project. The Project will make available several different samples for a roundrobin exercise. XRD results on the blind samples using the CheMin DM and CheMin IV instruments will be compared to the conventional analyses as a check on CheMin calibration and performance.

In addition to the blind samples provided by the MSL project, the CheMin science team is analyzing its own suite of 140 blind samples provided by CheMin Co-I Dick Morris of Johnson Space Center as a round robin exercise. Many of these samples are also being analyzed by other MSL instrument testbeds such as ChemCam and SAM. Once the samples are analyzed using the CheMin IV testbed instruments at JPL, NASA/ARC and NASA/JSC, the compiled analyses will be compared with results obtained by XRD in the laboratory of CheMin Co-I David Bish of Indiana University. Selected samples from this suite will be analyzed in the DM as deemed appropriate. 
Table 12 Minerals to be examined in CheMin testbed systems (potential "problem minerals" in red)

\begin{tabular}{|ccccccc|}
\hline oxides & carbonates & sulfides & sulfates & phosphates & halides & silicates \\
\hline \hline rutile & calcite & pyrite & kieserite & apatite & sylvite & albite \\
hematite & dolomite & sphalerite & epsomite & & halite & bytownite \\
chromite & siderite & & gypsum & & & scapolite \\
ilmenite & ankerite & & fibroferrite & & & augite \\
ferrihydrite & & & $*$ Na,K-jarosite & & & $*$ olivine \\
& & & & & & biotite \\
& & & & & & Fe-smectite \\
& & & & & nontronite \\
& & & & & kaolinite \\
& & & & & \\
& & & & & \\
\hline
\end{tabular}

*Solid-solution minerals of known composition used to examine capability of the CheMin design for using unit-cell parameters to constrain composition

\subsubsection{Other Tests}

Sample Preparation to Test Grain-Size Effects (Preliminary CheMin IV Test, Followed by DM Test) The transmission geometry of CheMin is complex in that much of the elastic and inelastic photon interaction will occur from particle edges and along a dynamic pathway, where both the source particle and particles in the path of a fluoresced or diffracted photon can have absorption and secondary fluorescence effects influenced by particle size and by the distribution of minerals in polymineralic grains. To evaluate effects other than polymineralic interactions, crushed and sieved samples will be prepared of three homogeneous minerals (amphibole, sylvite, and chromite) in several grain sizes.

Preparation of Synthetic Rocks to Test QXRD (CheMin DM and CheMin IV Instruments) Synthetic rocks have been prepared from well-characterized mineral stocks to evaluate igneous and sedimentary lithologies representative of potential MSL targets. These include a basalt, an altered basalt, a synthetic evaporite, and a synthetic clay-mineral-bearing evaporite. The descriptions shown in Table 10 include the minerals used in synthesis, their source, and the weight percentages used.

Determination of RIR Factors in the CheMin IV Instrument for FULLPAT Analysis A suite of $100+$ purified minerals including a variety of clay mineral standards will be analyzed in the CheMin IV instrument at Ames Research Center and Johnson Space Center; a subset of these samples will also be analyzed in the DM. Reference Intensity Ratio (RIR) factors will be compiled in order to perform accurate FULLPAT quantification of minerals such as phyllosilicates that cannot be quantified using Rietveld refinement.

A Representative "Problem Mineral" Suite It is possible that certain minerals could occur on Mars that would cause problems if introduced into the CheMin funnel or sample cells. These minerals generally fall into the category of hydrous silicates or salt hydrates that could release moisture or "ball up" if excavated from shallow cold conditions at high humidity and introduced into the warmer and drier interior of the rover where CheMin resides. Some sulfates may also be aggressive in chemical attack, on either metal or cell window materials. Potential problem minerals that will be tested in breadboards are listed in red in Table 12.

Representative Solid-Solution Series Determination of accurate unit-cell parameters in solid-solution series can provide an ability to constrain mineral chemical composition. For 
Fig. 18 Difference in peak position for end-members of $\mathrm{K}-\mathrm{Na}$ jarosite (red o's) and Fo-Fa olivine (black x's), plotted against average $2 \theta$ position for each peak $(\mathrm{Co} \mathrm{K} \alpha)$. Dashed line shows resolution (FWHM) for the flight model of CheMin

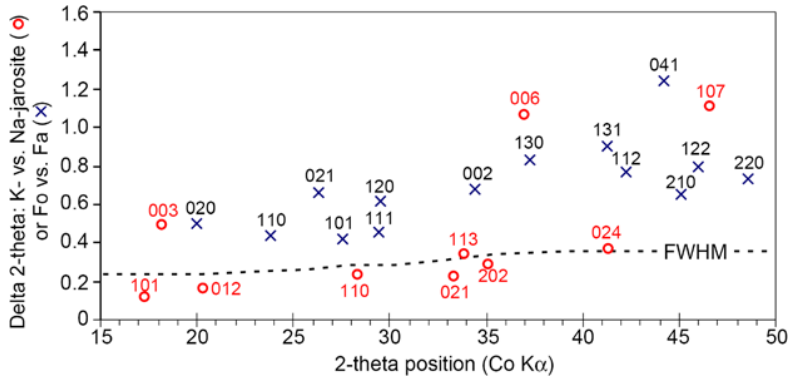

most solid-solution series the attainable accuracy depends directly on the accuracy of unitcell parameters refined using measured data. Unit-cell parameters determined from Rietveld refinements use complete diffraction patterns and do not depend on only a single diffraction peak. Because the Rietveld method uses entire diffraction patterns, estimation of composition within a solid solution is possible even when differences based on single diffraction peaks are small, on the order of the instrument resolution. Not all solid solutions have variation in unit-cell parameters sufficient to provide meaningful estimates of composition when using estimates based on single peaks. For example, Fig. 18 compares olivine Fo-Fa mixtures and jarosite $\mathrm{K}-\mathrm{Na}$ mixtures in terms of the range in $2 \theta(\Delta 2 \theta)$ between the endmembers, shown on the vertical scale. The horizontal scale shows the average $2 \theta$ position for each peak. All $2 \theta$ values are for $\mathrm{Co} \mathrm{K} \alpha$. The dark dashed line labeled "FWHM" is the modeled full-width half-maximum peak resolution expected of the CheMin flight model, which varies with $2 \theta$. When considering single diffraction peaks, the range of $\Delta 2 \theta$ must be above this dashed line if the peaks listed are to be used to resolve pure end-members, and well above it for any meaningful scaling of Fo-Fa or K-Na composition to be possible. All of the olivine peaks have $\Delta 2 \theta$ values well above the expected FWHM resolution, but only three of those for jarosite will be resolvable as distinct between the $\mathrm{Na}$ and $\mathrm{K}$ end-members; two of those are redundant along the $c$-axis and the third one has mostly a c-axis component. However, refinement of a set of unit-cell parameters using the full diffraction pattern will facilitate discrimination between compositionally similar materials. Jarosite presents additional complications due to the possibility of hydronium substitution for $\mathrm{Na}$ and $\mathrm{K}$, which results in significant difficulties in determining composition from unit-cell parameters, even when using laboratory diffraction data. Data in Fig. 18 show that Fo-Fa composition can be estimated well with CheMin, but the ability to determine jarosite composition from unitcell parameters will be limited due to complex substitutions. To examine performance of the CheMin design in determining composition from solid-solution series, both olivine and jarosite of known Fo-Fa or K-Na composition will be examined using the CheMin IV instruments. Any compositional estimates will be made using refined unit-cell parameters rather than single diffraction peaks.

Analysis of X-Ray Amorphous Materials X-ray amorphous materials have broad X-ray scattering spread over several degrees $2 \theta$, without the sharper diffraction peaks that result from well-ordered crystalline solids. Among the amorphous phases anticipated on Mars are volcanic glass, impact glasses (including maskelynite), some amorphous sulfates, and fully amorphous silica (opal-A). In addition to X-ray amorphous materials, poorly crystalline materials including Fe-oxides such as ferrihydrite and some sulfates can have very broad and poorly resolved diffraction peaks, although the presence of multiple poorly resolved peaks reveal these as poorly crystalline and not fully X-ray amorphous. In some cases that 
may occur in actual MSL operations, only a general "amorphous constituent" will be fit and other information (ChemCam, MAHLI "hand lens" information, etc.) must be used to infer whether the amorphous component is volcanic glass, opal-A, or some other amorphous material.

Analysis of the Organic Check Material (OCM) The MSL rover will carry an organic check material (OCM) to be analyzed as an organic blank by the SAM instrument. The OCM consists of amorphous silica in a solid form, mounted on the rover, for drilling and periodic analysis by SAM after passage through SA/SPaH. Splits of this material will be characterized by the CheMin DM and CheMin IV to provide a baseline characterization. This will provide some capability for recognizing the OCM as a contaminant should remnants appear in CheMin cells along with subsequent sample deliveries through SA/SPaH. Conversely, analyzing OCM in a previously used CheMin sample cell will provide a quantitative assessment of remnant contamination from previously analyzed samples.

\subsubsection{Performance Checks}

Instrument XRD and EDH performance checks were conducted on the FM during ThermoVac testing and will be conducted during the deployment of the FM on Mars, to evaluate instrument degradation and instrument drift. Instrument performance checks will be conducted using the same algorithms developed for routine data analysis (Sect. 1.9). Performance checks will be conducted in concert with routine calibration, approximately once every 40 sols, or as needed should data downlink indicate off-normal operation.

Monitoring in X-Ray Diffraction Mode XRD performance checks will use one or more of the mineral standards, which include a number of strong lines between 5 and 50 degrees $2 \theta$. From these minerals a suite of $2 \theta$ positions, $2 \theta$ FWHM values versus $2 \theta$ position, and peak intensities versus ICDD powder file peak intensity will be determined. Plots will be made of radial distance from the primary beam versus known $2 \theta$ ( $2 \theta$ calibration), $2 \theta$ versus $2 \theta \mathrm{FWHM}$, and measured intensity of peaks versus baseline values developed in the FM during ThermoVac testing, and in the DM. An instrumental broadening function will be determined based on the known composition and thickness of the sample, for reference to prior calibration.

Monitoring in Energy-Dispersive Mode Energy-dispersive performance checks will use the mineral standards to calibrate elemental peak energies versus measured energy, FWHM of element peak versus energy, and total intensity of individual peaks versus time (mission duration). Relative intensities of the peaks will be compared with known concentrations in the standards. The quantity and nature of split events will be evaluated and monitored.

\section{Characterization of the FM During ThermoVac (TVAC) Testing}

\subsection{Overview}

In early 2009, the CheMin FM was evaluated under a variety of environmental conditions during MSL project ThermoVac testing. RAMP temperatures were varied from $-40{ }^{\circ} \mathrm{C}$ to $+26{ }^{\circ} \mathrm{C}$ under both vacuum and Mars atmospheric pressure (modeled with 7 torr Argon) 
conditions. XRD and XRF processing modes were evaluated for all of the standards, plus empty Mylar ${ }^{\circledR}$ and Kapton ${ }^{\circledR}$ cells. A partial description of the FM ThermoVac results is shown below. Two off-nominal performance issues were discovered which will potentially impact the quality of returned Mars data:

(1) The performance of the CCD for energy discrimination and the peak to background of detected XRD patterns is a function of CCD temperature. Under vacuum, the CCD could be cooled to the baselined temperature of $-60{ }^{\circ} \mathrm{C}$ (required to reduce background noise in the CCD) regardless of RAMP temperature. However, under Mars atmosphere conditions, the minimum attainable CCD temperature was found to co-vary with RAMP temperature. On further testing, it was found that, under Mars atmosphere conditions, the CCD can be cooled to an ultimate temperature only 48 degrees lower than the RAMP temperature. This dependence of CCD temperature on RAMP temperature is thought to be the result of a parasitic heat load on the cryocooler created by thermal conduction between cryocooler components and cryocooler support structures in the instrument under Mars atmosphere conditions. Several attempts were made to remedy this problem, but none were found to be satisfactory. Removing the cryocooler support structures is not a possible solution because they are necessary in order for the cryocooler's mechanical components to survive launch vibration loads. Because the anticipated RAMP temperature at Gale crater is predicted to be $0{ }^{\circ} \mathrm{C}$ to $+26{ }^{\circ} \mathrm{C}$ during the times when CheMin will be operating, this will have a moderately negative impact on the quality of the EDH data. However, data collection strategies have been devised and tested which can largely overcome this problem.

(2) Quantitative analyses of the beryl:quartz 88:12 mixture in the FM varied dramatically between minor frames, causing the instrument to fail a principal requirement that it be capable of quantifying mineralogical mixtures with an accuracy of $\pm 15 \%$ of the amount present. There are three possible reasons for this off-nominal result that are discussed below (Sect. 4.2.1).

\subsection{XRD Characterization}

\subsubsection{XRD Mineral Detection and Quantification: Quartz/Beryl Analyses}

Quantification of Mineral Mixtures XRD mineral detection and quantification in the FM was evaluated during ThermoVac utilizing the sealed beryl:quartz 88:12 and 97:3 standards. Measurements were made in vacuum and in 7 Torr Ar at a RAMP temperatures ranging from $-40{ }^{\circ} \mathrm{C}$ to $+26{ }^{\circ} \mathrm{C}$. In vacuum, the $\mathrm{CCD}$ could be cooled to its ultimate temperature of $-60{ }^{\circ} \mathrm{C}$ regardless of RAMP temperature. However, with the test chamber filled with 7 Torr of Argon to simulate a Mars atmosphere, the CCD could be cooled to only $48^{\circ}$ below ramp temperature, with the result that at RAMP temperatures above $-12{ }^{\circ} \mathrm{C}$ the preferred CCD operating temperature of $-60{ }^{\circ} \mathrm{C}$ could not be achieved. RAMP temperatures of $0{ }^{\circ} \mathrm{C}$ to $26^{\circ} \mathrm{C}$ are predicted for Gale Crater during MSL's nominal mission, with the consequence that some reduction in ultimate mineral detection limits will be experienced at the higher temperatures, as described below.

Figure 19 shows a major frame Co K $\alpha$ XRD pattern of the beryl:quartz 88:12 standard, compiled from 23030 -sec. frames ( $\sim 2 \mathrm{hrs}$.) of FM data at $0^{\circ}$ RAMP in a 7 Torr Ar atmosphere $\left(-48^{\circ} \mathrm{CCD}\right)$. The design-specified range of $5^{\circ}$ to $50^{\circ} 2 \theta$ is self-evident in the figure. Table 13 lists the measured values of the observed peaks. The positions of the peaks, their deviation in $2 \theta$ from reference values, and the measured $2 \theta$ FWHM are all within 
Fig. 19 XRD of beryl:quartz 88:12 mixture. This mixture will be analyzed at regular intervals on the Mars surface to characterize the performance of CheMin. The FWHM of the 100 peak of beryl at $\sim 12.95^{\circ} 2 \theta$ and the mid-range beryl and quartz peaks between 20 and $40^{\circ} 2 \theta$ will be used as a figure of merit for the resolution of the instrument

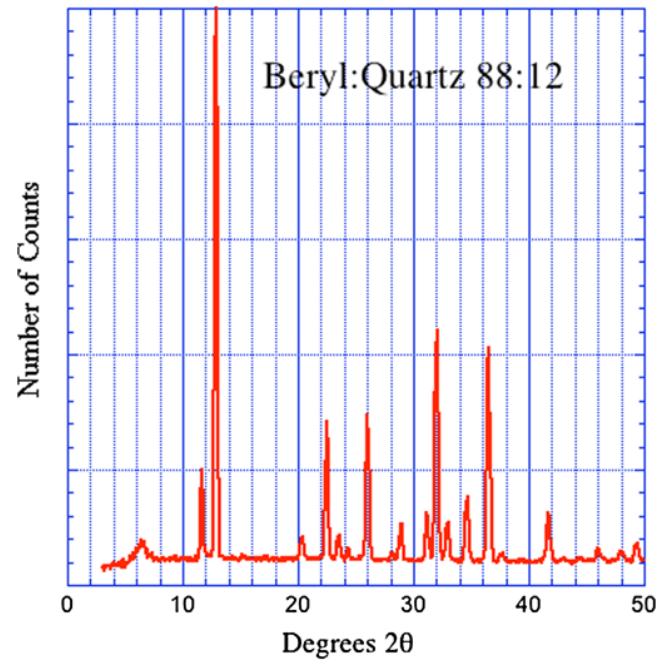

Table 13 CheMin FM data obtained during Thermo-Vac testing. Observed $2 \theta$ values, $d$-values, $\Delta d$ (obs.ref.), peak ID, peak rel. intensity and peak FWHM for Beryl:Quartz 88:12 standard mixture shown in Fig. 19

\begin{tabular}{|c|c|c|c|c|c|c|}
\hline $2 \theta$ (obs.) & $d$ (obs., $\AA$ ) & $d$ (ref., $\AA$ ) & $\Delta d(\AA)$ & Peak hkl & $I \%$ & FWHM $\left(^{\circ}\right)$ \\
\hline 12.95 & 7.95 & 7.98 & 0.03 & Be 100 & 100 & 0.275 \\
\hline 22.54 & 4.58 & 4.60 & 0.02 & Be 002,110 & 37.7 & 0.274 \\
\hline 24.41 & 4.24 & 4.255 & 0.016 & Qtz 100 & 3.5 & 0.190 \\
\hline 26.06 & 3.97 & 3.99 & 0.02 & Be 200 & 43.3 & 0.304 \\
\hline 31.17 & 3.33 & 3.343 & 0.013 & Qtz 101 & 12.9 & 0.294 \\
\hline 32.04 & 3.24 & 3.254 & 0.014 & Be 112 & 71.2 & 0.313 \\
\hline 34.68 & 3.00 & 3.015 & 0.015 & Be 210, 202 & 23.9 & 0.315 \\
\hline 36.52 & 2.854 & 2.867 & 0.013 & Be 211 & 74.1 & 0.325 \\
\hline 41.72 & 2.512 & 2.523 & 0.011 & Be 212 & 20.1 & 0.322 \\
\hline \multirow[t]{3}{*}{45.97} & 2.289 & 2.293 & 0.004 & Be 004, 302 & 5.2 & $0.383^{\mathrm{a}}$ \\
\hline & 2.272 & 2.282 & 0.010 & Qtz 012 & 1.7 & \\
\hline & 2.227 & 2.236 & 0.009 & Qtz 111 & 0.6 & \\
\hline \multirow[t]{2}{*}{47.89} & 2.204 & 2.213 & 0.009 & Be 310 & 1.6 & $0.367^{\mathrm{a}}$ \\
\hline & 2.200 & 2.208 & 0.008 & Be 104 & 2.1 & \\
\hline \multirow[t]{2}{*}{49.32} & 2.143 & 2.152 & 0.009 & Be 213,311 & 9.3 & 0.352 \\
\hline & 2.118 & 2.128 & 0.010 & Qtz 020 & 0.8 & \\
\hline 51.78 & 2.048 & 2.058 & 0.010 & Be 114,222 & 3.2 & 0.321 \\
\hline 53.57 & 1.984 & 1.993 & 0.009 & Be 312, 204 & 17.7 & $0.395^{\mathrm{a}}$ \\
\hline
\end{tabular}

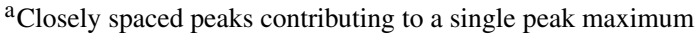

requirements - most importantly, the FWHM values, which figure prominently in analyzing complex mineral mixtures. The only observed maxima which exceed the $0.352 \theta$ FWHM design specification occur where several closely spaced peaks overlap each other.

Minor frames from the Beryl:Quartz 88:12 standard data were quantified using Rietveld refinement (Table 14). The results are not within the specified limits of precision and accu- 
Table 14 Quantitative analysis of minor frames in Beryl:Quartz 88:12 standard mixture

\begin{tabular}{llll}
\hline Minor Frame \# & Frame \# & Beryl \% & Quartz \% \\
\hline 1 & $1-50$ & 92.9 & 7.1 \\
2 & $51-100$ & 95.5 & 4.5 \\
3 & $101-150$ & 96.1 & 3.9 \\
4 & $151-200$ & 96.8 & 3.2 \\
5 & $201-230$ & 97.1 & 2.9 \\
Major Frame (Sum) & $1-230$ & 96.2 & 3.8
\end{tabular}

Fig. 20 XRD of beryl:quartz $88: 12$ mixture, emphasizing the quartz 101 and beryl 112 maxima. Individually summed 50-frame minor frame analyses are shown. Quantitative analyses of the 5 minor frames by Rietveld refinement, which utilizes all the peaks in the pattern, are shown in Table 13. However, the reduction in quartz 101 peak intensity during the course of analysis clearly shows a phase segregation problem

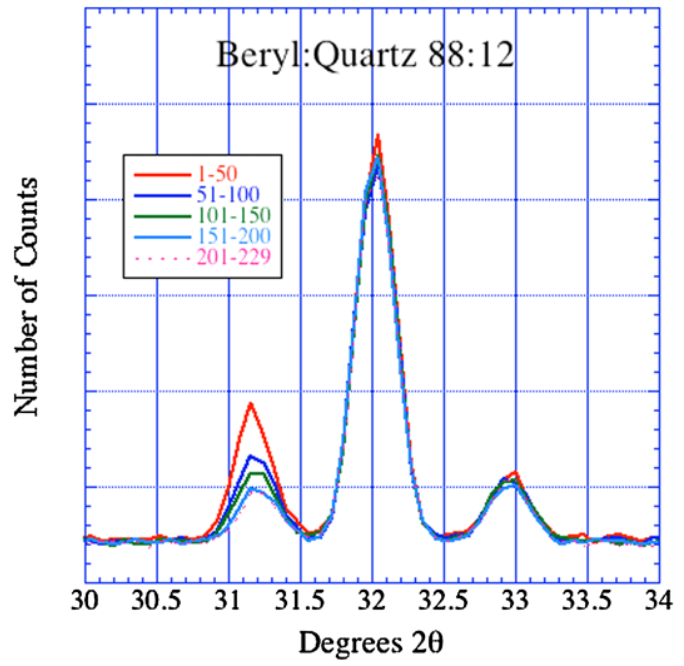

racy called out in the CheMin instrument requirements. Figure 20 illustrates this graphically, showing progressive reduction of the intensity of the 101 peak of quartz vs. the 112 peak of beryl during the analysis. Experiments using the CheMin testbeds are being performed to determine why this off-nominal behavior occurred. Several possibilities are being investigated:

1. The standard materials were all sieved to a grainsize of 45 to $90 \mu \mathrm{m}$. This differs from most of the known and unknown materials tested in the CheMin testbeds, which were crushed powders $<150 \mu \mathrm{m}$ (although the Inel tests used 90-45 $\mu$ m powders).

2. The standards in the FM are all sealed in the cells with HEPA filters, to keep the material in the cell for the duration of the mission. There could be electrostatic effects due to friction of the quartz grains with the HEPA material that cause phase segregation during shaking. Moreover, the HEPA filter material is mounted on rigid frames epoxy-bonded in the throat of the cell; this changes the center of mass and vibration modulus of the cell.

3. The style of piezovibration of the FM cells is different from that implemented in the CheMin testbeds. In the FM, the piezovibration frequency is locked onto the sample cell resonance, and only the amplitude of shaking is adjusted during an analysis. In the CheMin testbeds, the piezovibration frequency is ramped through a range that briefly includes the resonant frequency of the cell. There was insufficient time during FM ThermoVac testing to experiment with variations in shaking intensity. 
Fig. 21 Film mode XRD of beryl:quartz 97:3 mixture, showing detection of quartz 100 and 101 peaks $(\mathrm{K} \alpha)$ and quartz $101(\mathrm{~K} \beta)$

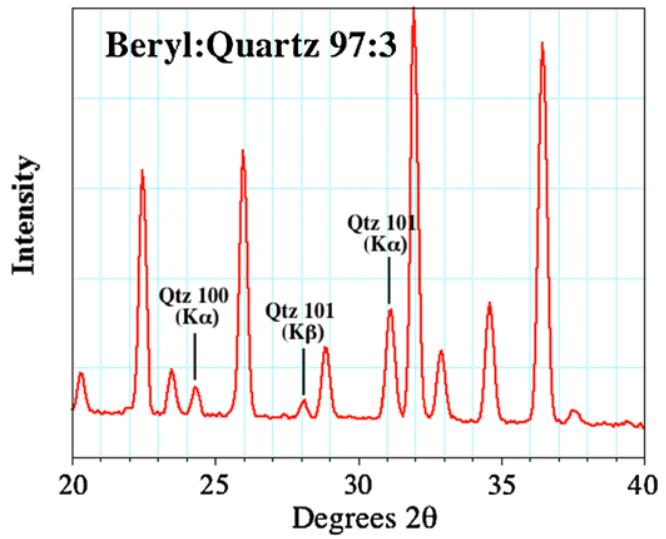

During the operation of the CheMin testbeds and precursor instruments, we were well aware that the style and intensity of piezovibration can cause phase separation in complex mixtures. Fortunately, by understanding the nature of the samples, conditions of analysis can be varied and phase separation minimized or mitigated. To understand these problems in the CheMin FM, a test chamber is being built at Ames Research Center to study grain motion, utilizing an FM cell driven by FM electronics. Similar experiments will be performed in the CheMin DM instrument.

Minimum Detection Limits in Mineral Mixtures Figure 21 shows a film mode XRD pattern of the Beryl:Quartz 97:3 standard (RAMP $-30^{\circ} \mathrm{C}, \mathrm{CCD}-60^{\circ}, 7$ Torr Ar, consisting of 640 30 -sec. frames). In film mode, there is increased background resulting from Bremsstrahlung radiation and sample-induced fluorescence (minor in this case), and $\operatorname{CoK} \beta$ diffraction is not removed. Quartz $101 \mathrm{~K} \alpha$ and $\mathrm{K} \beta$ peaks can clearly be seen at $\sim 31^{\circ}$ and $\sim 28^{\circ} 2 \theta$, in addition to quartz 100 at $\sim 24^{\circ} 2 \theta$. This detection validates the MDL of $3 \%$ listed in the instrument specifications. In real geological materials having many phases, especially $\mathrm{X}$-ray amorphous materials and minerals with broadened peaks such as clay minerals, this detection limit will probably not be achieved, and MDLs will have to be evaluated based on the nature of the sample.

\subsubsection{XRD and EDH Tests: Gore Mountain Amphibole}

Cross-Platform Comparison of XRD Patterns During ThermoVac testing of the CheMin FM, only standards in sealed cells were analyzed since samples put into any of the 27 open cells would contaminate the instrument during launch and spaceflight. Cross-platform comparisons were made between the CheMin FM, CheMin IV and Terra with samples of the Gore Mountain Amphibole. Figure 22 shows a comparison of patterns from each of these instruments, obtained for equivalent counting times.

Because Mars is an iron-rich planet, many of the materials analyzed by CheMin will exhibit strong $\mathrm{Fe} \mathrm{K} \alpha$ fluorescence from the sample. In film mode XRD patterns, this is manifested as increased background (and therefore decreased peak to background ratio) across the full $2 \theta$ range. Energy-selected $\mathrm{Co} \mathrm{K} \alpha$ mode patterns, which exclude photons having energies outside of a specified $\mathrm{Co} \mathrm{K} \alpha$ "energy window" are able to eliminate this background. In order to discriminate $\mathrm{Co} \mathrm{K} \alpha(6.93 \mathrm{KeV})$ from $\mathrm{Fe} \mathrm{K} \alpha(6.40 \mathrm{KeV})$ in iron containing samples, the CheMin instrument has a requirement to maintain the FWHM of Fe 


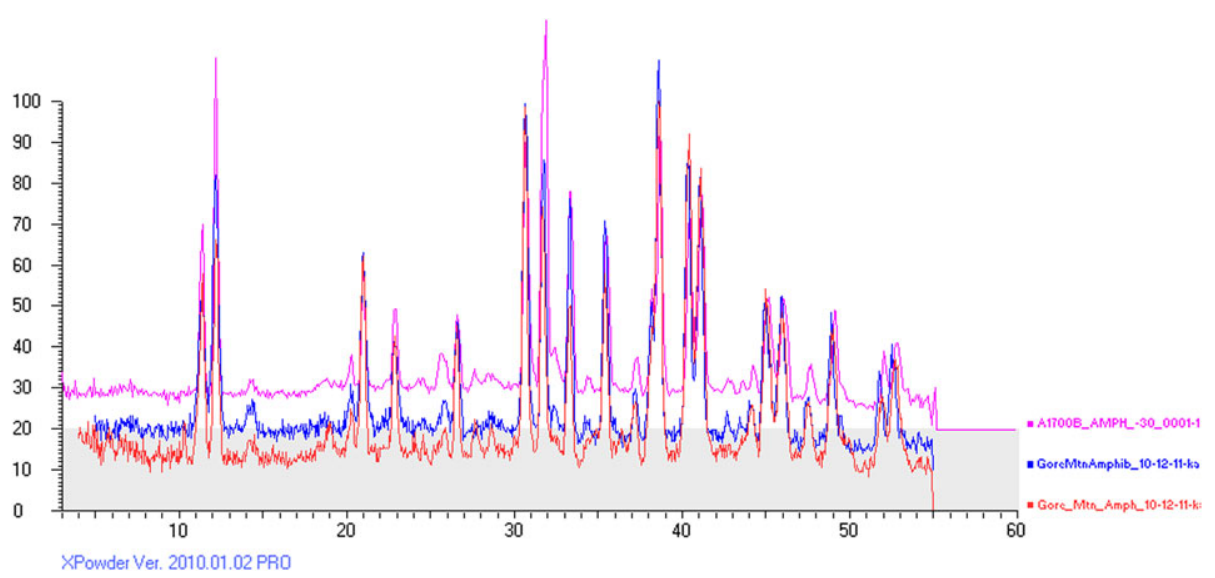

Fig. 22 Comparison of Gore Mountain amphibole XRD patterns between the CheMin FM, CheMin IV and a Terra field instrument. Pink = CheMin FM, consisting of 145030 -second frames of data (725 minutes). Blue = CheMin IV, consisting of 48,000 seconds of acquisition time, or 150030 -second frames of data. Red $=$ Terra, consisting of 10,000 seconds of acquisition time, or 1000 10-second frames. Terra has approximately $4 \mathrm{X}$ the flux of the other two instruments
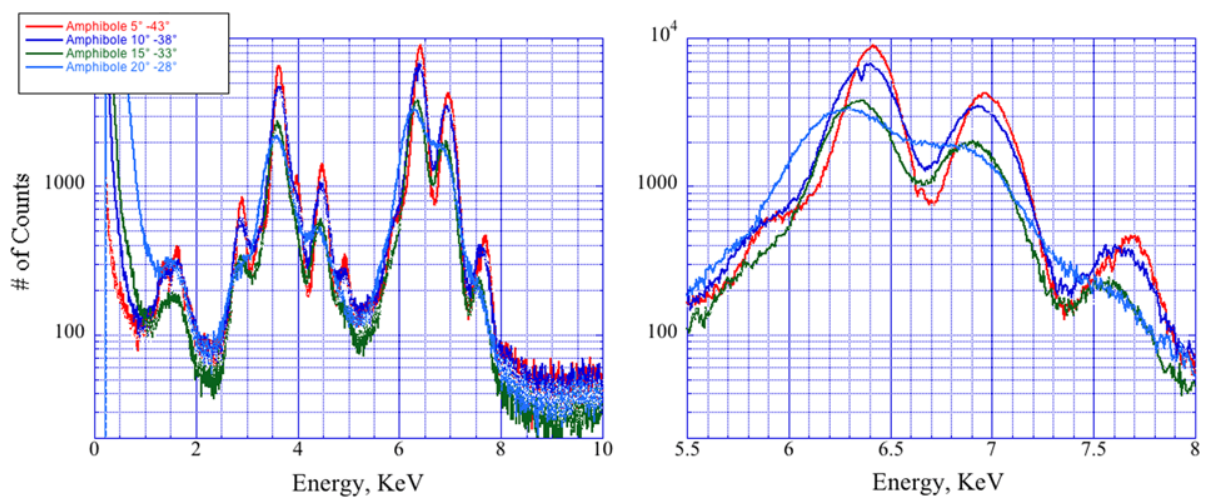

Fig. 23 Gore Mountain amphibole EDH for a series of RAMP temperatures predicted for MSL operations at Gale Crater. RAMP temperatures: red $=5{ }^{\circ} \mathrm{C}$, dark blue $=10^{\circ} \mathrm{C}$, green $=15^{\circ} \mathrm{C}$ and light blue $=20^{\circ} \mathrm{C}$

$\mathrm{K} \alpha$ and $\mathrm{Co} \mathrm{K} \alpha$ in $\mathrm{EDH}<250 \mathrm{eV}$. The Gore Mountain amphibole (which contains $12 \%$ $\mathrm{FeO}$ ) was included as a reference standard in the CheMin FM in part to evaluate $\mathrm{Fe} \mathrm{K} \alpha$ and $\mathrm{Co} \mathrm{K} \alpha$ FWHM energy resolution during the mission. The flight instrument can easily meet this requirement when the $\mathrm{CCD}$ is cooled to $-60^{\circ} \mathrm{C}$; however, as was described above, at the predicted RAMP $0^{\circ} \mathrm{C}$ to $+26{ }^{\circ} \mathrm{C}$ temperatures at Gale Crater, the $\mathrm{CCD}$ temperatures will vary between $-48{ }^{\circ} \mathrm{C}$ and $-22{ }^{\circ} \mathrm{C}$.

Figure 23 shows EDH spectra for the Gore Mountain amphibole taken over a range of temperatures that are predicted for the MSL RAMP during operations at Gale Crater. Above $0{ }^{\circ} \mathrm{C}$ (RAMP), the Fe $\mathrm{K} \alpha$ and $\mathrm{Co} \mathrm{K} \alpha \mathrm{FWHM}$ exceed the $<250 \mathrm{eV}$ requirement. However, even at $20{ }^{\circ} \mathrm{C}$ RAMP, energy-selected Co $\mathrm{K} \alpha$ patterns of the Gore mountain amphibole meet the required $2 \theta$ resolution and peak to background ratio of the instrument (Fig. 24). 


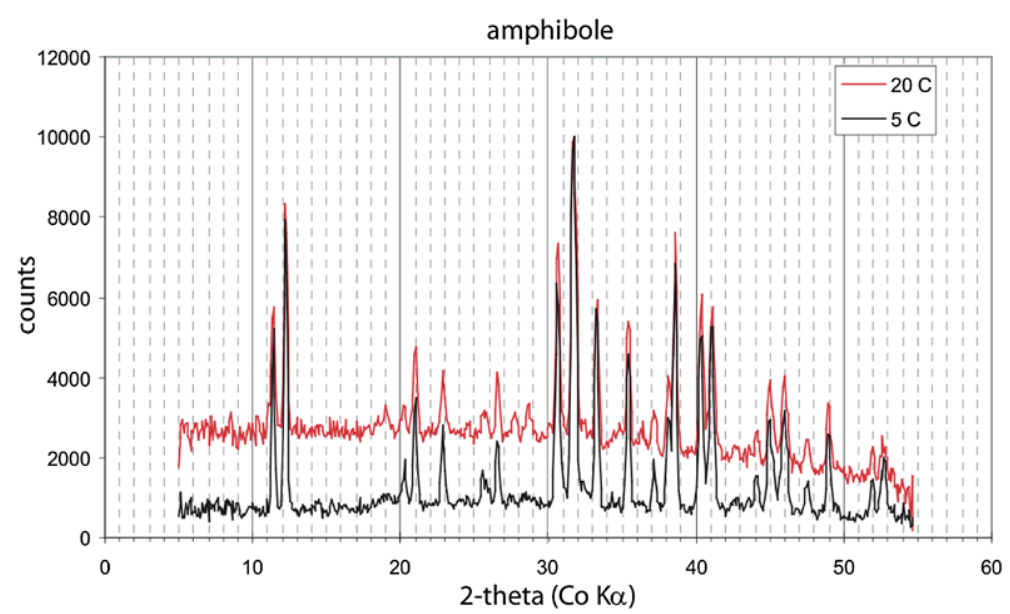

Fig. 24 Diffraction patterns from amphibole standard collected at $5{ }^{\circ} \mathrm{C}$ and $20{ }^{\circ} \mathrm{C}$ RAMP temperatures. Diffraction data meet required $2 \theta$ resolution and peak/background even at the higher RAMP temperatures expected at Gale Crater

Many additional samples containing a range of Fe concentrations will be tested in the DM to establish the detection limits of the FM instrument during the course of the mission.

\subsection{X-Ray Fluorescence Characterization $\left(\mathrm{CCD}\right.$ Temp. $\left.=-60{ }^{\circ} \mathrm{C}\right)$}

The XRF requirement for the CheMin instrument was descoped early in the instrument fabrication for technical and budgetary reasons. However, energy discrimination is still required in order to separate $\mathrm{Co} \mathrm{K} \alpha$, $\mathrm{Co} \mathrm{K} \beta$ and $\mathrm{Fe} \mathrm{K} \alpha$ for energy-selected XRD patterns. Furthermore, energy discrimination is important for producing other minor frame 2-D XRD images such as "single pixel," "split pixel" and "modified raw" patterns. Lastly, even with a degraded energy discriminating capability, information as to which elements are present in a sample will be invaluable in phase identification. All of the standard samples (whose compositions are shown in Table 11) are useful for characterizing the energy discriminating capability of the CheMin instrument: The ceramic sample contains most of the elements of geologic interest above $Z=13$, the Gore Mountain amphibole contains major Fe (to evaluate $\mathrm{Fe} \mathrm{K} \alpha \mathrm{FWHM}$ and Fe Ka energy separation from $\mathrm{Co} \mathrm{K} \alpha$ ), the arcanite contains $\mathrm{K}$ and $\mathrm{S}$, and the beryl in the beryl:quartz mixtures plus the doped ceramic contain 0.64 to 2.05 wt.\% Cr. Figure 25 shows an EDH pattern for the ceramic standard, collected with $\mathrm{CCD}$ temperature of $-60{ }^{\circ} \mathrm{C}$ to minimize background noise.

\subsection{CheMin Beginning of Life (BOL) and End of Life (EOL) Performance}

During the nominal MSL mission of one Mars year, the CheMin CCD will be damaged by high-energy neutrons from the nuclear power source. Strategies have been developed and tested to minimize the effect of this degradation by utilizing on-chip binning and reduced CCD exposure times. Tests performed during ThermoVac show that BOL instrument performance can be maintained throughout MSL's nominal mission using these strategies. 


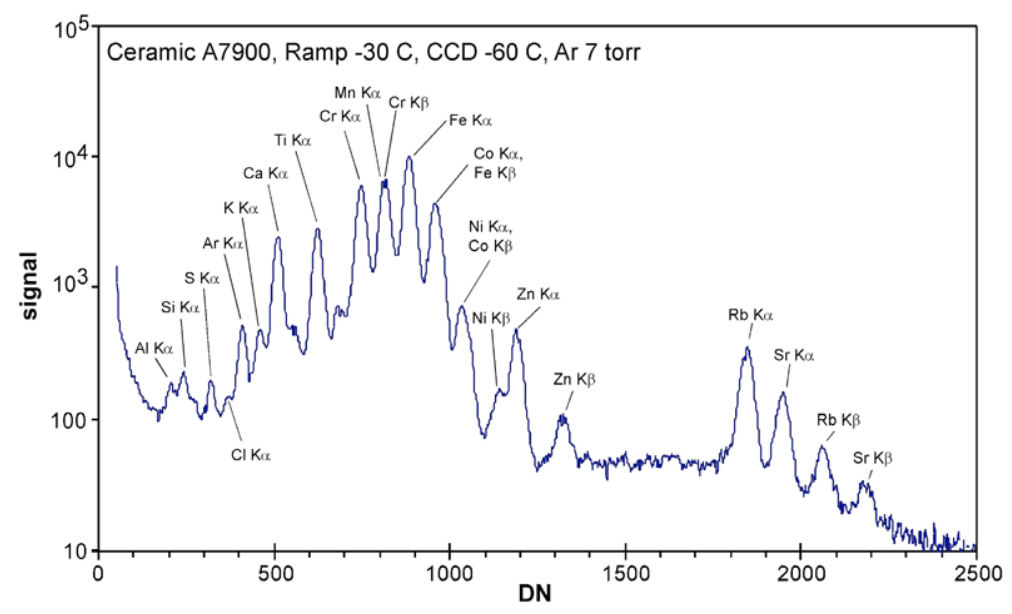

Fig. 25 Energy-dispersive histogram $(\mathrm{EDH})$ of the ceramic standard, RAMP $-30{ }^{\circ} \mathrm{C}, \mathrm{CCD}-60{ }^{\circ} \mathrm{C}$, simulated mars atmosphere

\section{Example Patterns from Mars Analog Rocks and Minerals}

\subsection{Basaltic and Ultramafic Rocks}

\subsubsection{Basaltic Rocks and Their Weathering Products}

Mars is a basaltic planet and much of the mineral alteration that will be seen there will be of igneous precursors. The nature of past alteration processes on the Mars surface can be elucidated by a better understanding of alteration mineralogy. Depending on conditions, volcanic glass can alter to a variety of mineral assemblages, including zeolites, smectites, kaolin minerals, hydrated volcanic glass, and opaline silica. For example, Zolotov and Mironenko (2007) suggested that amorphous silica, goethite, and kaolinite would form early under acid alteration conditions, whereas zeolites and carbonates would form later under more alkaline conditions. Yen et al. (2007) suggested that recently observed silica deposits on Mars could have formed from hydrothermal alteration or from acidic vapors with small amounts of liquid water. Formation of both smectites and zeolites from volcanic ash is common on Earth, with smectite formation occurring in below-neutral $\mathrm{pH}$ conditions and zeolites forming in alkaline conditions. Thus, detection of secondary zeolites would strongly imply the occurrence of alkaline conditions but detection of both smectites and zeolites would indicate a much more persistent and evolved hydrogeologic system (Bish et al. 2008). Kaolin minerals usually form under more acidic conditions, often with high water:rock ratios and they may be accompanied by amorphous silica deposits when formed hydrothermally. Figure 26 shows CheMin IV XRD results from an altered basaltic tephra found near the summit of Mauna Kea in Hawai'i. Table 15 compares a quantitative analysis of the Mauna Kea sample using CheMin IV data with an analysis using data from a commercial laboratory instrument. The identification of alunite and kaolinte as well as a large quantity of amorphous material in this case suggests alteration by acidic hydrothermal solutions.

\subsubsection{Ultramafic Rocks}

In this section, analyses of a suite of ultramafic rocks similar to those identified on Mars (Poulet et al. 2009; Ehlmann et al. 2009) are shown. We evaluated the ability of the Terra 


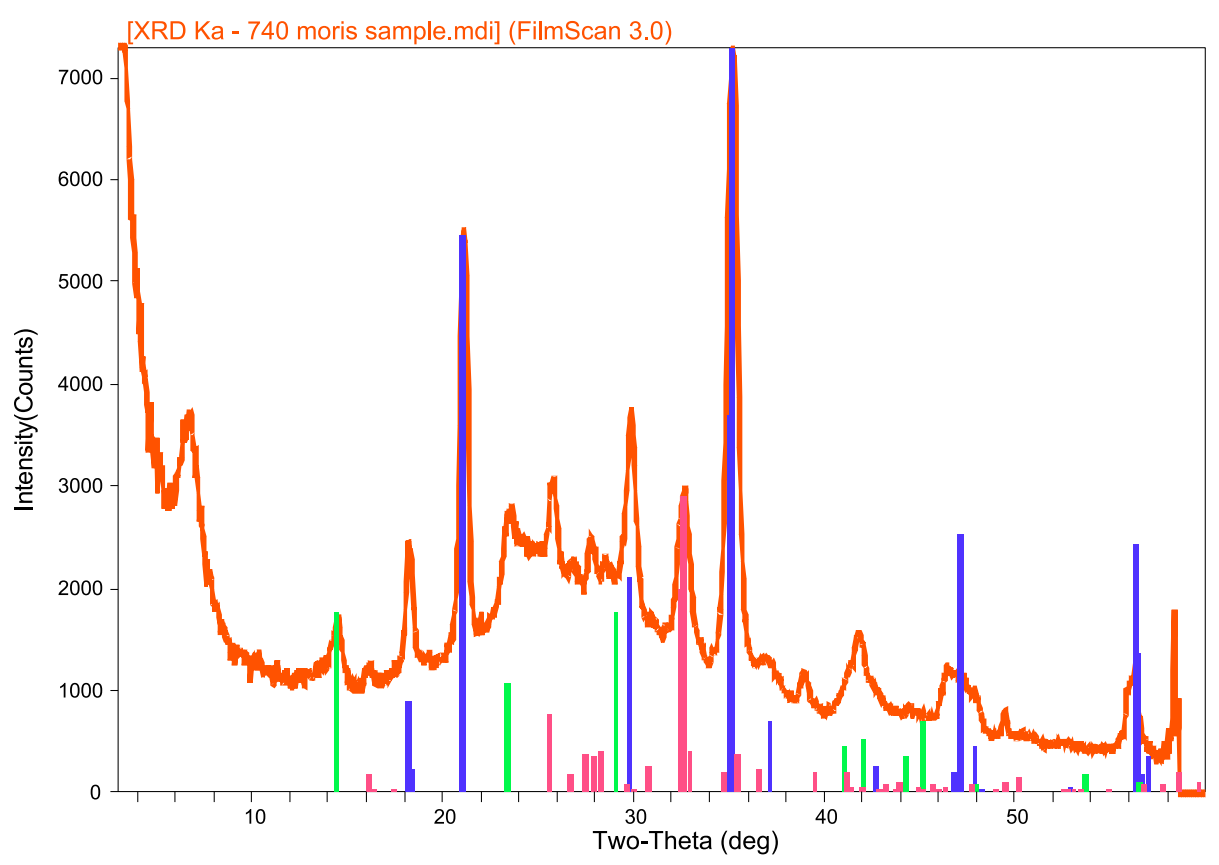

Fig. 26 CheMin IV XRD pattern of volcanic tephra from near the summit of Mauna Kea Volcano, Hawai'i (Hamilton et al. 2008) Alteration phases include alunite, smectite, kaolinite and amorphous phases formed by hydrothermal aqueous alteration of basaltic tephra. Peak markers: blue = alunite, red $=$ albite, green $=$ kaolinite; smectite not labeled, but 001 peak prominent at $7^{\circ} 2 \theta$. Large amorphous component evident as broad scattering hump centered at about $27^{\circ} 2 \theta$

Table 15 Rietveld refinement of XRD data shown in Fig. 26. Analyses obtained from CheMin IV data are compared to quantitative results from a laboratory Siemens D500 XRD instrument. Differences in relative wt.\% are compared with accuracy requirements for the CheMin flight instrument

\begin{tabular}{llccl}
\hline Phase & CheMin IV (wt.\%) & D500 (wt.\%) & CheMin IV - D500 (rel.wt.\%) & Accuracy \\
\hline Alunite & 30 & 34 & -12 & Within 15\% \\
Albite & 11 & 12 & -8 & Within 15\% \\
Amorphous & 45 & 29 & +55 & need to develop $^{\text {a }}$ \\
Smectite & 7 & 12 & -42 & $<4$ MDL $^{b}$ \\
Hematite & 1 & 1.3 & -23 & $<4$ MDL \\
Kaolinite & 5 & 12 & -58 & $<4$ XDL \\
\hline
\end{tabular}

${ }^{a}$ Accuracy for measurement of amorphous components depends on use of appropriate standards and instrument-specific data from those standards; this is yet to be done for CheMin IV and for the CheMin $\mathrm{DM}$

${ }^{\mathrm{b}} \mathrm{MDL}=$ minimum detection limit for accurate quantification within CheMin FM requirements

instrument to identify and quantify minor minerals in ultramafic mantle xenoliths and we evaluated the accuracy of analyses by comparing XRD results with thin section point counting measurements (optical petrography and electron microprobe analysis). Mantle xenoliths were collected on the 2008 AMASE (Astrobiology Mars Analog Svalbard Expedition) ex- 
Table 16 Mineral proportions in mantle xenoliths by petrographic point counting (wt.\%, calculated by multiplying area $\%$ by phase density) and quantitative XRD using the Terra instrument (wt.\%)

\begin{tabular}{|c|c|c|c|c|c|c|c|c|}
\hline \multirow[t]{2}{*}{ Xenolith } & \multicolumn{2}{|l|}{ UI-2B } & \multicolumn{2}{|l|}{ UI-3 } & \multicolumn{2}{|l|}{ UI-5 } & \multicolumn{2}{|l|}{ UI-21 } \\
\hline & Pet $\%$ & $\mathrm{XRD} \%$ & Pet $\%$ & $\mathrm{XRD} \%$ & Pet $\%$ & $\mathrm{XRD} \%$ & Pet $\%$ & $\mathrm{XRD} \%$ \\
\hline $\mathrm{Ol}$ & 65 & 66 & 10 & 8 & 76 & 83 & 63 & 76 \\
\hline Opx & 21 & 25 & 8 & 26 & 18 & 16 & 22 & 21 \\
\hline Cpx & 10 & 6 & 75 & 59 & 2.6 & 1 & 8.6 & 3 \\
\hline $\mathrm{Sp}$ & 2.0 & 1.4 & 3.1 & 2.9 & 1 & 0 & 1 & 0 \\
\hline $\mathrm{Pl}$ & $\sim 0.2$ & 0.6 & $\sim 2.4$ & 4.1 & $\sim 0.4$ & 0 & $\sim 0.8$ & 0 \\
\hline Am & 0 & 0 & 1.5 & 0 & 0 & 0 & 0 & 0 \\
\hline Altn & $\sim 1.5$ & 0 & 0 & 0 & 1.6 & 0 & 4.5 & 0 \\
\hline PM & 1.1 & - & 14.4 & - & 2.1 & - & 5.9 & - \\
\hline
\end{tabular}

Methods: Pet $=$ petrographic mapping; XRD $=$ Terra XRD w/Rietveld refinement. Minerals: Ol = olivine; $\mathrm{Opx}=$ orthopyroxene; $\mathrm{Cpx}=$ augite; $\mathrm{Sp}=$ spinel; $\mathrm{Pl}=$ plagioclase; $\mathrm{Altn}=$ "aqueous alteration" (carbonates, zeolites, clays); $\mathrm{Am}=$ amphibole; $\mathrm{PM}=$ "partial melt" ( 2/3 olivine, $1 / 6$ plagioclase, $1 / 6$ pyroxene $)$

pedition to Svalbard (Steele et al. 2008), from basalt outcrops on the Sverrefjell volcano (Skjelkvale et al. 1989). Each xenolith was split into several fragments (a few gm each) for thin sectioning, XRD, and petrographic analyses.

Mineral identifications were first made by optical microscopy. Mineral proportions were derived from optical images of the whole thin section area, manually annotated for mineral species and measured by area in an image-processing code (NIH Image; http://rsbweb.nih.gov/ij/). Weight percent was calculated from area percent by multiplying area percent by assumed phase densities. We believe that the proportion of total pyroxenes is accurate, but it was difficult in some samples to distinguish orthopyroxene from clinopyroxene. Mineral compositions were determined by wavelength-dispersive electron microprobe analysis (EMP) using well-characterized natural and synthetic standards (Treiman et al. 2010).

X-Ray Diffraction Analysis X-ray diffraction analyses were obtained with a Terra XRD. Qualitative analysis for mineral species identification was performed by comparison with the ICDD database, and mineral proportions were calculated via Rietveld refinement using the commercial MDI program Jade ${ }^{\mathrm{TM}}$.

The xenoliths span a range of compositions and degrees of alteration. From EMP analysis and optical petrography, it was determined that all but one are spinel lherzolites (Table 16) with olivine of $\mathrm{Fo}_{87-91}$, orthopyroxene of $\mathrm{Wo}_{01} \mathrm{En}_{90-91}$ and augite of $\mathrm{Wo}_{46-47} \mathrm{En}_{49}$ (Treiman et al. 2010). Spinels vary widely in $\mathrm{Cr}$ and $\mathrm{Al}$ contents. Xenolith UI-3 is a pyroxenite (websterite), with abundant augite $\left(\mathrm{Wo}_{47} \mathrm{En}_{47}\right)$, and lesser orthopyroxene $\left(\mathrm{Wo}_{01} \mathrm{En}_{86}\right)$, spinel, and amphibole.

The xenoliths contain two types of secondary material: partial melts and products of aqueous alteration. Partial melts are concentrated near and around the spinels and are composed of small (10's of $\mu \mathrm{m}$ ) crystals of olivine, plagioclase, pyroxenes and spinel with glass and void spaces. The aqueous alteration products are veinlets and space fillings (Treiman et al. 2002) that constitute less than a few percent of the xenoliths; the alteration materials include zoned spherules of ( $\mathrm{Mg}, \mathrm{Fe}) \mathrm{CO}_{3}$ (Treiman et al. 2002), smectitic clays, silica, zeolites, and hematite replacing the carbonate and clay. 
The mineral identifications and proportions determined by Terra XRD and by optical petrography are very similar. Terra detected all of the major minerals in the xenoliths, namely olivine, orthopyroxene, augite, and spinel. Mineral proportions are close to, but not identical to those determined petrographically. Most of the differences can be ascribed reasonably to heterogeneity in the xenoliths - the portion exposed in thin section may not be identical to that in the fragment powdered for XRD. Terra XRD and petrography gave nearly identical proportions of spinel. For some lherzolites, XRD gave slightly greater proportions of olivine than did petrography, but likely within counting uncertainties of the latter. Proportions of orthopyroxene versus augite were commonly different by the two methods; sample heterogeneity is the likely cause. Terra XRD detected plagioclase feldspar in several xenoliths. Before petrographic examination, the occurrence of plagioclase in these rocks was thought unlikely. However, the xenoliths do contain plagioclase in the partial melt material, and the measured proportions in thin sections are close to those from Terra XRD. Similarly Terra XRD detected olivine in UI-3, although none was seen as large crystals. However, the partially melted material includes olivine, which was discovered by EMP analyses.

XRD Detection Limits The Terra XRD was developed to be able to detect minerals at the $1 \%$ level, and our results indicate that this instrument meets and can exceed that specification for common ultramafic rock types. CheMin flight instrument analyses will have similar detection limits and accuracy/precision of quantification. Abundances of spinel in these xenoliths demonstrate detection limits within error: abundances above $1 \%$ (UI-2B \& UI-3) were detected at the same levels by XRD and petrography but spinel was not detected by XRD in xenoliths (UI-5 \& UI-21) where abundances measured in thin section are below $1 \%$. Amphibole in UI-3, present in petrographic analyses at $1.5 \%$ by vol., was not detected by Terra. Carbonate, smectite, hematite and zeolites were not detected by Terra XRD, but all are at abundance levels $\ll 1 \%$.

The Terra XRD (and CheMin by implication) will be useful for identifying minerals more abundant than $\sim 1 \%$ by volume, and the instrument is capable of producing data that can be used to retrieve mineral proportions in ultramafic rocks. It may be possible to reduce detection limits further through the judicious optimization of data collection strategies. With further analysis and calibration, CheMin XRD data will be useful in constraining the compositions of minerals in mafic and ultramafic rocks (e.g., Butterworth et al. 2006).

\subsection{Phyllosilicate Minerals}

Observations from the OMEGA imaging spectrometer aboard Mars Express (Bibring et al. 2004; Chicarro et al. 2004) have revealed a rich diversity of mineralogy on the surface of Mars, including the hydrated clay mineral nontronite in older cratered terrains (Bibring et al. 2005), along with montmorillonite and other clay minerals (Poulet et al. 2005). Recent observations of hydrated silicate minerals by the CRISM instrument on Mars Reconnaissance Orbiter have validated these observations and provided an even more detailed picture of the distribution of hydrous phyllosilicates on the Martian surface (Mustard et al. 2008; Bishop et al. 2008). OMEGA and CRISM data also suggest the presence of diverse clay minerals, including Fe,Mg,Al-phyllosilicates, kaolin group minerals, chlorites, and serpentine minerals, along with a variety of hydrous sulfate minerals. Clay minerals, including likely nontronite (Milliken et al. 2010), are among the primary targets at Gale Crater.

In XRD, discriminating between the variety of possible silicate clay minerals is traditionally done by taking advantage of the existence of distinct large repeat distances perpendicular to the phyllosilicate layers, seen as their $00 l$ diffraction peaks. Clay mineral discrimination is based primarily on these repeat distances in their structures. 


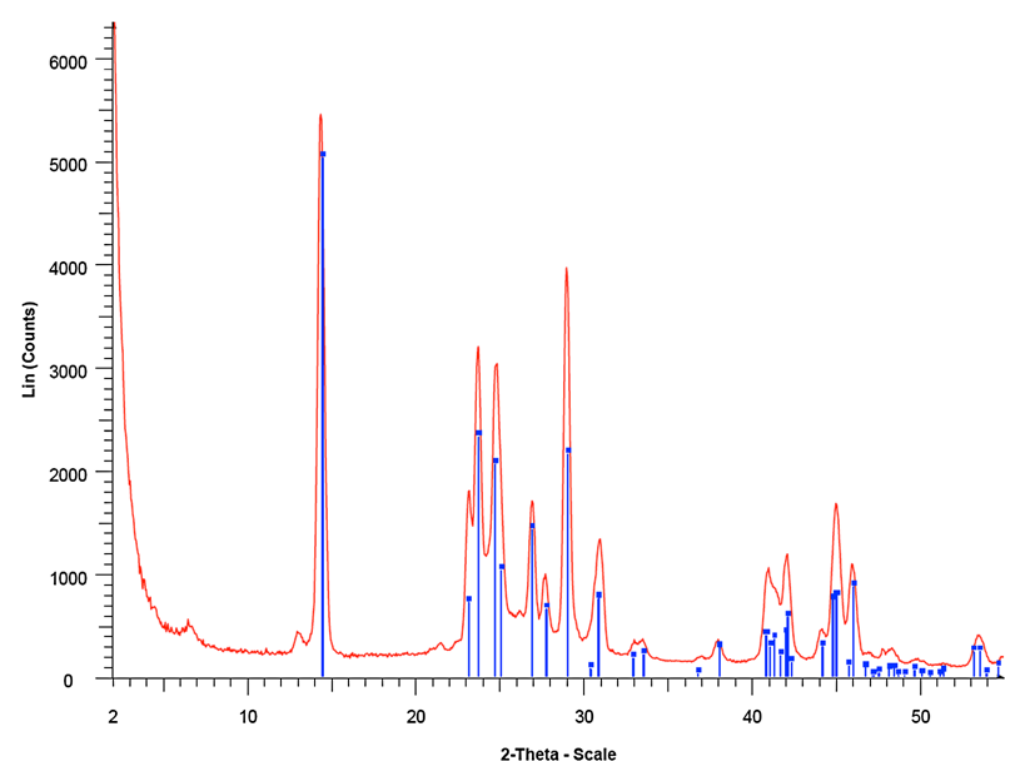

Fig. 27 CheMin IV Co K $\alpha$ XRD pattern of kaolinite (blue lines). Peak at $\sim 6.5^{\circ} 2 \theta$ results from the Kapton ${ }^{\circledR}$ window and other peaks are kaolinite $\operatorname{Co~} \mathrm{K} \beta$ peaks (Bish et al. 2008)

CheMin can identify and distinguish a number of clay minerals. For example, discrimination between 1:1 phyllosilicates (such as the kaolin minerals), with repeat distances of $\sim 7 \AA$ (e.g., Fig. 27), and smectites (e.g., montmorillonite, nontronite, saponite), with repeat distances from 10-15 $\AA$ (e.g., Fig. 28) is straightforward (Bish et al. 2008). However, it is important to note that the variety of treatments used in terrestrial laboratories to aid in discrimination of clay minerals will not be accessible on Mars (e.g., saturation with ethylene glycol vapor, heat treatments). Although these treatments will not be available on Mars, dehydration within the CheMin instrument could be used to advantage in discriminating between phyllosilicate minerals that exhibit different dehydration behavior, such as chlorite vs. smectite. In addition, it should be possible to identify the hydrated kaolin mineral halloysite. The lowest-angle 001 diffraction peak from $10.1 \AA$ hydrated halloysite occurs at $\sim 10.2^{\circ} 2 \theta$ with Co radiation and is easily detectable; the mineral may readily dehydrate to $\sim 7 \AA$, making its identification possible based on this transition. Some discrimination among the various smectites may be made by utilization of CheMin EDH spectra (to distinguish Fesmectites, for example) and correlative elemental data from the APXS and ChemCam instruments. Additional information may be obtained from dehydration and dehydroxylation temperatures determined in stepwise heating within the SAM instrument.

The study of clay mineralogy in situ on Mars will begin with the arrival of CheMin on Curiosity in 2012. Gale Crater shows evidence of sedimentary processes along with spectral signatures of both clays and sulfates. Clay mineralogy will be a critical component of determining hydrogeologic history and habitability and the CheMin instrument is well suited for the task.

\subsection{Mg- Fe- Ca-Sulfate Hydrates}

We expect to find sulfate minerals in abundance at Gale Crater, particularly polyhydrated sulfates and kieserite (Milliken et al. 2010). The polyhydrated forms are not well constrained 


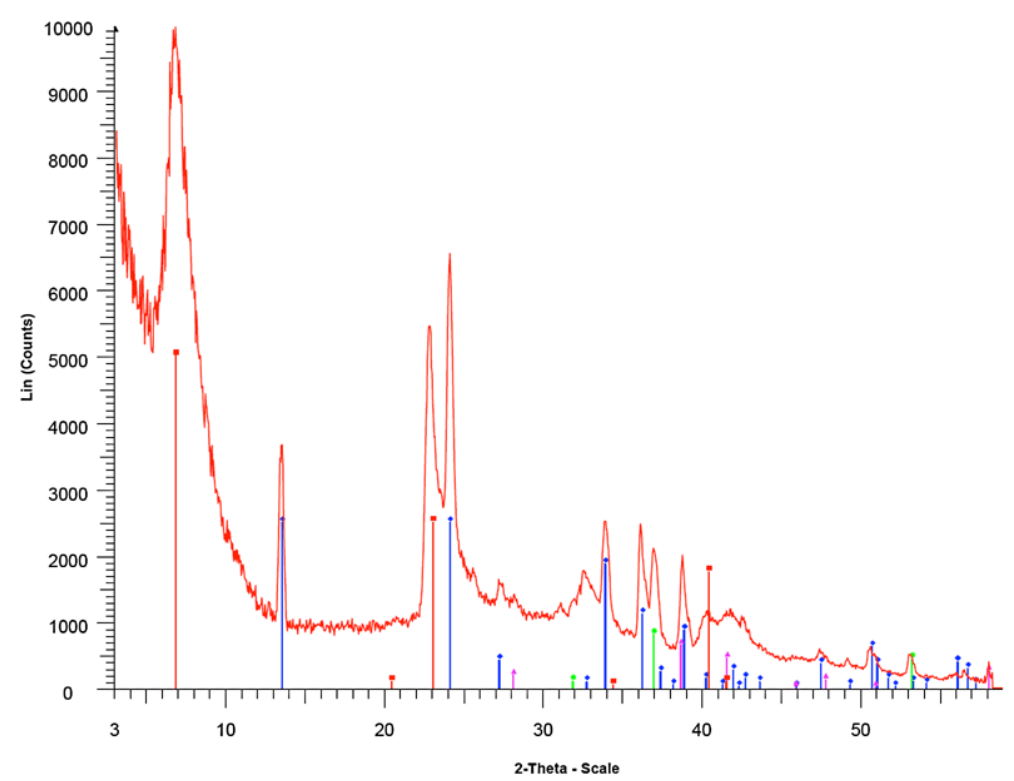

Fig. 28 CheMin IV Co K $\alpha$ XRD pattern of nontronite (61 wt.\%, red), gypsum (25 wt. \%, blue), halite (8.7 wt.\%, green) and hematite (5.3 wt.\%, purple) (Bish et al. 2008)

but are likely to include members of the Mg-sulfate system, which contains at least seven different crystalline hydrates (all of which are readily identified by XRD), as well as an amorphous hydrated form. The association of Mg-sulfates with smectites that are also identified at Gale Crater (Milliken et al. 2010) suggests that Ca-sulfate is also likely be present as a result of cation exchange between smectite and $\mathrm{Mg}$-sulfate brine (Vaniman and Chipera 2006). Experience with CheMin IV and Terra instruments has proven the capabilities of the CheMin design in identifying and quantifying complex mixtures of $\mathrm{Mg}-\mathrm{Fe}-$ and $\mathrm{Ca}$-sulfates. Figure 29 shows a relatively complex mixture of sulfates, analyzed in the field in Rio Tinto, Spain using a CheMin IV instrument.

Field deployments of the Terra instrument have demonstrated the capability of CheMinlike instruments to determine complex sulfate mineral mixtures that include a range of ferric sulfate phases (e.g., Chipera et al. 2009). Figure 30 shows for example a Terra XRD analysis of an efflorescent mineral sample collected and analyzed in the field at an abandoned mine site near Leadville, Co. The sample was found to contain a mixture of melanterite $\left(\mathrm{FeSO}_{4} \cdot 7 \mathrm{H}_{2} \mathrm{O}\right)$ and siderotil $\left(\mathrm{FeSO}_{4} \cdot 5 \mathrm{H}_{2} \mathrm{O}\right)$ with minor gypsum.

A significant challenge to sample acquisition and processing by SA/SPaH-CHIMRA and analysis by CheMin could result from changes in the hydration state of the hydrated sulfate minerals after they are collected. For example, the sample whose XRD pattern is shown in Fig. 30 had completely altered to Siderotil when returned to the lab for XRD analysis on a conventional instrument. Other samples analyzed at the Leadville site with Terra contained predominantly epsomite $\left(\mathrm{MgSO}_{4} \cdot 7 \mathrm{H}_{2} \mathrm{O}\right)$, but when returned to the laboratory for XRD analysis, had completely altered to mixtures of the 4-hydrate starkeyite and the 6hydrate hexahydrite. End-to-end tests of some of these challenging salt hydrates are planned with MSL testbed systems, as well as with the CheMin DM. With experience on Mars and interpretation based on phase stability data, we hope to understand the nature of such transformations and develop methods to analyze unstable and metastable sulfate hydrates safely 


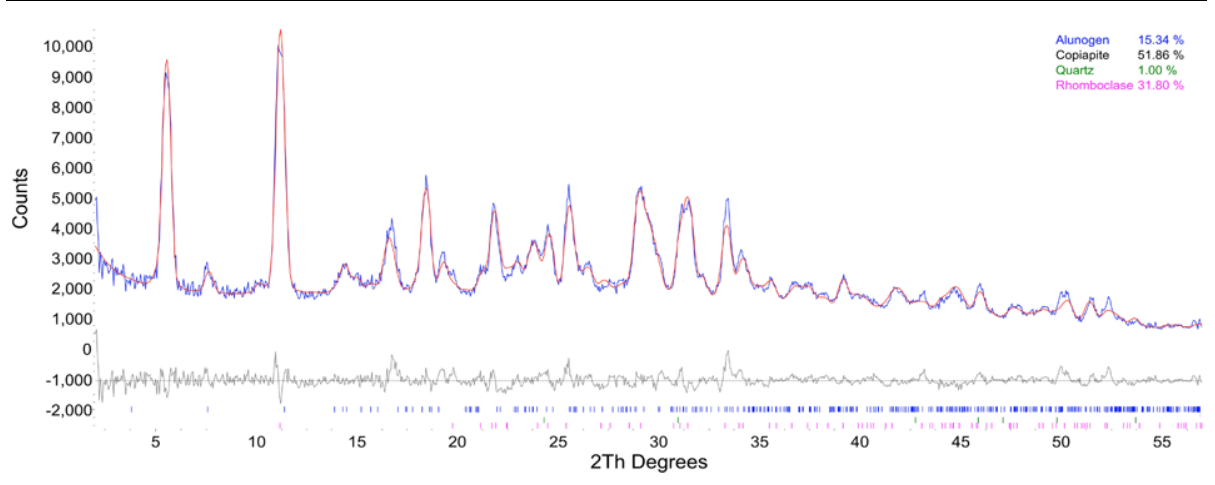

Fig. 29 XRD pattern of a complex Fe-Al sulfate hydrate from Rio Tinto, Spain. The sample, which was analyzed in the field using a CheMin IV instrument, contains $20 \%$ ferricopiapite $\left(\mathrm{Fe}^{3+}{ }_{2 / 3} \mathrm{Fe}^{3+}{ }_{4}\left(\mathrm{SO}_{4}\right)_{6}(\mathrm{OH})_{2} \cdot 20 \mathrm{H}_{2} \mathrm{O}\right), 22 \%$ alunogen $\left(\mathrm{Al}_{2}\left(\mathrm{SO}_{4}\right)_{3} \cdot 17 \mathrm{H}_{2} \mathrm{O}\right), 56 \%$ rhomboclase $\left[\left(\mathrm{H}_{5} \mathrm{O}_{2}\right)^{+} \mathrm{Fe}^{3+}\left(\mathrm{SO}_{4}\right)_{2} \cdot 2\left(\mathrm{H}_{2} \mathrm{O}\right)\right]$, and minor quartz

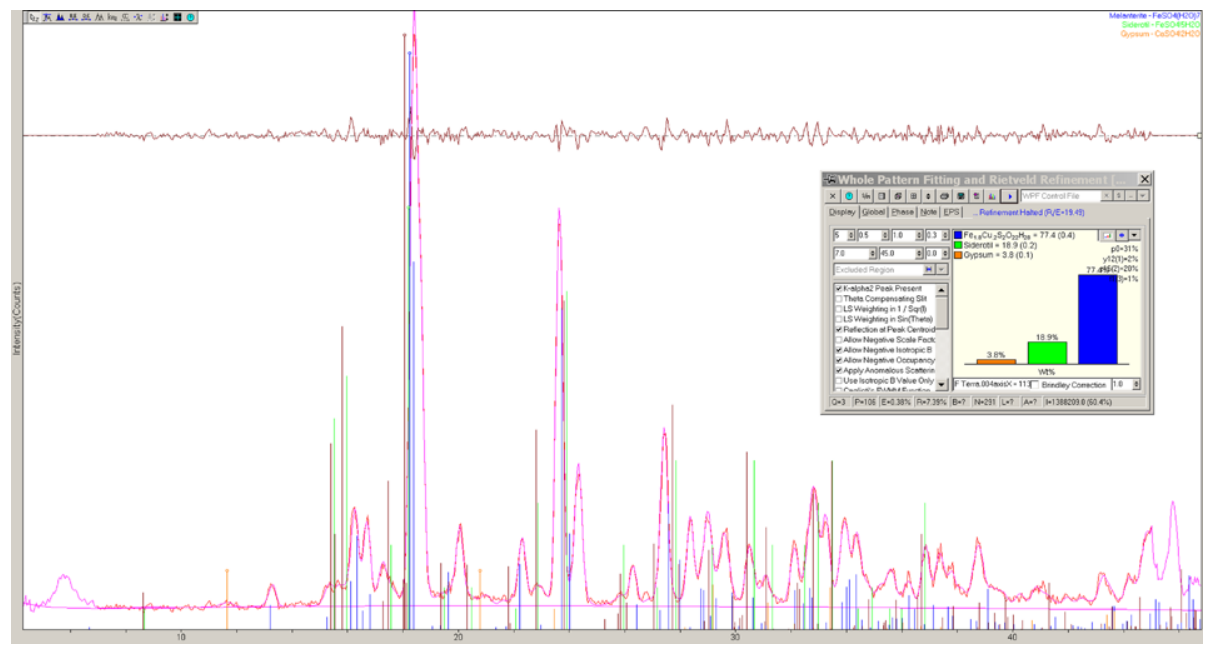

Fig. 30 XRD pattern of an efflorescent sample collected and analyzed in the field by a Terra XRD instrument at an abandoned mine site near Leadville, CO (Chipera et al. 2009). The sample contains a mixture of $77 \%$ melanterite $\left(\mathrm{FeSO}_{4} \cdot 7 \mathrm{H}_{2} \mathrm{O}\right), 19 \%$ siderotil $\left(\mathrm{FeSO}_{4} \cdot 5 \mathrm{H}_{2} \mathrm{O}\right)$, and $4 \%$ gypsum

and accurately. Regardless of their hydration states, the identification of diverse Fe- MgCa-sulfate hydrates at Gale, especially in concert with phyllosilicates, would be extremely interesting and informative with regard to habitability.

\subsection{Carbonates}

The existence of carbonate minerals on Mars has long been postulated, based on evidence of past water along with a $\mathrm{CO}_{2}$ atmosphere that may have been denser during the Noachian era (Gooding et al. 1978; Pollack et al. 1987). More recently, carbonates have been identified as minor phases in Martian meteorites (Romanek et al. 1994) and in orbital observations (Ehlmann et al. 2008; Brown et al. 2010; Michalski and Niles 2011). Carbonates were first 


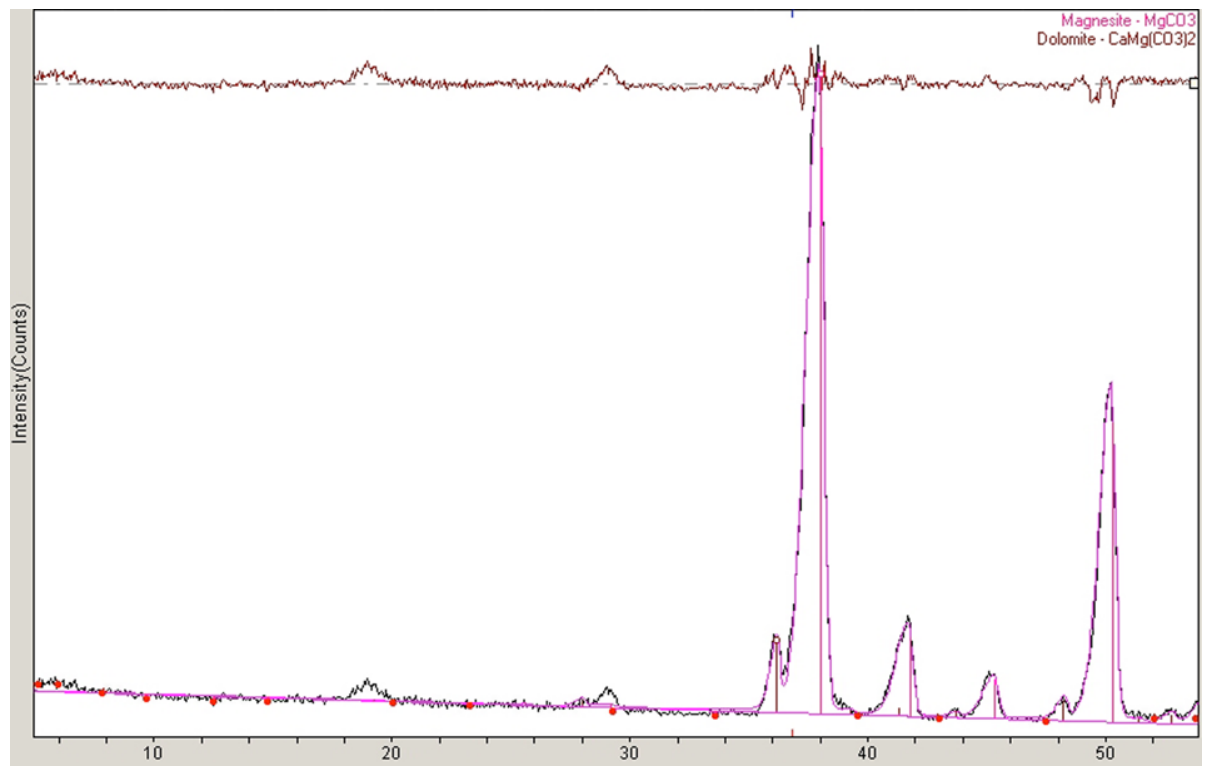

Fig. 31 Terra XRD pattern of "breccia cave carbonate" identified by Morris et al. $(2010,2011)$ as the closest terrestrial analog to the Comanche carbonate in the Columbia Hills. Rietveld refinement of the data show $95 \%$ magnesite and $5 \%$ dolomite. Line markers for stoichiometric magnesite shown. Deviation from stoichiometry is due to Ca substituting for Mg in the structure (as shown by EMP analyses; Blake et al. 2011)

identified in outcrops on the Mars surface by the Spirit rover in the Columbia Hills of Gusev crater (Morris et al. 2010). The best analogs on Earth to the ALH84001 meteorite are ultramafic xenoliths found on the Spitsbergen archipelago (Treiman et al. 2002), which contain carbonates with complex compositional zoning. However, the carbonate globules contained in these rocks are below the detection level of CheMin (Sect. 5.1.2). Other carbonate occurrences in the Bockfjord volcanic province of Spitsbergen (Blake et al. 2010) are the highest fidelity terrestrial analogs to the Comanche carbonates in the Columbia Hills (Morris et al. 2010, 2011; Blake et al. 2011). Occurrences of carbonate associated with volcanic rocks on the Sverrefjell volcano appear to be cements deposited by late-stage hydrothermal systems occupying volcanic pipes. The carbonates are complexly zoned $\mathrm{Ca}-\mathrm{Fe}-\mathrm{Mg}$ carbonates as shown by EMP analysis (Blake et al. 2011).

In the rhombohedral carbonate system, the position of the 104 peak can be used to determine $\mathrm{Ca}-\mathrm{Mg}$ cation ratios and the 015 peak, when present, provides an indication of dolomite-like ordering of cations along the $c$-axis (Goldsmith and Graff 1958). The intensity of individual peaks also provides some information about site occupancies. A search-match of the pattern shown in Fig. 31, for example, identifies the minerals dolomite and siderite, but the X-ray fluorescence data show that only a small amount of Fe is present. A Rietveld refinement of the data using siderite fits moderately well, but the site occupancy refinement suggests that the structure is more like magnesite. The best fit for the pattern is a somewhat disordered, fine-grained $\mathrm{Ca}$-substituted magnesite. The carbonates are $\mathrm{Ca}-\mathrm{Mg}$ - and $\mathrm{Fe}$ - rich with zoned compositions that are probably the result of rapidly changing fluid compositions during deposition; thus the magnesite identification represents an averaged structure. The complex cation substitutions that can occur in zoned rhombohedral carbonates are challenging when only XRD data are available but this is a case in which the combination of CheMin EDH data along with XRD can assist in characterization. 
Carbonate minerals on Earth are quite commonly associated with habitable zones such as hot springs (low-temperature hydrothermal zones), marine or lacustrine sediments, or biominerals. Carbonate minerals are also a common byproduct of serpentinization, the process by which ultramafic mantle minerals are transformed into serpentine at low temperatures in the presence of water (Schulte et al. 2006). Serpentinization is an important source of hydrogen, which is used as an energy source by chemosynthetic microbes on Earth.

\section{The CheMin Mineralogical Instrument at Gale}

MSL's rover Curiosity is scheduled to land in Gale Crater in August 2012. The crater, which is $\sim 155 \mathrm{~km}$ in diameter, has a large central mound that exhibits fine-scale layering suggestive of a sedimentary sequence of rocks deposited in the presence of or beneath water. The layers at the base of the central mound contain phyllosilicates and sulfates and these strata grade upwards into sulfate-dominated units, as determined from orbital IR observations. Because Gale is one of the oldest and deepest craters on Mars, the sediment pile in the central mound could have preserved a record of aqueous mineralogy from a time in Mars' history that parallels that of the early Earth when terrestrial life was thought to have had its origin. The phyllosilicate minerals and sulfates identified in the central mound of Gale are well known from their Earthly counterparts to trap and preserve organic compoundsbiogenic or otherwise - and cementation during early diagenesis could have protected them from oxidation or removal by subsequent aqueous fluids.

If we review the compositional and mineralogical interpretations from the Watchtower rocks at Gusev Crater, shown in Tables 1 and 2, what mineralogies could represent similar starting compositions at Gale, in the absence of oxidation? The impact that produced Gale crater must have penetrated through the Mars crust and into the upper mantle, which contains predominantly ultramafic minerals such as olivine. The tremendous heat of the impact would have caused extensive melting, and as the rocks cooled, hydrothermal systems would have formed and could have persisted for hundreds of thousands of years (e.g., Schwenzer et al. 2010). Serpentinization is one process that may have taken place, by which olivine is converted to serpentine, magnetite, hydrogen and other product phases (Schulte et al. 2006). The reaction can be self-catalyzing in that it is exothermic and the attendant volume increase would create further cracking to allow entry of water into unreacted rock. In terrestrial settings, the serpentinization process and the hydrogen that it produces fuels chemosynthetic ecosystems, which are thought to be among the earliest examples of life on Earth.

In its traverse from the landing ellipse to the central mound of Gale, Curiosity will encounter most of the sediments deposited since the crater's formation. The array of sediment types is stunning and the record of sedimentation points to multiple environments of deposition, ranging from what appear to be cemented units of high thermal inertia within the landing ellipse to nontronite-rich deposits near the base of the mound and a range of strata ranging from clay mineral-rich to sulfate-rich, with the latter dominating upper units. Eolian processing has distributed dune material rich in mafic igneous detritus within Gale's moat and etched yardang features from some of the middle to higher strata; eolian processes are also inferred to have filled and exhumed Gale crater in a manner similar to other comparable craters on Mars (Malin and Edget 2000). The overall history of sedimentation at Gale appears to be one of progressive desiccation along with a transition from phyllosilicateforming to sulfate-precipitating conditions (Milliken et al. 2010).

This sequence of events is of course, highly speculative. Many scenarios are possible, and we won't know anything with certainty until Curiosity lands in Gale crater and begins 
surface operations. The geologic history of the Mars surface resides in its rocks. The rocks play the dual role of recording the history of surface and near-surface conditions, and providing a geologic context to the imaging, chemical, organic, isotopic, and other analyses that MSL will perform.

Acknowledgements The CheMin flight instrument could not have been realized without long-term support from NASA's research and technology programs and institutions, including: Ames Research Center's Director's Discretionary Fund, the Exobiology Instrument Development program, the Planetary Instrument Definition and Development program (PIDDP), the Mars Instrument Definition and Development program (MIDDP), the Astrobiology Science and Technology Instrument Development program (ASTID), the Astrobiology Science and Technology for Exploration of Planets program (ASTEP), NASA's Small Business Innovative Research program (SBIR), and the diligent efforts engineers and scientists of the Jet Propulsion Laboratory, California Institute of Technology under a contract with NASA. We also thank Thomas Chatham of Chatham Created Gemstones for the donation of synthetic emerald for the beryl:quartz standard materials.

Open Access This article is distributed under the terms of the Creative Commons Attribution License which permits any use, distribution, and reproduction in any medium, provided the original author(s) and the source are credited.

\section{References}

C.N. Achilles, D.W. Ming, R.V. Morris, D.F. Blake, LPSC XXXXII, abstr. \#2671 (2011)

J.-P. Bibring et al., ESA SP 1240, 37 (2004)

J.-P. Bibring et al., Science 307, 1576-1581 (2005)

D.L. Bish, J.E. Post, Am. Mineral. 78, 932-942 (1993)

D.L. Bish, D.L. Vaniman, D. Blake, P. Sarrazin, S. Chipera, LPSC 29 Abstr. \#1256 (2008)

J.L. Bishop, E.Z. Noe Dobrea, N.K. McKeown, M. Parente, B.L. Ehlmann, J.R. Michaelski, R.E. Milliken, F. Poulet, G.A. Swayze, J.F. Mustard, S.L. Murchie, J.-P. Bibring, Science 321, 830-833 (2008)

D.F. Blake et al., LPSC XXXX, abstr. \#1484 (2009)

D.F. Blake et al., AbSciCon 2010, abstr. \#5119 (2010)

D.F. Blake, A.H. Treiman, R. Morris, D. Bish, H.E.F. Amundsen, A. Steele, the AMASE team, LPSC 42 abstr. \#2167 (2011)

A.J. Brown, S.J. Hook, A.M. Baldridge, J.K. Crowley, N.T. Bridges, B.J. Thomson, G.M. Marion, C.R. de Souza Filho, J.L. Bishop, in EPSL (2010)

Butterworth et al., LPSC 37 abstr. \#2144 (2006)

Chicarro et al., ESA SP 1240, 3 (2004)

S.J. Chipera, D.L. Bish, J. Appl. Crystallogr. 35, 744-749 (2002)

S.J. Chipera, P. Sarrazin, L. Alcantar-Lopez, D.T. Vaniman, D.L. Bish, D. Blake, G. Chiari, LPSC 40 Abstr. \#1328 (2009)

F.H. Chung, J. Appl. Crystallogr. 7, 519-525 (1974)

R.T. Downs, M. Hall-Wallace, Am. Mineral. 88, 247-250 (2003)

B. Ehlmann et al., Science 322, 1828 (2008)

B. Ehlmann et al., LPSC 40, abstr. \#1787 (2009)

R. Gellert et al., J. Geophys. Res. 111, E02S05 (2006). doi:10.1029/2005JE002555

J.R. Goldsmith, D.L. Graff, Am. Mineral. 43, 84-101 (1958)

J.L. Gooding et al., Icarus 33, 483 (1978)

V.E. Hamilton, R.V. Morris, J.E. Gruener, S.A. Mertzman, J. Geophys. Res. 113, E12S43 (2008). doi:10.1029/2007JE003049

G. Hölzer, M. Fritsch, M. Deutsch, T. Härtwig, E. Förster, Phys. Rev. A 566, 4554-4568 (1997)

L. Jandura, in Proc. $40^{\text {th }}$ Aero. Mech. Symp. (2010), pp. 233-248

R.P. Kraft, D.N. Burrows, G.P. Garmire, D.H. Lumb, J.A. Nousek, M.A. Skinner, J.R. Janesick, S.A. Collins, P. Vu, Proc. SPIE 2280, 320 (1994)

M.C. Malin, K.S. Edget, Science 290, 1927-1937 (2000)

J.D. Martin, www.xpowder.com. D.L. GR 1001/04. ISBN 84-609-1479-6. 105 p. Spain (2004)

J.R. Michalski, P.B. Niles, Nat. Geosci. (2011). doi:10.1038/NGEO971

R.E. Milliken, J.P. Grotzinger, B.J. Thomson, Geophys. Res. Lett. 37, L04201 (2010). doi:10.1029/ 2009GL041870 
D.W. Ming, D.W. Mittlefehldt, R.V. Morris, D.C. Golden, R. Gellert, A. Yen, B.C. Clark, S.W. Squyres, W.H. Farrand, S.W. Ruff, R.E. Arvidson, G. Klingelhofer, H.Y. McSween, D.S. Rodionov, C. Schroeder, P.A. de Souza Jr., A. Wang, J. Geophys. Res. (2006). doi:10.1029/2005JE002560

R.V. Morris et al., J. Geophys. Res. 111, E02S13 (2006)

R.V. Morris et al., J. Geophys. Res. 113, E12S42 (2008)

R.V. Morris, S.W. Ruff, R. Gellert, D.W. Ming, R.E. Arvidson, B.C. Clark, D.C. Golden, K. Siebach, G. Klingelhofer, C. Schroeder, I. Fleischer, A.S. Yen, S.W. Squyres, Science 329, 421 (2010)

R.V. Morris, D.F. Blake, D. Bish, D.W. Ming, D.G. Agresti, A.H. Treiman, A. Steele, H.E.F. Amundsen, the AMASE Team, LPSC 42, abstr. \#1699 (2011)

J. Mustard et al., Nature 454, 305-309 (2008)

J.B. Pollack, J.F. Kasting, S.M. Richardson, K. Poliakoff, Icarus 71, 203 (1987)

F. Poulet et al., Nature 431, 623-627 (2005)

F. Poulet et al., Icarus 201, 84-101 (2009)

C.S. Romanek et al., Nature 372, 655-657 (1994)

M. Schulte, D. Blake, T. Hoehler, T. McCollom, Astrobiology 6(2), 364-376 (2006)

S.P. Schwenzer, O. Abramov, C.C. Allen, S. Clifford, J. Filiberto, D.A. Kring, J. Lasue, P.J. McGovern, H.E. Newsom, A.H. Treiman, D.T. Vaniman, R.C. Wiens, A. Wittmann, LPSC 41, Abstr. \#1589 (2010)

B.-L. Skjelkvale et al., J. Volcanol. Geochem. Res. 37, 1-19 (1989)

F.S. Spear, Metamorphic Phase Equilibria and Pressure-Temperature-Time Paths (Mineralogical Society of America, Washington, 1993), 799 p.

A. Steele et al., LPSC 39 abstr. \#2368 (2008)

D. Sunshine, in Proc. 40 ${ }^{\text {th }}$ Aero. Mech. Symp. (2010), pp. 249-262

G.J. Taylor, L.M.V. Martel, P.G. Lucey, S. Crites, D.F. Blake, LPSC XXXXIII, abstr. \#2316 (2012)

A.H. Treiman, H.E.F. Amundsen, D.F. Blake, T. Bunch, Earth Planet. Sci. Lett. 204, 323-332 (2002)

A.H. Treiman, K.L. Robinson, D.F. Blake, D. Bish, LPSC 41 Abstr. \#1472 (2010)

D.T. Vaniman, S.J. Chipera, Am. Mineral. 91, 1628-1642 (2006)

A. Yen et al., EOS trans. AGU, 88, Abstract \#P23A-1095 (2007)

R.A. Young, Introduction to the Rietveld Method (Oxford University Press, Oxford, 1993)

M.Y. Zolotov, M.V. Mironenko, J. Geophys. Res. 112, E07006 (2007) 